\section{omin}

OAK

RIDGE

NATIONAL

LABORATORY

\section{UNION \\ CARBIDE}

NUREG/CR-1627

ORNL/NUREG/TM-401

\title{
Heavy-Section Steel Technology Program Quarterly Progress Report for April-June 1980
}
G. D. Whitman
R. H. Bryan

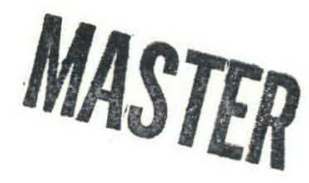

\section{OPERATED BY}

UNION CARBIDE CORPOBATION FOR THE UNITED STATES DEPARTMENT OF ENERGY 


\section{DISCLAIMER}

This report was prepared as an account of work sponsored by an agency of the United States Government. Neither the United States Government nor any agency Thereof, nor any of their employees, makes any warranty, express or implied, or assumes any legal liability or responsibility for the accuracy, completeness, or usefulness of any information, apparatus, product, or process disclosed, or represents that its use would not infringe privately owned rights. Reference herein to any specific commercial product, process, or service by trade name, trademark, manufacturer, or otherwise does not necessarily constitute or imply its endorsement, recommendation, or favoring by the United States Government or any agency thereof. The views and opinions of authors expressed herein do not necessarily state or reflect those of the United States Government or any agency thereof. 


\section{DISCLAIMER}

Portions of this document may be illegible in electronic image products. Images are produced from the best available original document. 


\section{The following pages are an exact representation of what is in the original document folder.}




\section{Printed in the United States of America. Available from National Technical Information Service \\ U.S. Department of Commerce 5285 Port Royal Road, Springfield, Virginia 22161}

\begin{tabular}{|c|}
\hline Available from \\
GPO Sales Program \\
Division of Technical Information and Document Control \\
U.S. Nuclear Regulatory Commission \\
Washington, D.C. 20555
\end{tabular}

This report was prepared as an account of work sponsored by an agency of the United States Government. Neither the United States Government nor any agency thereof, nor any of their employees, makes any warranty, express or implied, or assumes any legal liability or responsibility for the accuracy, completeness, or usefulness of any information, apparatus, product, or process disclosed, or represents that its use would not infringe privately owned rights. Reference herein to any specific commercial product, process, or service by trade name, trademark. manufacturer, or otherwise, does not necessarily constitute or imply its endorsement, recommendation, or favoring by the United States Government or any agency thereof. The views and opinions of authors expressed herein do not necessarily state or reflect those of the United States Government or any agency thereof. 
NUREG/CR-1627

ORNL/NUREG/TM-401

Dist. Category RF

\author{
Contract No. W-7405-eng-26 \\ Engineering Technology Division
}

NUREG/CR--1627

TI85 015910 PROGRESS REPORT FOR APRIL-JUNE 1980

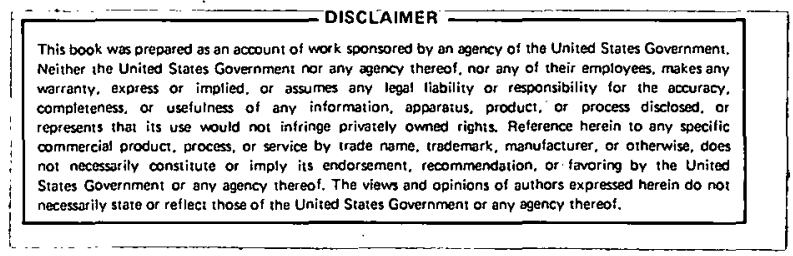

Manuscript Completed - September 30, 1980 Date Puhlished - nctoher 1980

NOTICE This document contains information of a preliminary nature. It is subject to revision or correction and therefore does not represent a final report.

\author{
Prepared for the \\ U.S. Nuclear Regulatory Commission \\ Office of Nuclear Regulatory Research \\ Under Interagency Agreements DOE 40-55.1-75 and 40-552-75
}

NRC FIN No. B0119

Prepared by the

OAK RIDGE NATIONAL LABORATORY

nak Ridge, Tennessee 37830

operated by

'UNION CARBIDE CORPORATION

for the

DEPARTMENT OF ENERGY 


\section{THIS PAGE}

\section{WAS INTENTIONALLY \\ LEFT BLANK}




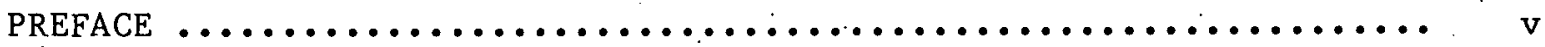

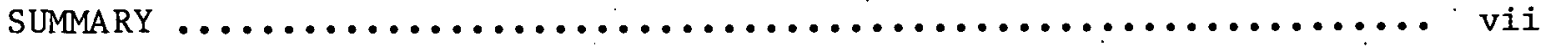

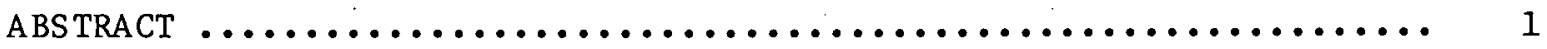

1. PROGRAM ADMINISTRATION AND PROCUREMENT $\ldots \ldots \ldots \ldots \ldots \ldots \ldots \ldots \ldots \ldots$

2. FRACTURE MECHANICS ANALYSES AND INVESTIGATIONS $\ldots \ldots \ldots \ldots \ldots \ldots . . . \ldots$

2.1 Determination of K-Factors for Nozzle-Corner.Flaws Under Combined Pressure-Thermal Loading ............... 3

2.2 A Computer Program (NOZ-FLAW) for Direct Evaluation of K-Factors for Arbitrarily Shaped Flaws at Pressure Vesse1 Nozzle Corners ........................... 5

2.3 Investigation of Damping and of Cleavage-Fibrous Transition in Reactor-Grade Steel ..................... 7

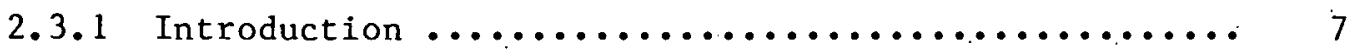

2.3.2 Progress to date $\ldots \ldots \ldots \ldots \ldots \ldots \ldots \ldots \ldots \ldots \ldots \ldots . \ldots \ldots$

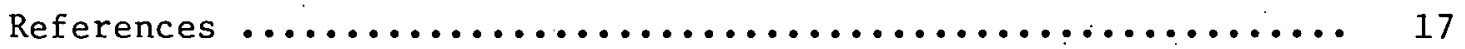

3. INVESTIGATIONS OF IRRADIATED MATERIALS $\ldots \ldots \ldots \ldots \ldots \ldots \ldots \ldots \ldots \ldots$

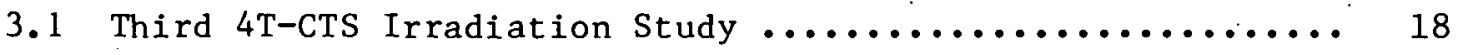

3.2 Fourth HSST Irradiation Series ................... 25

References ................................. 27

4. THERMAL SHOCK InVESTIGATIONS $\ldots \ldots \ldots \ldots \ldots \ldots \ldots \ldots \ldots \ldots \ldots \ldots \ldots \ldots . \ldots \ldots$

4.1 Selection of Tempering Temperature for TSC-2 (TSE-5A) .... 28

4.2 Tempering of TSC-2 Prolongation .................. 31

4.3 Residual-Stress Study with TSC -2 Prolongation .......... 32

4.4 Machining of TSC-2 (TSE-5A Test Cylinder) ........... 33

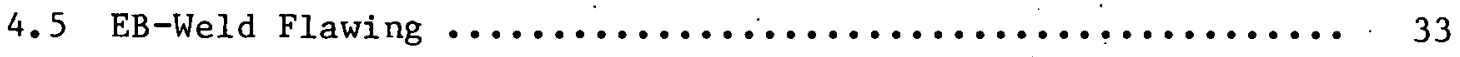

4.6 Rubber Cement Coating Development ................ 34

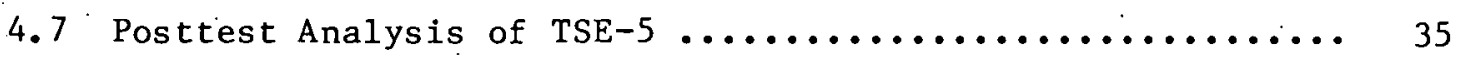

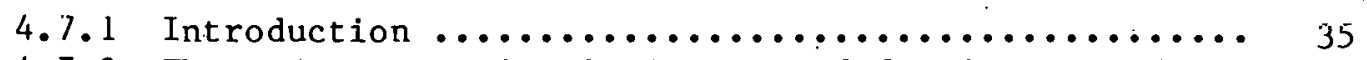

4.7.2 Three-dimensional calculations of final arrested

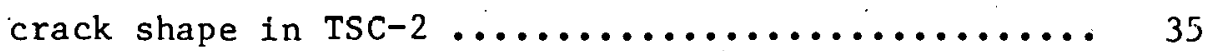

4.7.3 Two-dimensional. LEFM analysis of long axial crack modeled as $90^{\circ}$ segment ...................... 39

4.8 Thermal Shock Material Characterization .............. 42 


\section{$\underline{\text { Page }}$}

4.9 Fractographic Studies ....................... 44

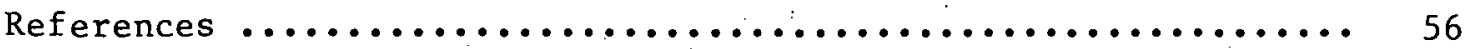

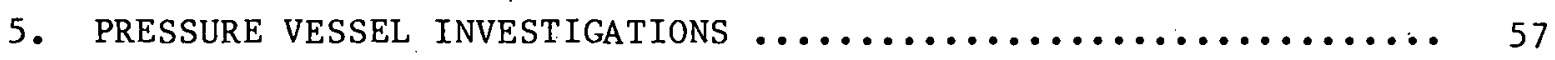

5.1 Intermediate Test Vessel V-8A ................. 57

5.2 Pressurized Thermal Shock Studies $\ldots \ldots \ldots \ldots \ldots \ldots \ldots \ldots \ldots . \ldots$

References $\ldots \ldots \ldots \ldots \ldots \ldots \ldots \ldots \ldots \ldots \ldots \ldots \ldots \ldots \ldots \ldots \ldots \ldots \ldots, 58$ 


\section{$v / v i$}

PREFACE

The Heavy-Section Steel Technology (HSST) Program, which is sponsored by the Nuclear Regulatory Commission, is an engineering research activity devoted to extending and developing the technology for assessing the margin of safety against fracture of the thick-walled steel pressure vessels used in light-water-cooled nuclear power reactors. The program is being carried out in close cooperation with the nuclear power industry. This report covers HSST work performed in April through June 1980, except for subcontractor contributions which may cover the three-month period ending in May. The work performed by Oak Ridge National Laboratory (ORNL) and by subcontractors is managed by the Engineering Technology Division. Major tasks at ORNL are carried out by the Engineering Technology Division and the Metals and Ceramics Division. Prior progress reports on this program are ORNL-4176, ORNL-4315, ORNL-4377, ORNL-4463; ORNL-4512, ORNL-4590, ORNL-4653, ORNL-4681, ORNL-4764, ORNL-4816, ORNL-4855, ORNL-4918, ORNL4971, ORNL/TM-4655 (Vol. II), ORNL/TM-4729 (Vol. II), ORNL/TM-4805 (Vol. II), ORNL/TM-4914 (Vo1. II), ORNL/TM-5021 (Vo1. II), ORNL/TM-5170, ORNL/NUREG/TM-3, ORNL/NUREG/TM-28, ORNL/NUREG/TM-49, ORNL/NUREG/TM-64, ORNL/NUREG/TM-94, ORNL/NUREG/TM-120, ORNL/NUREG/TM-147, ORNL/NUREG/TM-166, ORNL/NUREG/TM-194, OKNL/NUREG/TM-209, ORNL/NUREG/TM-239, NUREG/CR-0476 (ORNL/NUREC/TM-275), NUREG/CR-0656 (ORNL/NUREG/TM-298), NUREG/CR-0818 (ORNL/NUREG/TM-324), NUREG/CR-0980 (ORNL/NUREG/TM-347), NUREG/CR-1197 (ORNL/NUREG/TM-370), NUREG/CR-1305 (ORNL/NUREG/TM-380), and NUREG/CR-1477 (ORNL/NIIRFS/TM-393). 
vii

\section{SUMMARY*}

\section{PROGRAM ADMINISTRATION AND PROCUREMENT}

The Heavy-Section Steel Technology (HSST) Program is an engineering research activity conducted by the Oak Ridge National Laboratory (ORNL) for the Nuclear Regulatory Commission (NRC) in coordination with other research sponsored by the federal government and private organizations. The program comprises studies related to all areas of the technology of materials fabricated into thick-section primary-coolant containment systems of light-water-cooled nuclear power reactors. The principal area of investigation is the behavior and structural integrity of steel pressure vessels containing cracklike flaws. Current work is organized into the following tasks: (1) program administration and procurement, (2) fracture mechanics analyses and investigations, (3) investigations of irradiated materials, (4) thermal shock investigations, and (5) pressure vessel investigations.

The work performed under existing research and development subcontracts is included in this report.

Eighteen program briefings, reviews, or presentations were made during this quarter.

\section{FRACTURE MECHANICS ANALYSES AND INVESTIGATIONS}

Stress-intensity factors $\left(\mathrm{K}_{\mathrm{I}}\right)$ were calculated for nozzle-corner cracks in an HSST intermediate vessel under a combind pressure and thermal shock loading. Finite-element codes ADINAT and ADINA were used to generate the stress distributions put into the calculation of $\mathrm{K}_{\mathrm{I}}$ by the BIGIF code.

Several sample problems were successfully executed by ORNL with the IBM version of NOZ-FLAW, a program for calculating KI distributions along arbitrarily shaped nozzle-corner flaws. The mesh generation overlay will

* Conversions from SI to English units for all SI quantities are listed on a foldout page at the end of this report. 
not yet generate a correct three-dimensional mesh for a nozzle-to-vessel junction.

Mechanisms of ductile-cleavage transitions are being studied at the University of Maryland by scanning electron microscopic examination of fracture surfaces and by measurement of fracture specimen contraction. Energy losses in dynamic fracture have been measured in Homalite 100 specimens; experiments show a dependence on late-breaking ligaments, specimen size, and crack depth.

\section{INVESTIGATIONS OF IRRADIATED MATERIALS}

Impact testing of several Charpy V-notch specimens from the Third HSST Irradiation Series has been completed. The four irradiated welds tested exhibited a loss of upper-shelf impact energy and a shift in the 41-J reference temperature. In only one of eight welds studied to date has the measured loss in upper-shelf energy exceeded that predicted by the procedures of Regulatory Guide 1.99.

Irradiation of capsule A in the Fourth HSST Irradiation Series is continuing. In the first six months of irradiation, temperatures of the specimens have remained within a temperature band of about $\pm 9 \mathrm{~K}$.

\section{THERMAL SHOCK INVESTIGATIONS}

The tempering temperature for the next thermal shock test cylinder was selected, and the prolongation of the cylinder was tempered accordingly. Static fracture toughness characterization of the prolongation was completed. Residual stresses in the tempered prolongation were evaluated and are not expected to affect the test. Machining of the test cylinder was completed, and studies were made of the flawing and coating procedures. Additional calculations of stress-intensity factors were made for interpretation of the results of the last thermal shock test.

\section{PRESSURE VESSEL INVESTIGATIONS}

Work was initiated under subcontract with the Babcock and Wilcox Company to develop a special low-uppper-shelf seam welding process for 
preparation of intermediate test vessel V-8A for an elasto-plastic fracture mechanics test.

Analyses of nozzle-corner cracks in an intermediate test vessel are being made for combined pressure and thermal loadings to guide the development of test facility design requirements. 


\title{
HEAVY-SECTION STEEL TECHNOLOGY PROGRAM QUARTERLY PROGRESS REPORT FOR APRIL-JUNE 1980
}

\author{
G. D. Whitman : R. H. Bryan
}

\begin{abstract}
The Heavy-Section Steel Technology Program is an engineering research activity conducted by the Oak Ridge National Laboratory for the Nuclear Regulatory Commission. The program comprises studies related to all areas of the technology of materials fabricated into thick-section primary-coolant containment systems of light-water-cooled nuclear power reactors. The investigation focuses on the behavior and structural integrity of steel pressure vessels containing cracklike flaws. Current work is organized into five tasks: (1) program administration and procurement, (2) fracture mechanics analyses and investigations, (3) investigations of irradiated materials, (4) thermal shock investigations, and (.5) pressure vessel investigations. Nozzle-corner cracks under combined pressure and thermal loadings are being analyzed. Mechanisms of damping in crack propagation are being studied. Irradiation of the first specimens in the Fourth HSST Irradiation Series continued, and impact tests of several Charpy specimens from the previous series were completed. Heat-treatment conditions for the next thermal shock test were selected, and preparation of the test cylinder was initiated. Work was initiated to develop a low-upper-shelf seam weld for intermediate test vessel $\mathrm{V}-8 \mathrm{~A}$, and facility planaing for pressurized thermal shock tests continued.
\end{abstract}

1. PROGRAM ADMINISTRATION $\Lambda$ ND PROCUREMENT

G. D. Whitman

The Heavy-Section Steel Technology (HSST) Program, a major safety program sponsored by the Nuclear Regulatory Commission (NRC) at the Oak Ridge National Laboratory (ORNL), is concerned with the structural integrity of the primary systams (particularly the reactor pressure vessels) of light-water-cooled nuclear power reactors. The structural integrity of these vessels is ensured by (1) designing and fabricating them according to standards set by the code for nuclear pressure vessels, (2) detecting flaws of significant size that occur during fabrication and in service, and (3) developing. methods of producing quantitative estimates 
of conditions under which fracture could occur. The program is concerned mainly with developing pertinent fracture technology, including knowledge of (1) the material used in these thick-walled vessels, (2) the flaw growth rate, and (3) the combination of flaw size and load that would cause fracture and thus limit the life and/or operating conditions of this type of reactor plant.

The program is coordinated with other government agencies and with the manufacturing and utility sectors of the nuclear power industry in the United States and abroad. The overall objective is quantification of safety assessments for regulatory agencies, for professional code-writing bodies, and for the nuclear power industry. Several activities are conducted under subcontracts by research facilities in the United States and through informal cooperative efforts on an international basis. Two research and development subcontracts are currently in force.

Administratively, the program is organized into five tasks, as reflected in this report: (1) program administration and procurement, (2) fracture mechanics analyses and investigations, (3) investigations of irradiated material, (4) thermal shock investigations, and (5) pressure vessei investigations.

Two blocks of HSST Plate 03 were shipped to the U.S. Naval Ship Research and Development Center.

A subcontract with the Babcock and Wilcox Company was initiated to develop a special welding process for use on HSST vessel V-8A - to weld vessel $\mathrm{V}-8 \mathrm{~A}$ and to characterize the weld material.

During this quarter, 18 program briefings, reviews, or presentations were made by the HSST staff at technical meetings and at program reviews for the NRC staff or visitors: 


\section{FRACTURE MECHANICS ANALYSES AND INVESTIGATIONS*}

\subsection{Determination of K-Factors for Nozzle-Corner Flaws}

Under Combined Pressure-Thermal Loading

\section{J. W. Bryson B. R. Bass ${ }^{\dagger}$}

R. H. Bryan

$\mathrm{K}_{\mathrm{I}}$ distributions are being determined for quarter-circular-shaped flaws in intermediate test vessels (ITVs) under combined pressure-thermal loadings. The ADINAT, ${ }^{1}$ ADINA, ${ }^{2}$ and $B I G I F{ }^{3}$ computer codes are being used in performing this work. During this report period, an ITV model was subjected to the moderate pressure-thermal shock depicted in Fig. 2.1 in

*Conversions from SI to English units for all SI quantities are listed on a foldout page at the end of this report.

${ }^{\dagger}$ Computer Sciences Division, Union Carbide Corporation Nuclear Division.

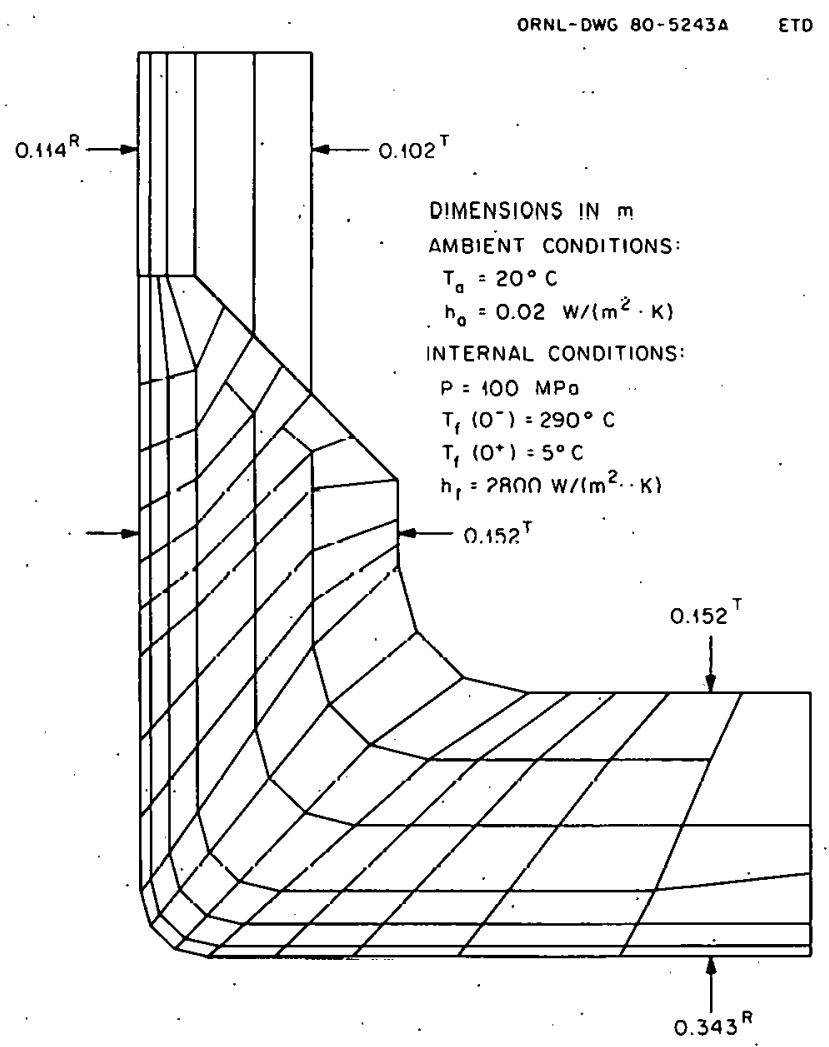

Fig. 2.1. Pressure-thermal environment, dimensions, and finiteelement grid (ADINAT) for ITV configuration. 
which a system initially at $290^{\circ} \mathrm{C}$ underwent a step change in fluid temperature from 290 to $5^{\circ} \mathrm{C}$. ADINAT provided a complete transient heat flow analysis, which in turn was used by ADINA for calculating stress distributions at specified time steps. Stress distributions were then input to BIGIF, where $K_{I}$ distributions were determined for three different crack depths. These crack depths correspond to cases studied photoelastically by C. W. Smith at Virginia Polytechnic Institute and State University and calculated by S. N. Atluri and K. Kathiresan at Georgia Institute of Technology $(a / T=0.14,0.29$, and 0.53 where $a=\operatorname{depth}$ and $T=$ thickness $)$. Table 2.1 shows results from the study for four times in the transient and for steady-state conditions. For purposes of comparison, Table 2.2 provides $\mathrm{K}_{\mathrm{I}}$ distributions for the same flaws under internal pressure loading acting alone, again calculated by BIGIF.

Table 2.1. Combined pressure-thermal loading $K$.values for ITV nozzle-corner flaws $a$

\begin{tabular}{|c|c|c|c|c|c|c|c|c|}
\hline \multirow{2}{*}{$\begin{array}{c}t \\
(s)\end{array}$} & \multirow{2}{*}{$a / T^{b}$} & \multirow{2}{*}{$\stackrel{a}{(m)}$} & \multicolumn{3}{|c|}{$\mathrm{K}_{\mathrm{I}}(\mathrm{MPa} \cdot \sqrt{\mathrm{m}})$} & \multicolumn{3}{|c|}{$\mathrm{K}_{\mathrm{I}} / \mathrm{P} \sqrt{\pi \mathrm{a}}$} \\
\hline & & & $\phi \approx 0^{c}$ & $\psi=\pi / 4$ & $\phi \approx \pi / 2$ & $\phi \approx 0$ & $\phi=\pi / 4$ & $\phi \approx \pi / 2$ \\
\hline 83 & $\begin{array}{l}0.14 \\
0.29 \\
0.53\end{array}$ & $\begin{array}{l}0.032 \\
0.067 \\
0.123\end{array}$ & $\begin{array}{l}219.2 \\
263.1 \\
268.2\end{array}$ & $\begin{array}{l}232.9 \\
209.6 \\
165.0\end{array}$ & $\begin{array}{l}226.0 \\
281.6 \\
261.4\end{array}$ & $\begin{array}{l}6.91 \\
5.74 \\
4.32\end{array}$ & $\begin{array}{l}7.34 \\
4.57 \\
2.65\end{array}$ & $\begin{array}{l}7.13 \\
6.14 \\
4.20\end{array}$ \\
\hline 227 & $\begin{array}{l}0.14 \\
0.29\end{array}$ & $\begin{array}{l}0.032 \\
0.067\end{array}$ & $\begin{array}{l}215.7 \\
262.0\end{array}$ & $\begin{array}{l}225.0 \\
229.2\end{array}$ & $\begin{array}{l}224.5 \\
287.3\end{array}$ & $\begin{array}{l}6.80 \\
5.71\end{array}$ & $\begin{array}{l}7.10 \\
5.00\end{array}$ & $\begin{array}{l}7.08 \\
6.26\end{array}$ \\
\hline 323 & $\begin{array}{l}0.14 \\
0.29\end{array}$ & $\begin{array}{l}0.032 \\
0.067\end{array}$ & $\begin{array}{l}210.2 \\
254.5\end{array}$ & $\begin{array}{l}215.1 \\
228.1\end{array}$ & $\begin{array}{l}219.1 \\
281.5\end{array}$ & $\begin{array}{l}6.63 \\
5.55\end{array}$ & $\begin{array}{l}6.78 \\
4.97\end{array}$ & $\begin{array}{l}6.91 \\
6.14\end{array}$ \\
\hline 683 & $\begin{array}{l}0.14 \\
0.29 \\
0.53\end{array}$ & $\begin{array}{l}0.032 \\
0.067 \\
0.123\end{array}$ & $\begin{array}{l}186.7 \\
227.1 \\
244.0\end{array}$ & $\begin{array}{l}192.8 \\
209.5 \\
189.0\end{array}$ & $\begin{array}{l}195.5 \\
254.1 \\
251.3\end{array}$ & $\begin{array}{l}5.89 \\
4.95 \\
3.92\end{array}$ & $\begin{array}{l}6.08 \\
4.57 \\
3.04\end{array}$ & $\begin{array}{l}6.17 \\
5.54 \\
4.04\end{array}$ \\
\hline $\begin{array}{l}\text { Steady } \\
\text { state }\end{array}$ & $\begin{array}{l}0.14 \\
0.29 \\
0.53\end{array}$ & $\begin{array}{l}0.032 \\
0.067 \\
0.123\end{array}$ & $\begin{array}{l}137.3 \\
164.1 \\
180.4\end{array}$ & $\begin{array}{l}139.1 \\
156.7 \\
159.2\end{array}$ & $\begin{array}{l}144.3 \\
186.6 \\
189.9\end{array}$ & $\begin{array}{l}4.33 \\
3.58 \\
2.90\end{array}$ & $\begin{array}{l}4.39 \\
3.42 \\
2.56\end{array}$ & $\begin{array}{l}4.55 \\
4.07 \\
3.06\end{array}$ \\
\hline
\end{tabular}


Table 2.2. Pressure loading $K$ values for ITV nozzle-corner flaws ${ }^{a}$

\begin{tabular}{|c|c|c|c|c|c|c|c|}
\hline \multirow{2}{*}{$\mathrm{a} / \mathrm{T}^{b}$} & \multirow{2}{*}{$\stackrel{a}{(m)}$} & \multicolumn{3}{|c|}{$\mathrm{K}_{\mathrm{I}}(\mathrm{MPa} \cdot \sqrt{\mathrm{m}})$} & \multicolumn{3}{|c|}{$\mathrm{K}_{\mathrm{I}} / \mathrm{P} \sqrt{\pi \mathrm{a}}$} \\
\hline & & $\phi \approx 0^{c}$ & $\phi=\pi / 4$ & $\phi \approx \pi / 2$ & $\phi \approx 0$ & $\phi=\pi / 4$ & $\phi \approx \pi / 2$ \\
\hline 0.14 & 0.032 & 135.8 & 137.9 & 145.8 & 4.28 & 4.35 & 4.60 \\
\hline $0.29^{\circ}$ & 0.067 & 160.7 & 157.2 & 191.5 & 3.50 & 3.43 & 4.17 \\
\hline 0.53 & 0.123 & 176.3 & 159.3 & 198.0 & 2.84 & 2.56 & 3.18 \\
\hline
\end{tabular}

$a_{\mathrm{P}}=100 \mathrm{MPa}$.

${ }^{b}$ Ratio of flaw depth a to juncture thickness $T$ (i.e., flaw penetration).

${ }_{\text {Measured from vessel inside free surface. }}$

\subsection{A Computer Program (NOZ-FLAW) for Direct Evaluation of K-Factors for Arbitrarily Shaped Flaws at Pressure Vesse1 Nozzle Corners}

$$
\begin{aligned}
& \text { J. W. Bryson B. R. Bass* } \\
& \text { W. G. Johnson * }
\end{aligned}
$$

Work continues on the development of a finite-element computer program (NOZ-FLAW) ${ }^{4}$ for calculating stress-intensity factors along arbitrarily shaped flaw fronts at pressure vessel nozzle corners. During this quarter, a rough draft of a user's manual for the NOZ-FLAW program was delivered to ORNL by S. N. Atluri of Georgia Institute of Technology. The program was written for use on a CDC 7600 computer, and work is under way to make NOZ-FLAW operational on the Union Carbide Corporation Nuclear Division (UCCND) IBM computers.

Various options in the program, as well as the two sample problems (semielliptical surface flaw in a cylinder and a slab) described in the user's manual, have been successfully executed at UCCND with the IBM version of the program. These options include tension-loaded flat plates with central, edge, and double-edge through-cracks as well as plates with semielliptical or semicircular surface flaws. Cylinders having straightedge through-cracks and inner-surface semielliptical cracks have also

\footnotetext{
${ }^{*}$ Computer Sciences Division, Union Carbide Corporation Nuclear
} Division. 
been successfully executed on the IBM version of NOZ-FLAW for internal pressure loading. At the present time, however, several options, including the nozzle-corner-flaw option, are not operational on the UCCNC computers. Hopefully, all of the available options in the program will have been debugged and executed by the next report period.

A listing of the various mesh generation options (i.e., possible crack geometries) is given in Table 2.3. Those options not currently operational on the UCCND computers are noted.

Table 2.3. Crack geometries available via NOZ-FLAW automatic mesh generation

\begin{tabular}{l} 
Plate \\
Through-thickness central crack \\
Through-thickness single-edge crack \\
Through-thickness double-edge crack \\
Through-thickness edge crack in three-point bending \\
Corner crack \\
Surface crack \\
Buried crack \\
$\quad$ Plate with single hole \\
Through-thickness single-edge crack \\
Through-thickness double-edge crack \\
S1ngle-corner crack \\
Symmetric double corner crack \\
Surface crack ${ }^{a}$ \\
Through-thickness meridional crack \\
Through-thickness circumferential crack \\
Axisymmetric inner-edge crack ${ }^{a}$ \\
Axisymmetric outer-edge crack \\
Inner-surface meridional flaw \\
Outer-surface meridional flaw \\
Inner-surface circumferential flaw \\
Outer-surface circumferential flaw \\
Single-corner flaw, longitudinal plane \\
Symmetric double-corner flaw, longitudinal plane \\
\hline
\end{tabular}

$a_{\text {Not presently operational on UCCND IBM com- }}$ puters. 
2.3 Investigation of Damping and of Cleavage-Fibrous Transition in Reactor-Grade Stee ${ }^{*}$

W. L. Fourney ${ }^{\dagger}$

\subsubsection{Tntroduction}

The aim of this research program is to investigate the effects of damping on fracture propagation and to study in detail the transition region between cleavage and ductile fracture. A complete understanding of both of these phenomena is extremely important in predicting fast fracture behavior in a structure.

The program is broken into four main tasks:

A to examine the phenomenon of ductile-to-cleavage transition during fracture;

B. to examine closely the effects of damping on the determination of $k$ and on propagation behavior;

C. to conduct dynamic two-dimensional finite-element computations to support our findings in Tasks $A$ and $B$;

D. to examine further the effect of higher-order terms on the accuracy of stress-intensity-factor $(K)$ determinations from photoelastic data to make possible more accurate damping computations.

Task $A$ is aimed at increasing the understanding of the brittle-toductile transition in fracturing. By conducting electron microprobe studies of the fracture surfaces and by investigating thickness changes (variations in lateral dimensions) of fractured samples, hopefully a plausible model of the stress-strain conditions that control cleavagefibrous fracturing will be developed. The ultimate aim of this task is to recommend a plan for developing an adequate understanding of the transition region in relation to the use of $J-R$ curves, $K_{I c}$, and $K_{I a}$ data.

\footnotetext{
*Work sponsored by HSST Program under UCCND Subcontract 7778 between Union Carbide Corporation Nuclear Division and the University of Maryland.

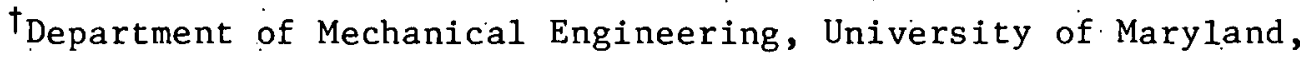
College Park, MD 20742.
} 
With regard to Task $B$, we would like to be able to divide the energy loss during fracture into two parts: energy lost during propagation and that lost after arrest. An attempt is being made to identify major mechanisms through which losses occur and to develop some index of importance that would reveal how much loss could be attributed to each mechanism.

Since fracture energies are proportional to the square of the stressintensity factor, knowing $\dot{K}$ as accurately as possible is important. Through Task $D$, we hope to refine the $K$ values determined photoelastically so that the mimimum amount of computational error is introduced into our damping calculations.

The finite-element computations with the computer code, Task $C$, are being used to support findings from both Tasks $A$ and $B$. In addition, the computer code is being used to predict run-arrest events in thick-walled cylindrical pressure vessels.

\subsubsection{Progress to date}

Task A: Brittle-to-ductile transition

Seventeen A-36 three-point bend specimens tested at the Del Research Corporation and nine A-533B compact-tension specimens tested at the Naval Ship Research and Development Center (NSRDC) were delivered to the University of Maryland. Specimen identification numbers and test conditions are summarized in Tables 2.4 and 2.5. In addition to the fractured specimens, records of load vs crack-opening displacement (COD) for A-533B specimens and plots of $\mathrm{J}$ vs crack extension, $\Delta \mathrm{a}$, for three of the A-533B specimens (FSH-TL-30, -31 , and -32 ) were provided.

On the basis of visual observation of fracture surfaces and test conditions, four A-36 specimens (Nos. 3, 11, 13, and 15) have been selected for scanning electron microscope (SEM) examination. The procedure deve1oped for the SEM examination is as follows:

1. to map the area from the end of the fatigue crack through the ductile shear zone and the brittle cleavage zone at low magnification ( $30 x)$ to gain an overall view of physical features;

2. to study the shear zone, particularly the end, in stereo view, to gain a three-dimensional perspective; 
Table 2.4. A-36 steel test conditions

\begin{tabular}{ccc}
\hline $\begin{array}{c}\text { Specimen } \\
\text { No. } a\end{array}$ & $\begin{array}{c}\text { Test } \\
\text { temperature } \\
\left({ }^{\circ} \mathrm{C}\right)\end{array}$ & $\begin{array}{c}\text { Spring plate span } \\
(\mathrm{mm})\end{array}$ \\
\hline 1 & 121 & \\
2 & 22 & \\
3 & 22 & 305 \\
4 & 121 & 305 \\
5 & 121 & 457 \\
6 & 121 & 711 \\
7 & 121 & 711 \\
8 & 121 & 838 \\
9 & 93 & 838 \\
10 & 66 & 838 \\
11 & 79 & 838 \\
12 & 52 & 838 \\
13 & 38 & 838 \\
15 & 22 & 838 \\
16 & 121 & \\
17 & 22 & \\
18 & 52 & \\
\hline
\end{tabular}

$a_{\text {Specimen dimensions [American So- }}$ ciety for Testing and Materials (ASTM) standard E 399 nomenclature]: $W=76 \mathrm{~mm}$; $\mathrm{B}=38 \mathrm{~mm} ; \mathrm{B}_{\mathrm{N}}=30 \mathrm{~mm} ; \mathrm{a}_{\mathrm{o}} / \mathrm{W}=0.6$.

Table 2.5. A-533B specimen test conditions

\begin{tabular}{rc}
$\begin{array}{c}\text { Spectimen } \\
\text { No. }\end{array}$ & $\begin{array}{c}\text { Test } \\
\text { temperature } \\
\left({ }^{\circ} \mathrm{C}\right)\end{array}$ \\
\hline FSH-TL-21 & 59 \\
22 & 55 \\
27 & 57 \\
30 & Ruoul Lemperiuture \\
31 & 149 \\
32 & 79 \\
33 & 82 \\
34 & 54 \\
35 & 61 \\
\hline
\end{tabular}


3. to examine selected locations of interest identified in steps (1) and (2) at higher magnifications (100x to 1000x). The locations of interest are possible sites of crack initiation, cleavage facets near the shear zone, and inclusions in ductile dimples.

In addition to the SEM observation of fracture surfaces, measurements of the specimen thickness reduction have begun. These measurements provide information as to the crack-front stress state (degree of planestrain constraint). To improve the accuracy and efficiency of thicknessreduction measurements, a semiautomated thickness-reduction measuring device was designed and fabricated. The equipment is shown in Fig. 2.2. With this equipment, the thickness reduction is measured as a function of position along the crack path. The measurement can be repeated as a function of the distance from the fracture surface.

Currently, the relationship between thickness and position along the crack path is being recorded on an $\mathrm{X}-\mathrm{Y}$ recorder. Figures 2.3 through 2.5 show examples of such measurements for several distances from the fracture surface for specimens FSH-TL-30, -32 , and -31 respectively. The corresponding J-vs-crack-extension plots are shown in Fig. 2.6. The load-vsCOD record for FSH-TL-30 is shown in Fig. 2.7.

A computer program to analyze the percentage reduction in thickness and map contours showing the out-nf-plane deformation of the sperimen surface is being prepared. A detailed analysis of the results is currentiy under way.

This information, along with results from the SEM studies, will be used to develop a model to describe brittle-to-ductile transition behavior.

\section{Task B: Damping studies}

Approximately 30 tests with modified compact-tension (MCT) specimens of Homalite 100 have been conducted and analyzed to date to evaluate the damping losses in a run-arrest event. Results of these tests are briefly summarized in the following paragraphs.

1. Effect of ligaments. Eight tests were conducted with models that had artificial ligaments of a tougher material (epoxy) located so that the crack was forced to propagate through them. Small part-through grooves 


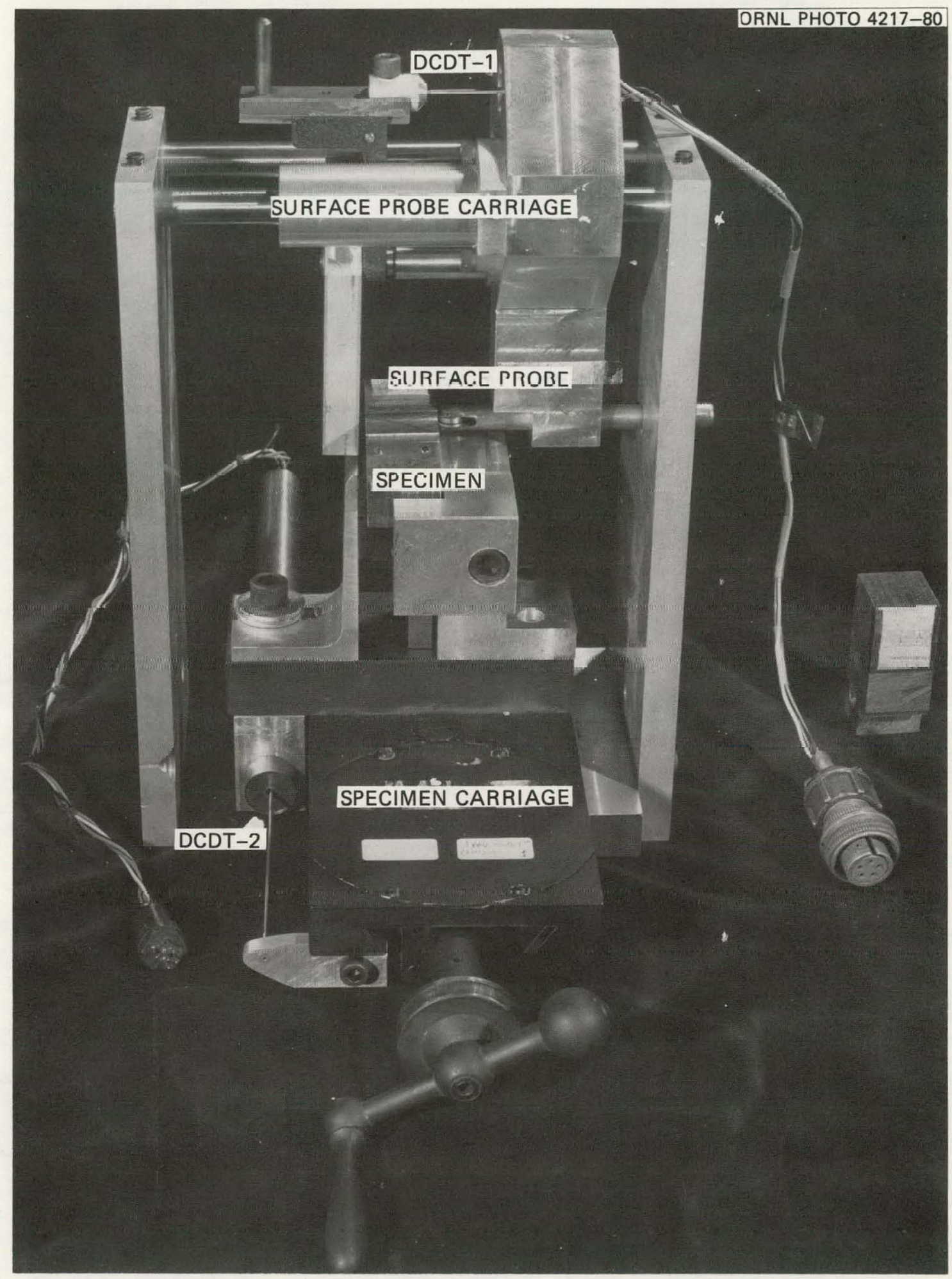

Fig. 2.2. Thickness-reduction measurement device. 


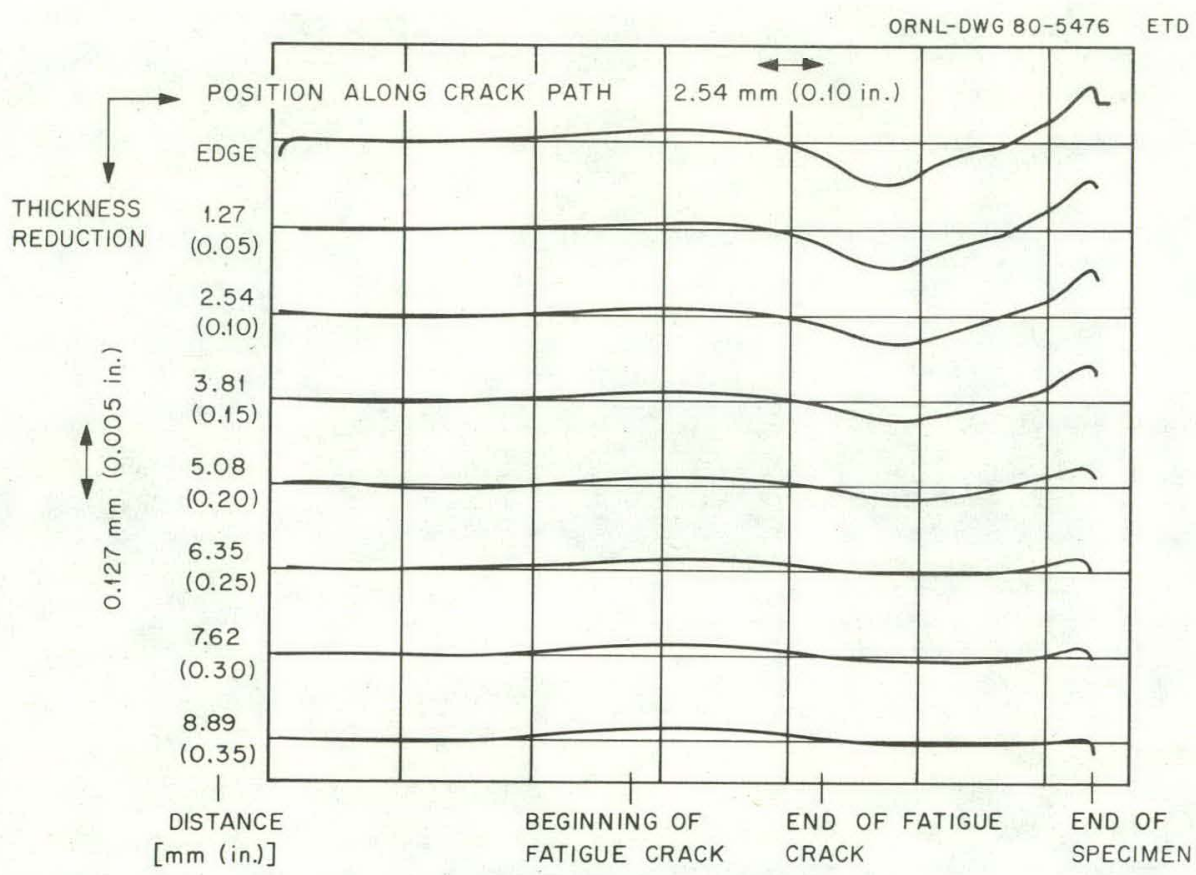

Fig. 2.3. Thickness-reduction profiles at several distances from fracture surface for FSH-TL-30.

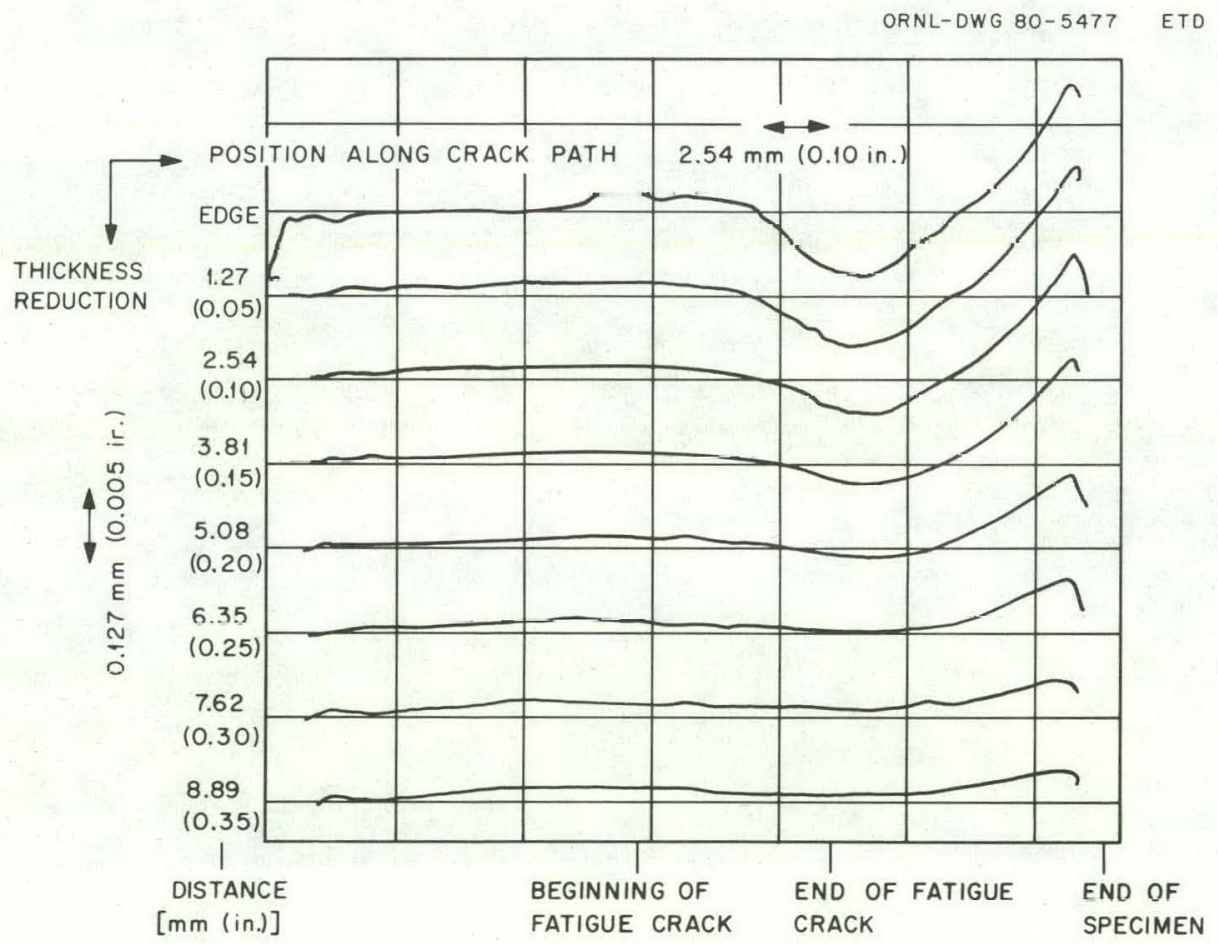

Fig. 2.4. Thickness-reduction profiles at several distances from fracture surface for FSH-TL-32. 


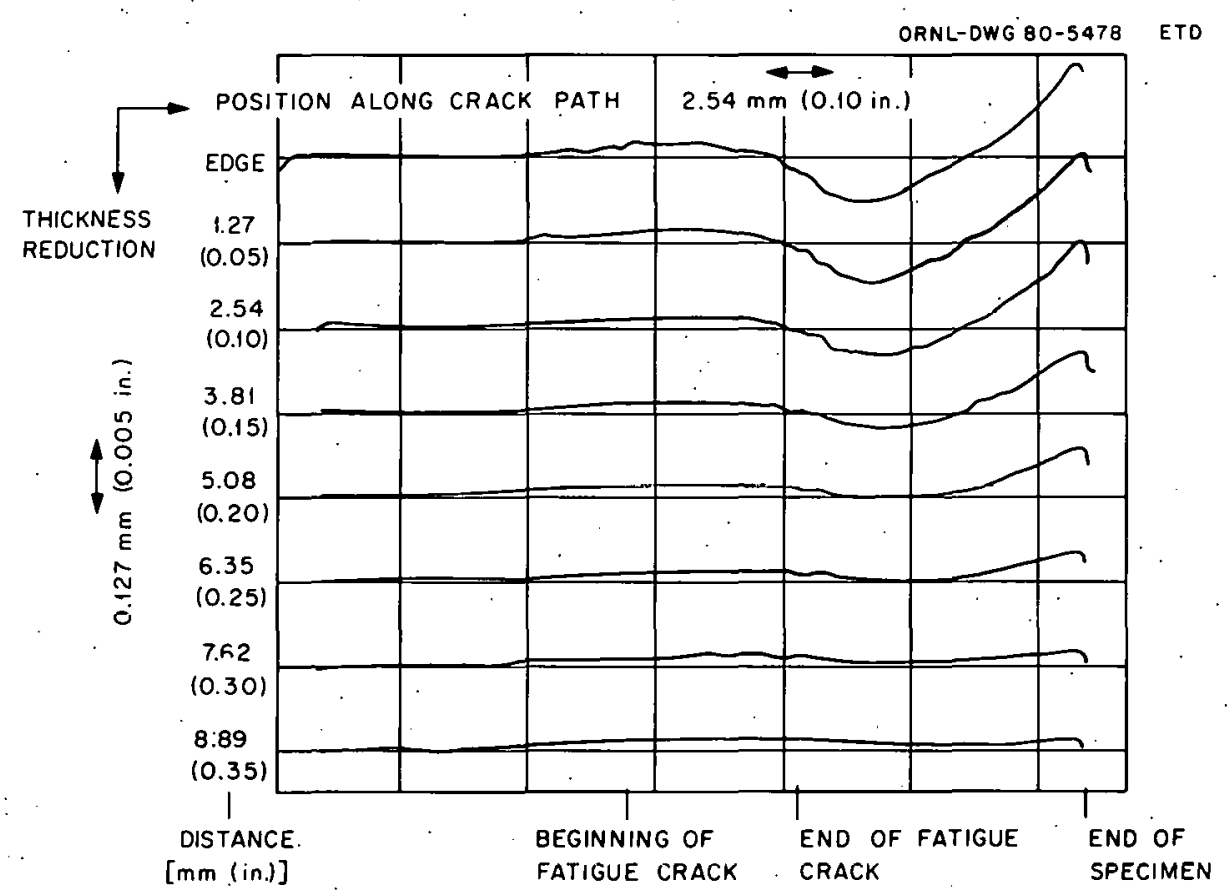

Fig. 2.5. Thickness-reduction profiles at several distances from fracture surface for FSH-TL-31.

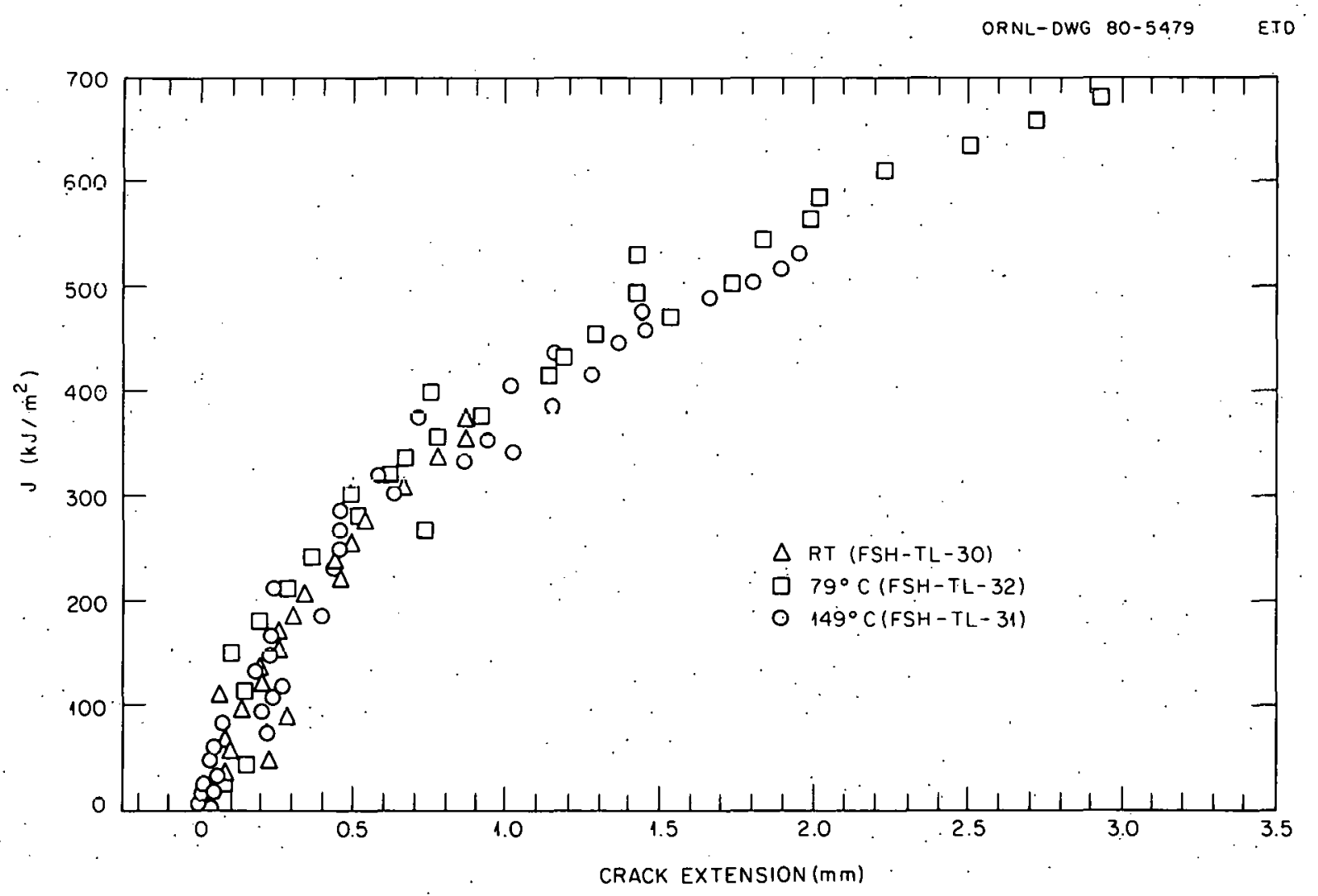

Fig. 2.6. J vs crack extension for specimens FSH-TL-30, -31 , and -32 . 


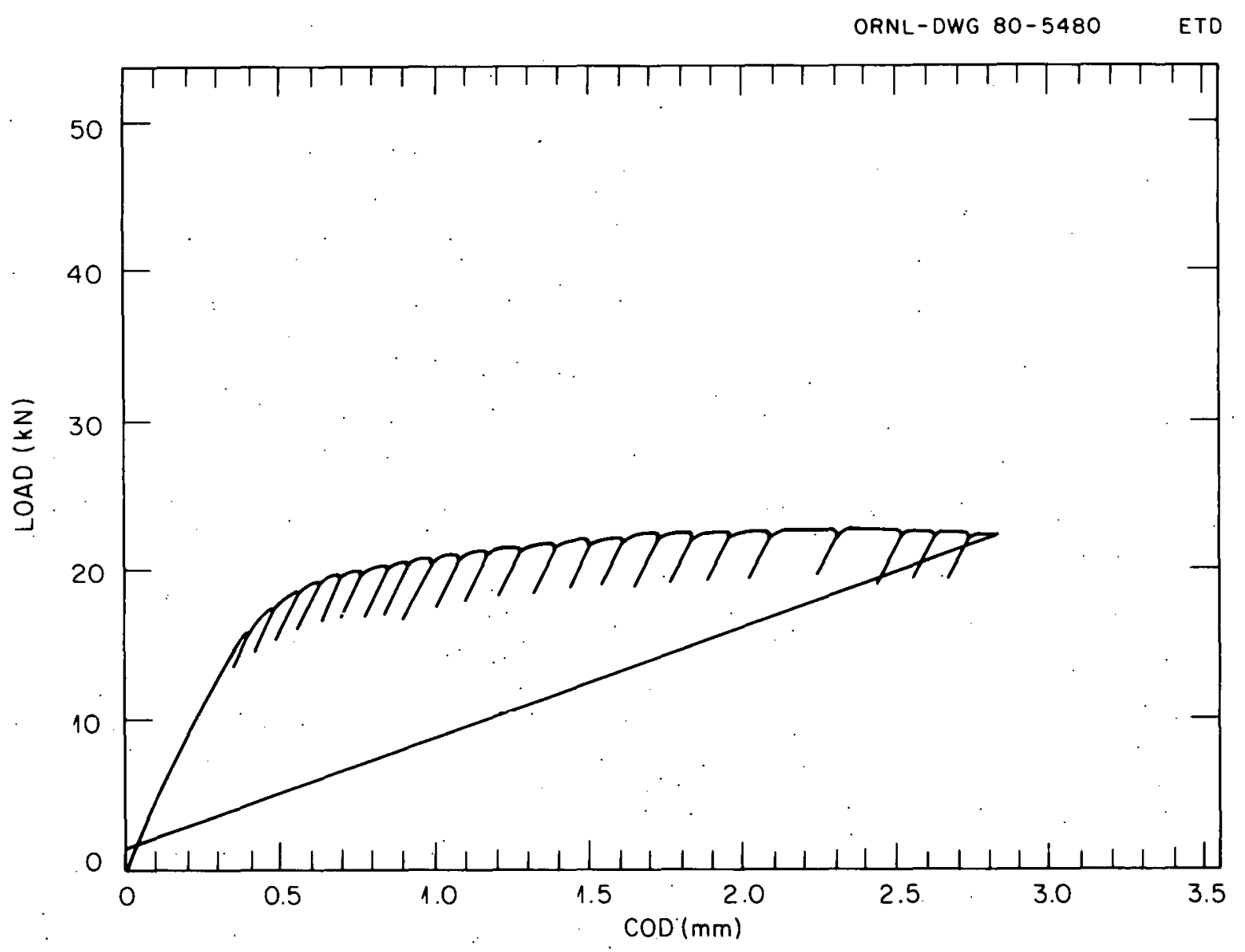

Fig. 2.7. Load vs COD for specimen FSH-TL-30.

were routed on both faces of the model perpendicular to the intended crack path. These grooves were filled with a tough epoxy, creating a ligament of known dimensions through which the crack was forced to propagate. . In addition to tests with no ligaments, four tests were conducted with one ligament on each face, and four tests were conducted with two ligaments on each face.

Damping losses for the models with no ligaments agreed well with earlier results and were found to be about $37 \%$ of the initial strain energy in the specimen prior to crack initiation. This loss increased to $40 \%$ for one set of ligaments and to $50 \%$ for two sets.

2. Effects of specimen size. A total of 12 tests at a fixed $a_{0} / w$ ratio have been completed in specimens of three different sizes. Four tests were run with standard-sized $(W=203 \mathrm{~mm})$ MCT specimens, and damping 
losses were compared with those obtained in three small-sized $(W=152 \mathrm{~mm})$ specimens and five large-sized $(W=305 \mathrm{~mm})$ specimens. The damping loss was found to decrease from $37 \%$ of initial strain energy for the standardsized specimens to $35 \%$ for the smaller models; an increase in damping losses to $40 \%$ was obtained for the larger specimens.

3. Effect of initial crack length. Nine tests were conducted at a fixed ratio of initial strain energy to stress intensity $\left(U_{i} / K_{Q}\right)$ while the Inftial crack length was varied in the larger-sized ( $W=305 \mathrm{~mm}$ ) MCT specimens. Three tests were conducted at $a_{0} / w=0.35$, five tests at $a_{o} / w=0.44$, and one test at $a_{o} / w=0.58$. Damping losses increased with an increase in initial crack length for a fixed $U_{i} / K_{Q}$ ratio; these losses were $30 \%$ for the smallest initial crack length, $40 \%$ for the intermediate initial crack length, and 50\% for the longest initial crack length.

4. Vibrational losses. Two experiments have been conducted in which CODs were recorded at the location of the initial crack tip. The purpose of these tests was to determine if large oscillations or vibrations were occurring in the specimen arms during propagation and after arrest, which could account for significant energy losses as these vibrations were damped out. Neither of the two tests showed very large or high-frequency vibrations; thus, the energy lost via this mechanism would seem to be extremely small.

5. Stress wave energy losses. One-dimensional bar wave tests in various materials are currently being conducted to determine their damping characteristics with regard to stress wave propagation. Although we believe this wave-damping mechanism is not a major contributor to overall damping losses, it should be investigated. Research at ORNL. and other laboratories has shown stress wave generation at the instant of crack initiation and during propagation, and an indication of wave amplitude loss per distance propagated would be useful in assigning importance to the various mechanisms.

Task C: Two-dimensional finite-element computations

Our finite-element code (SAMCR) is currently being used to predict crack-extension behavior in small-sized ( $W=152 \mathrm{~mm})$ MCT specimens of 
Homalite 100 and MCT specimens $(W=210 \mathrm{~mm})$ of 4340 steel $\left(R_{c} 46\right)$. Experimental photoelastic data of the run-arrest event for both cases is available for purposes of comparison. Preliminary finite-element meshes and static displacement fields have been generated for both the steel and plastic specimens. Initial runs of the dynamic code have also been completed.

First indications are that too large a mesh size was selected along the crack path in both cases. The main reason for the mesh size chosen was the desire to obtain a uniform element height in the y-direction (perpendicular to the crack line), since a nonuniform height was suggested as one possible source of oscillations in the stress intensity that had been observed previously with SAMCR. The oscillatory behavior of $\mathrm{K}$ was not found to have changed appreciably, and the meshes will be regenerated to provide a finer mesh size along the crack path. This procedure should not take long, and preliminary comparisons for both cases should be available by the end of July.

Modifications of the code required to accommodate the geometry and thermal loading encountered in ORNL thermal shock experiment TSE-5 have been completed. A $90^{\circ}$ segment of the cylinder has been modeled, and a dynamic run is ready for submission. Results from this computation should be available within the next month. The effects on the staticdisplacement field of using a $90^{\circ}$ segment instead of a $180^{\circ}$ segment have been investigated.

Results obtained to date indicated a difference of about $5 \%$ in the predicted stress intensity at the initial crack tip in the two cases. In view of this finding, use of a $90^{\circ}$ segment in the dynamic computation appears to be justified. The increased density of the mesh that is permitted by the $90^{\circ}$ segment is considered necessary from the standpoint of computational accuracy. The same density would he very difficult to acilieve with a $180^{\circ}$ segment, given the computer facilities currently available to the University of Maryland staff.

\section{Task D: Higher-order terms}

The specific aim of this task is to determine the influence of specimen size and geometry on higher-order terms necessary for accurate 
determination of stress intensity from photoelastic isochromatic fringe patterns.

Three different sizes ( $W=76,102$, and $152 \mathrm{~mm}$ ) of MCT specimens to be used for this study have been selected, and model preparation has begun. Testing is currently in progress to identify and resolve possible problems with residual stresses that have been reported by other investigators working with three-dimensional stress-freezing.

Analytical work to support this task is continuing. The exact cracktip location is frequently uncertain in photoelastic data, especially in dynamic work. Computer programs written earlier to determine up to six coefficients of the static series stress-function representation have been modified to incorporate the crack-tip location as an additional parameter.

The dynamic stress field has also been represented in series form, and programs are currently being written to permit making calculations of $\mathrm{K}$ and the associated higher-order terms to provide information similar to that reported previously for the static situation.

\section{References}

1. K. J. Bathe, ADINAT - A Finite Element Program for Automatic Dynamic Incremental Nonlinear Analysis of Temperatures, Report 82448-5, Mechanical Engineering Department, Massachusetts Institute of Technology (May 1977).

2. K. J. Bathe, ADINA - A Finite Element Program for Automatic Dynamic Incremental Nonlinear Analysis, Report 82448-1, Mechanical Engineering Mepartment., Massachusetts Institute of Technology (May 1977).

3. P. M. Besuner, D. C. Peters, and R. C. Cipolla, BIGIF: Fracture Mechanics Code for Structures, NP-838, Failure Analysis Associates (July 1978).

4. S. N. Atluri and K. Kathiresan, "A Computer Program for Direct Evaluation of K-Factors tor Arbitrarily Shaped Cracks at Pressure Vessel Nozzle Corners," Heavy-Section Steel Technology Program Quart. Prog. Rep. July-September 1.97.9, NUREG/CR-1197 (ORNL/NUREG/TM-370), pp. 3-6. 


\section{INVESTIGATIONS OF IRRADIATED MATERIÁLS*}

\subsection{Third 4T-CTS Irradiation Study}

$$
\text { D. A. Canonico T. N. Jones }
$$

R. G. Berggren

Testing of a number of the Charpy V-notch $\left(C_{V}\right)$ impact specimens has been completed. Results from the control specimens and irradiated specimens are provided in Table 3.1 .

The nominal fluence ranges for the specimens tested to date are as follows:

1. $64 \mathrm{~W}-3.4$ to $4.6 \times 10^{18}$ neutrons $/ \mathrm{cm}^{2}(\mathrm{E}>1 \mathrm{MeV})$;

2. $65 \mathrm{~W}-3.0$ to $4.0 \times 10^{18}$ neutrons $/ \mathrm{cm}^{2}(\mathrm{E}>1 \mathrm{MeV})$;

3. $66 \mathrm{~W}-4.2$ to $6.2 \times 10^{18}$ neutrons $/ \mathrm{cm}^{2}(\mathrm{E}>1 \mathrm{MeV})$;

4. $67 \mathrm{~W}-3.6$ to $5.6 \times 10^{18}$ neutrons $/ \mathrm{cm}^{2}$ (E $\left.>1 \mathrm{MeV}\right)$.

The specimens selected for this initial test series were primarily those that were irradiated at lower temperatures. Some specimens from each weld metal series irradiated near the light-water-reactor (LWR) operating temperature, $288^{\circ} \mathrm{C}$, were also tested.

Plots of the test results are shown in Figs. 3.1 through 3.4 . The approximate 68-J CV temperature for the unirradiated welds are as follows.

\begin{tabular}{cc} 
Weldment & $\begin{array}{c}68-\mathrm{J} \text { temperature } \\
{\left[{ }^{\circ} \mathrm{C}\left({ }^{\circ} \mathrm{F}\right)\right]}\end{array}$ \\
\hline $64 \mathrm{~W}$ & $40(105)$ \\
$65 \mathrm{~W}$ & $0(30)$ \\
$66 \mathrm{~W}$ & $70(160)$ \\
$67 \mathrm{~W}$ & $-5(25)$
\end{tabular}

After irradiation, all the welds exhibited a loss of upper-shelf $C_{V}$ toughness and a shift in their reference temperatures. The shift was based on the temperature at which the specimens absorbed 41-J (30-ft-1b) $\mathrm{C}_{\mathrm{V}}$ energy. The actual losses in $\mathrm{C}_{\mathrm{V}}$ toughness were compared with those that would have been predicted on the basis of Regulatory Guide 1.99 (RG 1.99). This comparative information is included in each of the figures.

\footnotetext{
*Conversions from SI to English units for all SI quantities are
} 1isted on a foldout page at the end of this report. 
Tahle 3.1. Charpy V-notch impact test data from third $4 T-C T$ irradiation experiment

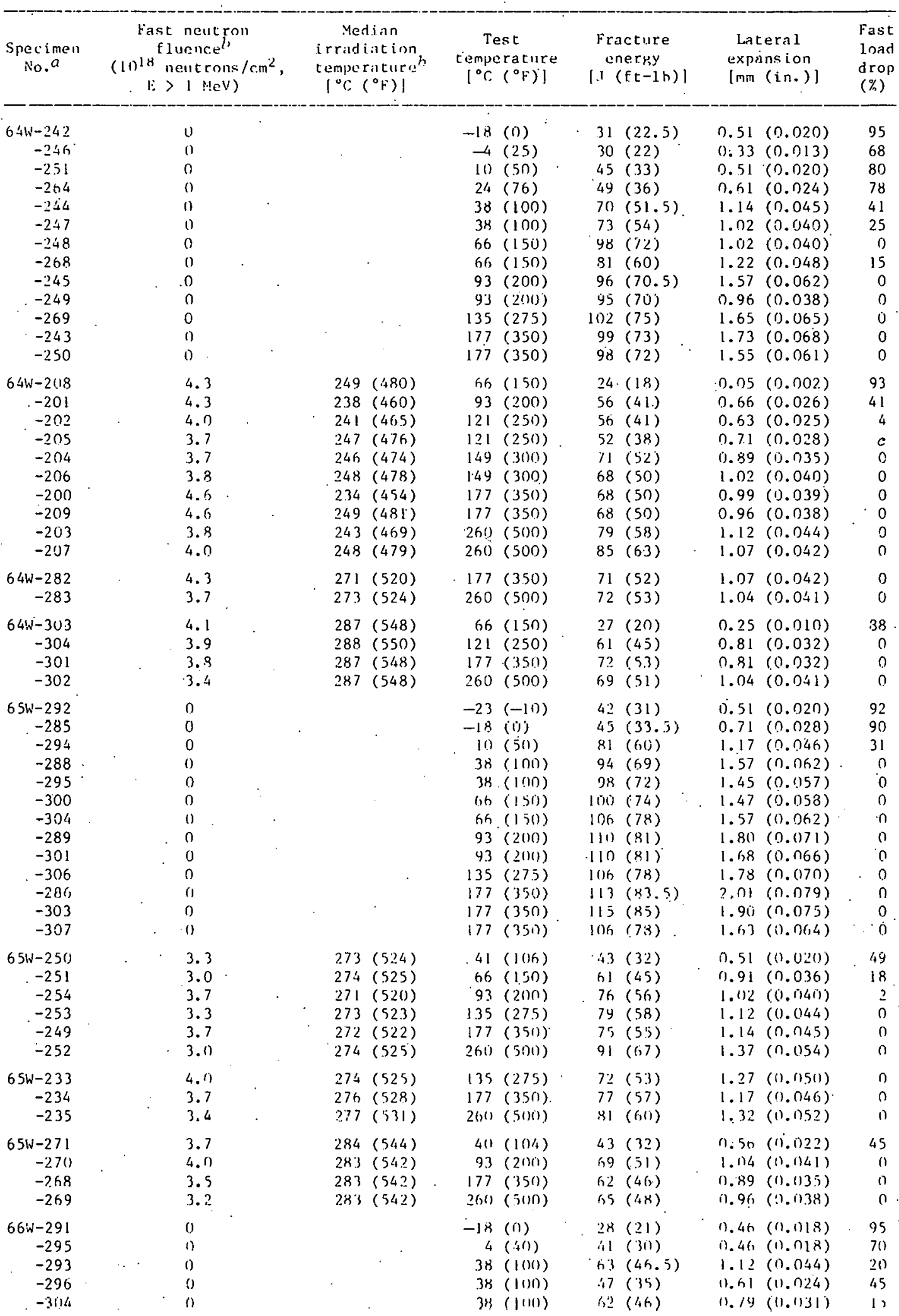


Table 3.1 (continued)

\begin{tabular}{|c|c|c|c|c|c|c|c|}
\hline $\begin{array}{l}\text { Specimen } \\
\text { No. } a\end{array}$ & $\begin{array}{r}\text { Fast } \\
f 1 \\
\left(10^{18}{ }^{n}\right. \\
E>\end{array}$ & $\begin{array}{l}\text { neutron } \\
\text { luence } \\
\text { neutrons } / \mathrm{cm}^{2} \\
>1 \mathrm{MeV})\end{array}$ & $\begin{array}{l}\text { Median } \\
\text { irradiation } \\
\text { temperature } \\
{\left[{ }^{\circ} \mathrm{C}\left({ }^{\circ} \mathrm{F}\right)\right]}\end{array}$ & $\begin{array}{c}\text { Test } \\
\text { temperature } \\
{\left[{ }^{\circ} \mathrm{C}\left({ }^{\circ} \mathrm{F}\right)\right]}\end{array}$ & $\begin{array}{c}\text { Fracture } \\
\text { energy } \\
{[\mathrm{J}(\mathrm{ft}-1 \mathrm{~b})]}\end{array}$ & $\begin{array}{l}\text { Lateral } \\
\text { expansion } \\
{[\mathrm{mm}(\mathrm{in} .)]}\end{array}$ & $\begin{array}{l}\text { Fast } \\
\text { load } \\
\text { drop } \\
(\%)\end{array}$ \\
\hline $\begin{array}{r}66 \mathrm{~W}-297 \\
-302 \\
-294 \\
-298 \\
-301 \\
-292 \\
-299\end{array}$ & & $\begin{array}{l}0 \\
0 \\
0 \\
0 \\
0 \\
0 \\
0\end{array}$ & . & $\begin{aligned} 66 & (150) \\
66 & (150) \\
93 & (200) \\
93 & (200) \\
135 & (275) \\
177 & (350) \\
177 & (350)\end{aligned}$ & $\begin{array}{ll}57 & (42) \\
71 & (52) \\
79 & (58) \\
73 & (54) \\
75 & (55) \\
75 & (55) \\
75 & (55)\end{array}$ & $\begin{array}{ll}0.71 & (0.028) \\
0.91 & (0.036) \\
1.30 & (0.051) \\
1.04 & (0.041) \\
1.07 & (0.042) \\
1.40 & (0.055) \\
1.07 & (0.042)\end{array}$ & $\begin{array}{r}17 \\
0 \\
0 \\
0 \\
0 \\
0 \\
0\end{array}$ \\
\hline $\begin{array}{r}66 W-215 \\
-217 \\
-216 \\
-219 \\
-224 \\
-220 \\
-218 \\
-223\end{array}$ & & $\begin{array}{l}6.2 \\
5.4 \\
5.7 \\
5.0 \\
6.2 \\
5.0 \\
5.1 \\
5.7\end{array}$ & $\begin{array}{ll}266 & (511) \\
269 & (517) \\
268 & (514) \\
272 & (521) \\
263 & (505) \\
271 & (519) \\
271 & (520) \\
265 & (509)\end{array}$ & $\begin{aligned} & 93(200) \\
& 116(240) \\
& 135(275) \\
& 177(350) \\
& 177(350) \\
& 218(425) \\
& 260(500) \\
& 260(500)\end{aligned}$ & $\begin{array}{ll}33 & (24) \\
41 & (30) \\
54 & (40) \\
54 & (40) \\
52 & (38) \\
56 & (41) \\
57 & (42) \\
65 & (48)\end{array}$ & $\begin{array}{ll}0.30 & (0.012) \\
0.48 & (0.019) \\
0.66 & (0.026) \\
0.66 & (0.026) \\
0.71 & (0.028) \\
0.76 & (0.030) \\
0.81 & (0.032) \\
0.71 & (0.028)\end{array}$ & $\begin{array}{r}40 \\
19 \\
2 \\
0 \\
0 \\
0 \\
0 \\
0\end{array}$ \\
\hline $\begin{array}{r}66 \mathrm{~W}-227 \\
-228\end{array}$ & & $\begin{array}{l}4.8 \\
4.2\end{array}$ & $\begin{array}{l}280(536) \\
280(536)\end{array}$ & $\begin{array}{r}93(200) \\
135(275)\end{array}$ & $\begin{array}{l}38(28) \\
57(42)\end{array}$ & $\begin{array}{ll}0.56 & (0.022) \\
0.86 & (0.034)\end{array}$ & $\begin{array}{r}50 \\
0\end{array}$ \\
\hline $\begin{array}{r}66 w-225 \\
-226\end{array}$ & & $\begin{array}{l}4.9 \\
5.4\end{array}$ & $\begin{array}{l}279(534) \\
279(534)\end{array}$ & $\begin{array}{l}177(250) \\
260(500)\end{array}$ & $\begin{array}{l}56(41) \\
61 \quad(45)\end{array}$ & $\begin{array}{ll}0.86 & (0.034) \\
0.94 & (0.037)\end{array}$ & $\begin{array}{l}0 \\
0\end{array}$ \\
\hline $\begin{array}{r}67 W-206 \\
-212 \\
-204 \\
-213 \\
-214 \\
-215 \\
-223 \\
-207 \\
-220 \\
-224 \\
-221 \\
-225 \\
-205 \\
-222\end{array}$ & & $\begin{array}{l}0 . \\
0 \\
0 \\
0 \\
0 \\
0 \\
0 \\
0 \\
0 \\
0 \\
0 \\
0 \\
0 \\
0\end{array}$ & . & $\begin{aligned}-57 & (-70) \\
-40 & (-40) \\
-18 & (0) \\
-18 & (0) \\
10 & (50) \\
38 & (100) \\
38 & (100) \\
38 & (100) \\
66 & (150) \\
66 & (150) \\
93 & (200) \\
135 & (275) \\
177 & (350) \\
177 & (350)\end{aligned}$ & $\begin{aligned} & 12(8.5) \\
& 41(30) \\
& 64(47) \\
& 65(48) \\
& 73(54) \\
& 79(58) \\
& 84(62) \\
& 87(64) \\
& 100(74) \\
& 95(70) \\
& 103(76) \\
& 103(76) \\
& 104(76.5) \\
& 100(74)\end{aligned}$ & $\begin{array}{ll}0.18 & (0.007) \\
0.51 & (0.020) \\
1.04 & (0.041) \\
0.81 & (0.032) \\
0.84 & (0.033) \\
1.02 & (0.040) \\
1.07 & (0.042) \\
1.35 & (0.053) \\
1.45 & (0.057) \\
1.42 & (0.056) \\
1.47 & (0.058) \\
1.50 & (0.059) \\
1.73 & (0.068) \\
1.55 & (0.061)\end{array}$ & $\begin{array}{r}96 \\
77 \\
55 \\
49 \\
50 \\
9 \\
22 \\
10 \\
0 \\
0 \\
0 \\
0 \\
0 \\
0\end{array}$ \\
\hline $\begin{array}{r}67 W .241 \\
-242 \\
-234 \\
-233 \\
-240 \\
-235\end{array}$ & & $\begin{array}{l}3.8 \\
4.5 \\
3.8 \\
4.5 \\
3.6 \\
3.6\end{array}$ & $\begin{array}{l}269(517) \\
268(514) \\
270(518) \\
269(516) \\
270(518) \\
270(518)\end{array}$ & $\begin{aligned} 52 & (125) \\
93 & (200) \\
135 & (275) \\
177 & (350) \\
177 & (350) \\
260 & (500)\end{aligned}$ & $\begin{array}{l}49(36) \\
62(46) \\
76(56) \\
84(62) \\
81 \quad(60) \\
88(65)\end{array}$ & $\begin{array}{ll}0.66 & (0.026) \\
0.81 & (0.032) \\
1.07 & (0.042) \\
1.27 & (0.050) \\
1.22 & (0.048) \\
1.17 & (0.046)\end{array}$ & $\begin{array}{r}57 \\
22 \\
0 \\
0 \\
0 \\
0\end{array}$ \\
\hline $\begin{array}{r}67 W-266 \\
-251 \\
-267 \\
-249 \\
-256 \\
-243 \\
-248\end{array}$ & . & $\begin{array}{l}4.5 \\
4.4 \\
3.9 \\
5.6 \\
3.8 \\
3.7 \\
4.8\end{array}$ & $\begin{array}{ll}282 & (540) \\
282 & (540) \\
282 & (540) \\
282 & (540) \\
282 & (540) \\
279 & (534) \\
282 & (540)\end{array}$ & $\begin{aligned} 38 & (100) \\
66 & (150) \\
93 & (200) \\
135 & (275) \\
177 & (350) \\
260 & (500) \\
260 & (500)\end{aligned}$ & $\begin{array}{ll}27 & (20) \\
60 & (44) \\
68 & (50) \\
75 & (55) \\
79 & (58) \\
73 & (54) \\
89 & (66)\end{array}$ & $\begin{array}{ll}0.36 & (0.014) \\
0.86 & (0.034) \\
0.91 & (0.036) \\
1.17 & (0.046) \\
1.14 & (0.045) \\
1.24 & (0.049) \\
1.42 & (0.056)\end{array}$ & $\begin{array}{r}68 \\
35 \\
0 \\
0 \\
0 \\
c \\
0\end{array}$ \\
\hline
\end{tabular}

$a_{\text {First two digits are HSST weldment numbers. }}$

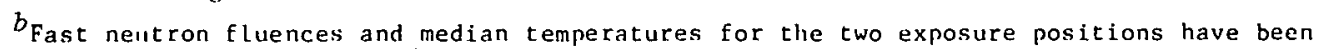
reported in Ref. 1 .

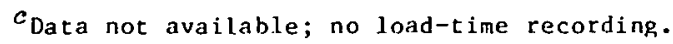




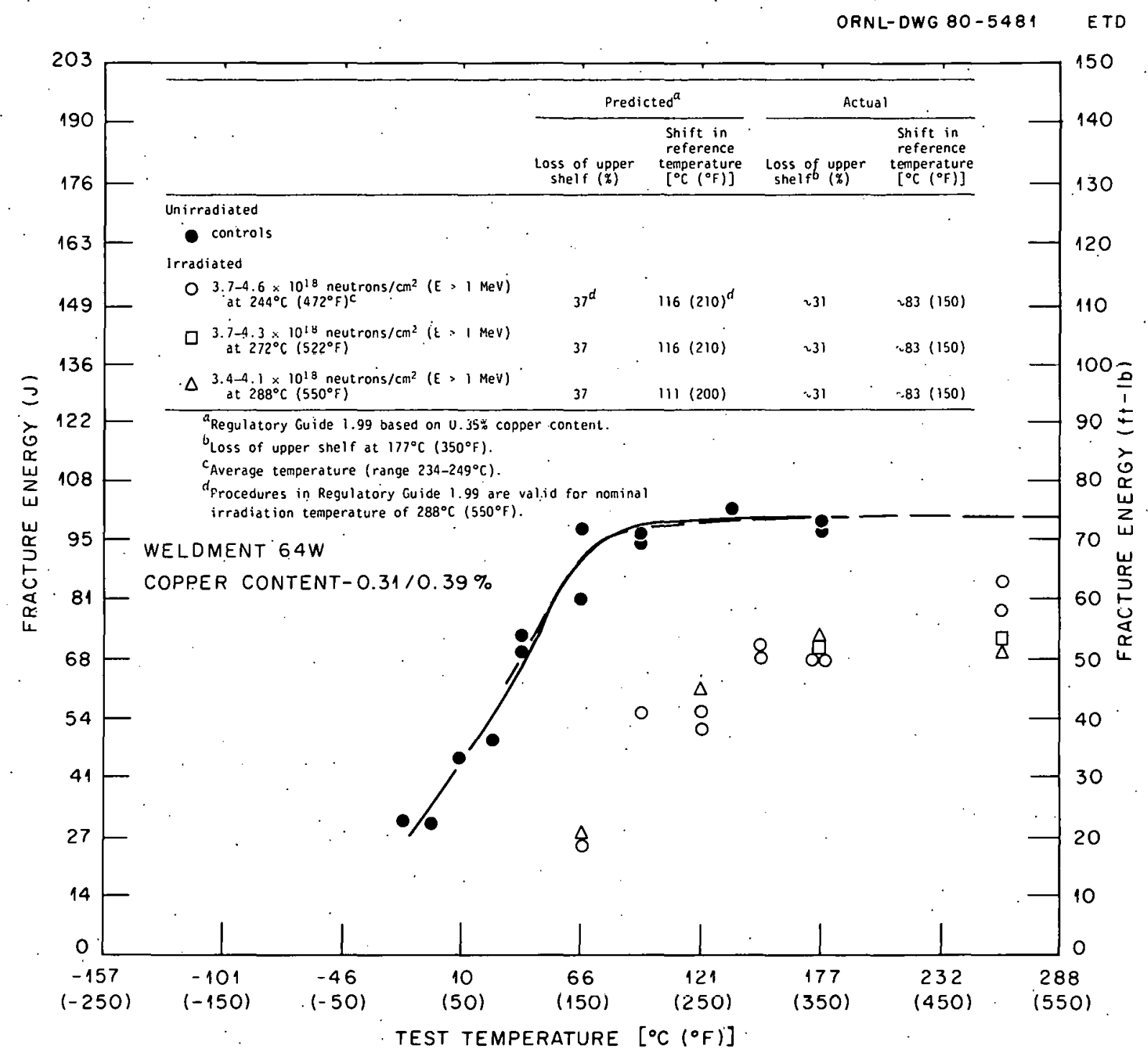

Fig. 3.1. Charpy V-notch impact data from weld 64W. Average copper content, $0.35 \%$.

A summary of the $C_{V}$ results obtained to date is as follows.

1. Weldment $64 \mathrm{~W}$. The loss of upper shelf obtained from the specimens irradiated at the low temperature (nominally $244^{\circ} \mathrm{C}$ ) was considerably less at $260^{\circ} \mathrm{C}$ than that obtained for the same material irradiated at $288^{\circ} \mathrm{C}$. At $177^{\circ} \mathrm{C}$ the upper-shelf $\mathrm{CV}$ toughness values were nearly the same (about $69 \mathrm{~J}$ ), regardless of the irradiation temperature. The shift in the 41-J temperature was about $83 \mathrm{~K}$, and the loss of $\mathrm{C}_{V}$ upper-shelf energy based on a 69-J upper shelf after irradiation was about $31 \%$. Regulatory 


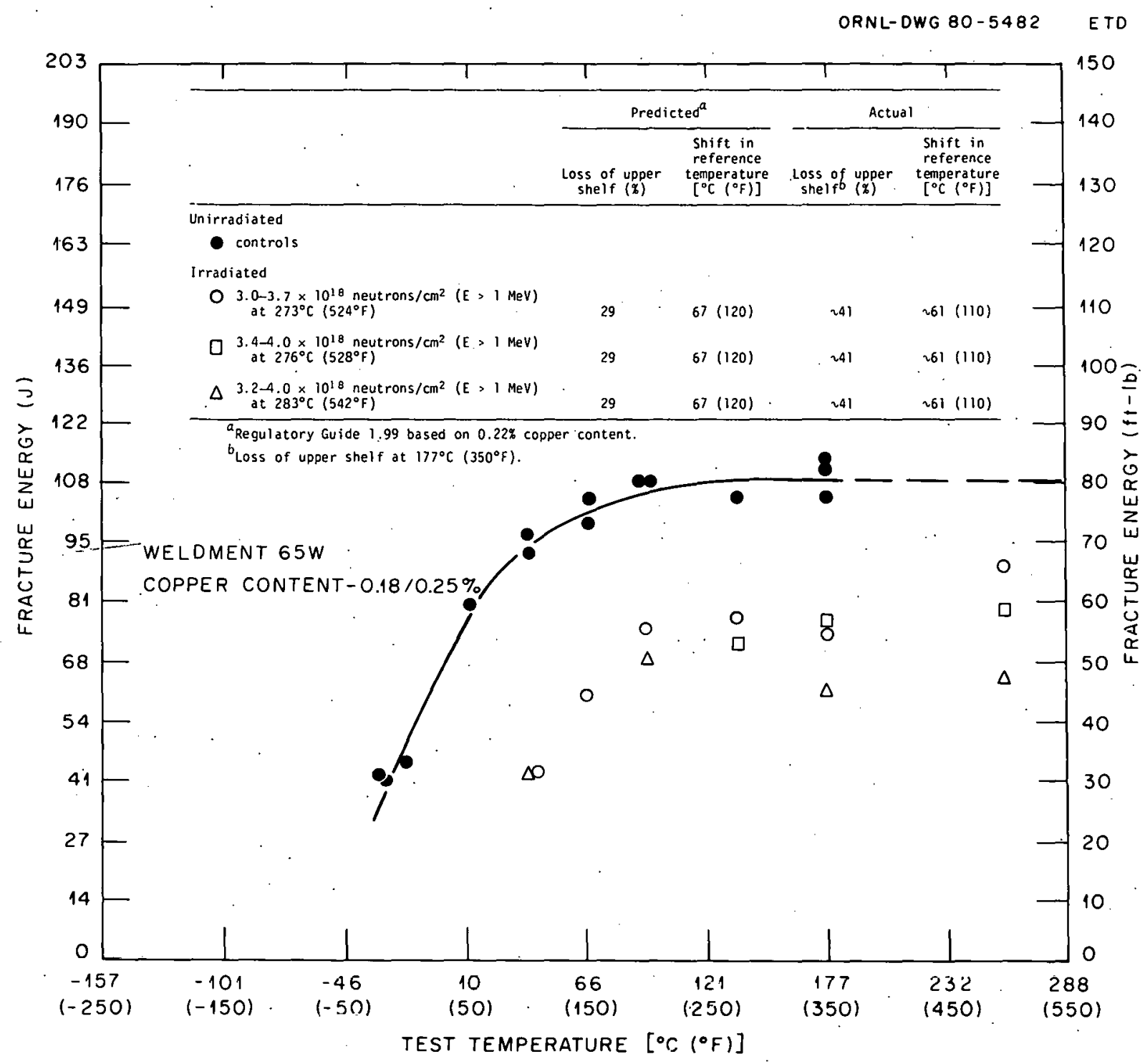

Fig. 3.2. Charpy V-notch impact data from weld 65W. Average copper content, $0.22 \%$.

Guide 1.99 predicted a $37 \%$ loss of upper shelf and a shift in reference temperature of about $115 \mathrm{~K}$. This information is provided. in Fig. 3.1.

2. Weldment 65W. This weldment exhibited the most scatter in $C_{V}$ test results after irradiation. Further, the specimens irradiated at $283^{\circ} \mathrm{C}$, a temperature near the $288^{\circ} \mathrm{C}$ target temperature, underwent the highest loss of upper-shelf $\mathrm{C}_{\mathrm{V}}$ toughness. After an irradiation to $3.6 \times 10^{18}$ neutrons $/ \mathrm{cm}^{2}(\mathrm{E}>1 \mathrm{MeV})$ at $283^{\circ} \mathrm{C}$, the upper-shelf toughness was about $65 \mathrm{~J}$. On the basis of this shelf toughness and an unirradiated 


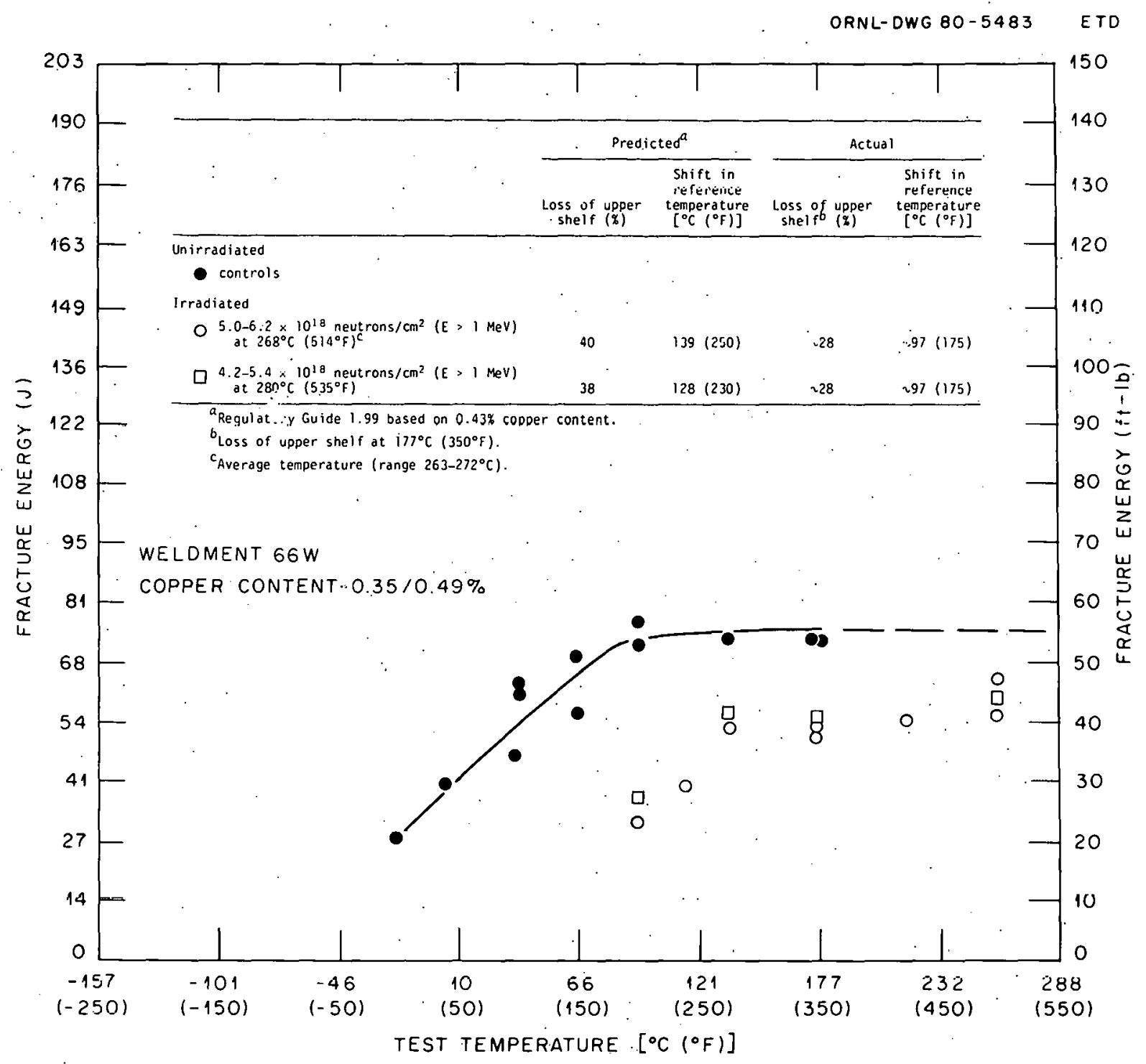

Fig. 3.3. Charpy V-notch impact data from weld $66 \mathrm{~W}$. Average copper content, $0.43 \%$.

shelf toughness of $110 \mathrm{~J}$, the loss was about $41 \%$, which corresponds to a predicted loss (from RG 1.99) of $29 \%$. This is the only weld (of eight studied to date) that exhibited a greater loss of upper-shelf toughness than is predicted from RG 1.99. The actual shift in reference temperature and the predicted shift are nearly the same. Finally, as was the case with weldment $64 \mathrm{~W}$, the specimens irradiated at the lower temperatures underwent a smaller loss of upper-shelf energy. This information is provided in Fir. 3.2. 


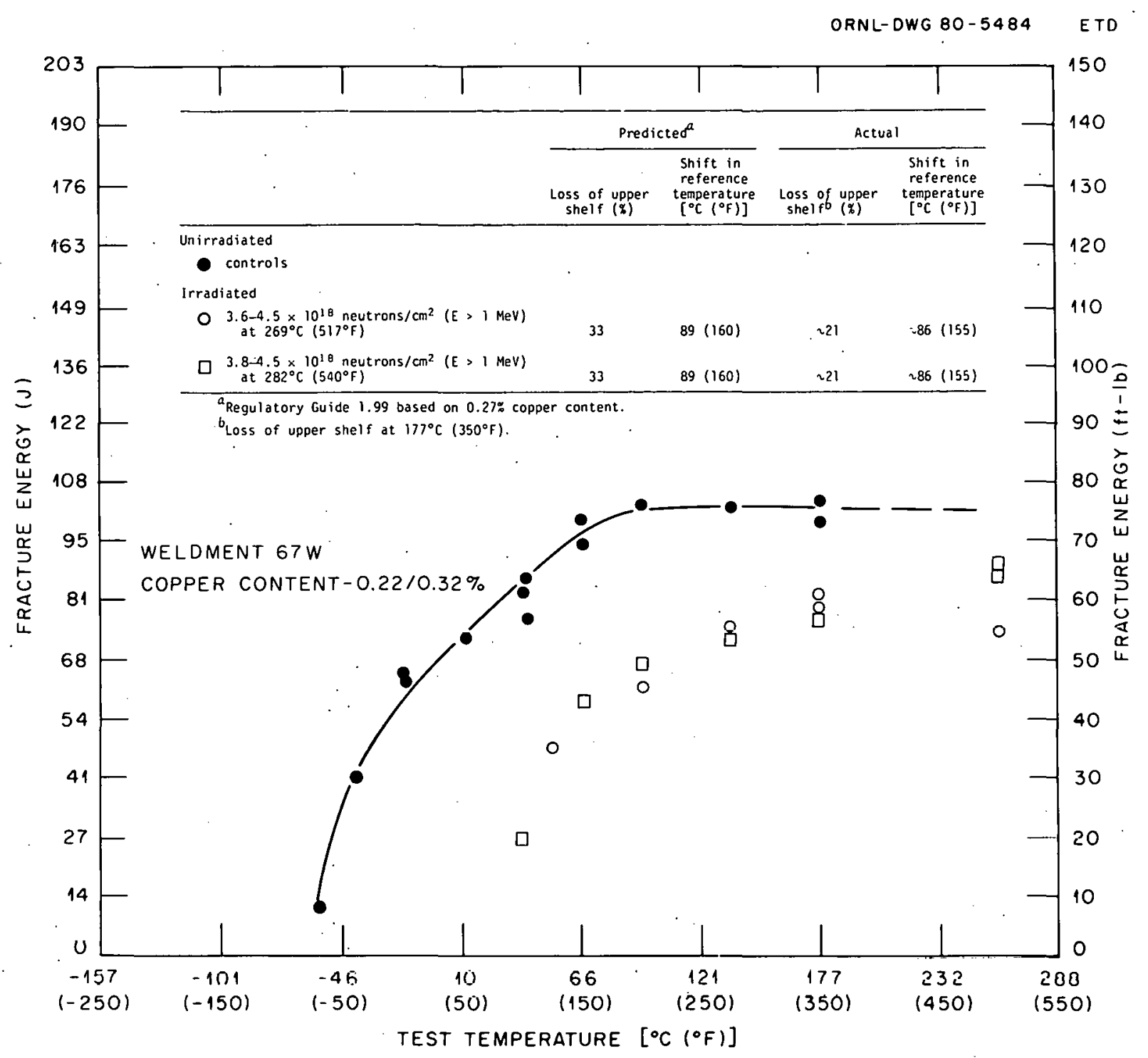

Fig. 3.4. Charpy V-notch impact data from weld 67W. Average copper content, $0.27 \%$.

3. Weldment $66 \mathrm{~W}$. This weldment contained the highest copper of any invcstigated to date. It had the lowest initial upper-shelf energy (76 J) of any tested and the highest initial $68-\mathrm{J}$ temperature $\left(70^{\circ} \mathrm{C}\right)$. The uppershelf $C_{V}$ energy of this weld is near $54 \mathrm{~J}$ after an irradiation of about $5.6 \times 10^{18}$ neutrons $/ \mathrm{cm}^{2}(\mathrm{E}>1 \mathrm{MeV})$. The loss of upper-shelf energy (about 28\%) was not so high as that predicted from RG 1.99 (about 40\%). Also, the shift in reference temperature is not so great. This information is provided in Fig. 3.3. 
4. Weldment $67 \mathrm{~W}$. At $177^{\circ} \mathrm{C}$ the $C_{V}$ upper-shelf energy of this weld dropped. from 103 to $81 \mathrm{~J}$. The $\dot{\mathrm{C}}_{\mathrm{V}}$ toughness at $260^{\circ} \mathrm{C}$ of the specimens irradiated at $282^{\circ} \mathrm{C}$ was superior to that of the weld metal irradiated at $269^{\circ} \mathrm{C}$. The actual loss of $C_{V}$ upper-shelf energy at $177^{\circ} \mathrm{C}$ was about $21 \%$, whereas RG 1.99 predicted a 33\% loss. The actual shift in reference temperature and the predicted shifts were nearly the same. This information is provided in Fig. 3.4 .

The data reported in Table 3.1 and shown in Figs. 3.1 through 3.4 are preliminary. Additional tests will be conducted to determine more conclusively the effect of irradiation. It is significant that the $C_{V}$ upper-shelf toughness in welds $64 \mathrm{~W}$ and $65 \mathrm{~W}$ are near $68 \mathrm{~J}$ after irradiation to fluence levels of near $4 \times 10^{18}$ neutrons $/ \mathrm{cm}^{2}(\mathrm{E}>1 \mathrm{MeV})$. These fluence levels are achieved in rather short times [about 5.5 years for a pressurized-water reactor whose design life and fluence are 40 years and $3 \times 10^{19}$ neutrons $/ \mathrm{cm}^{2}(\mathrm{E}>1 \mathrm{MeV})$ respectively]. For an irradiation $\mathrm{flu}-$ ence of about the same level, the $C_{V}$ upper-shelf energy in weld $67 \mathrm{~W}$ had dropped to near $81 \mathrm{~J}$. Weldment $66 \mathrm{~W}$, which contained the highest copper (about $0.43 \%$ ) and started with the poorest $\mathrm{C}_{\mathrm{V}}$ upper-shelf energy $(76 \mathrm{~J}$ ), exhibited an upper-shelf energy of $54 \mathrm{~J}$ after exposure to a fluence of about $5 \times 10^{18}$ neutrons $/ \mathrm{cm}^{2}(\dot{E}>1 \mathrm{MeV})$.

\subsection{Fourth HSST Irradiation Series}
J. W. Woods
R. G. Berggren
T. N. Jones
D. A. Canonico

Irradiation of capsule A, the first capsule of this irradiation series, l continued through this quarter. Accumulated exposure for the capsule is $2750 \mathrm{~h}$. Temperature control continues to be excellent, with variations in the last quarter near those previously reported. ${ }^{2}$ Figure 3.5 shows the maximum and minimum temperatures recorded each day at 8:00 AM since the start of the experiment on December 18, 1979. These values are the limits obtained from 39 thermocouples located throughout capsule A.

Further analysis of the neutron dosimetry experiment reported previously $y^{3}$ indicates that the specimens in capsule A will be irradiated to 


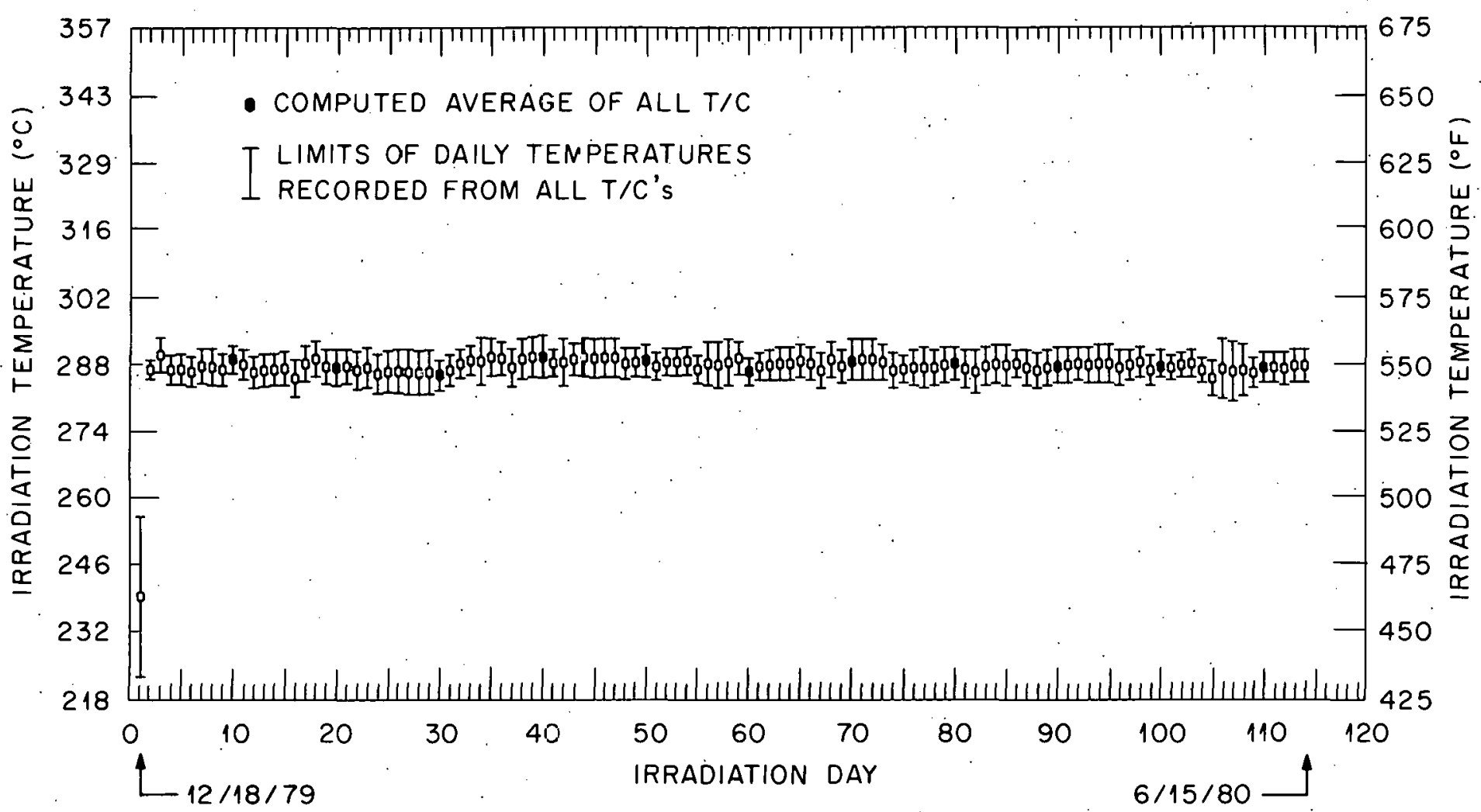

Fig. 3.5. Record of daily temperature range from analysis of 39 thermocouple readings made every morning at 8:00 AM. Average temperature is near the aim of $288^{\circ} \mathrm{C}$. Maximum temperature difference after nearly six months is near $\pm 9 \mathrm{~K}$. 
the desired fluence of $2 \times 10^{19}$ neutrons $/ \mathrm{cm}^{2}(E>1 \mathrm{MeV})$ by October 1 , 1980 .

A second dosimetry experiment has been conducted with a dummy capsule in the irradiation position of capsule B. A thermal shield was in place during this test. Results will be reported later.

Assembly and preirradiation testing of capsule $B$ have been completed. The capsule is located at the north face of the Bulk Shielding Reactor. Irradiation of capsule B began on June 26,1980 .

\section{$\underline{\text { References }}$}

1. R. G. Berggren et al., "Investigations of Irradiated Materials," Heavy-Section Steel Technology Program Quart. Prog. Rep. July September 1979 , ORNL/NUREG/TM-370, pp. 27-36.

2. R. G. Berggren et al., "Investigations of Irradiated Materials," Heavy-Section Steel Technology Program Quart. Prog. Rep. October December 1979 , ORNL/NUREG/TM-380, pp: 60-61.

3. R. G. Berggren et al., "Investigations of Irradiated Materials," Heavy-Section Steel Technology Program Quart. Prog. Rep. JanuaryMarch 1980, ORNL/NUREG/TM-393, pp. 14-15. 


\section{THERMAL SHOCK INVESTIGATIONS* \\ R. D. Cheverton D. A. Canonico \\ S. E. Bolt P. P. Holz}

S. K. Iskander

During this report period for the Thermal Shock Program, the tempering temperature for the TSE-5A test specimen (TSC-2) was selected, the TSC-2 prolongation was tempered at this temperature, a residual-stress study was conducted on the TSC-2 prolongation, machining of TSC-2 was completed, electron-beam (EB)-weld-flawing studies and coating development studies were conducted, and additional fracture mechanics calculations were made in connection with the interpretation of the results of TSE-5.

\subsection{Selection of Tempering Temperature for TSC-2 (TSE-5A)}

The scope of TSE-5A is the same as that intended for TSE-5 and includes (1) initiation and arrest of shallow long axial flaws and deep long axial flaws in a series of initiation-arrest events, (2) arrest in a rising $K_{I}$ field, and (3) a demonstration of warm prestressing. Additional phenomena were observed during TSE-5 (Ref. 1), but items (2) and (3) were not achieved because the material transition temperature was considerably higher than planned. 2

Following TSE-5, an unusually extensive material characlerization study $^{2}$ revealed a large scatter (approximately $\pm 50 \%$ ) in the $\mathrm{K}_{\mathrm{Ic}}$ data for the TSE-5 test-cylinder material (A508 class 2 tempered at $613^{\circ} \mathrm{C}$ ). Thus, a similar study was conducted as a part of the TSE-5A feasibility studies. Tempering temperatures included in these studies were 677 and $707^{\circ} \mathrm{C}$, and the corresponding fracture toughness data ${ }^{\dagger}$ from $1 T-C T$ specimens are shown in Figs. 4.1 and 4.2. Data from another source ${ }^{3}$ for tempering temperatures of 677 and $660^{\circ} \mathrm{C}$ are also included in Fig. 4.1. In both figures the

*Conversion from SI to English units for all SI quantities are listed on a foldout page at the end of this report.

$t_{\text {Values of }} \mathrm{K}_{\mathrm{Ic}}$ are calculated in accordance with the expressions given in ASTM E 399, with the load $\mathrm{P}_{\mathrm{O}}$ being given by $\sqrt{2 \mathrm{kE}_{\max }}$, where $\mathrm{k}$ is the slope of the linear portion of the load-dispacement record and $E_{\max }$ is the area under the record up to maximum load. 


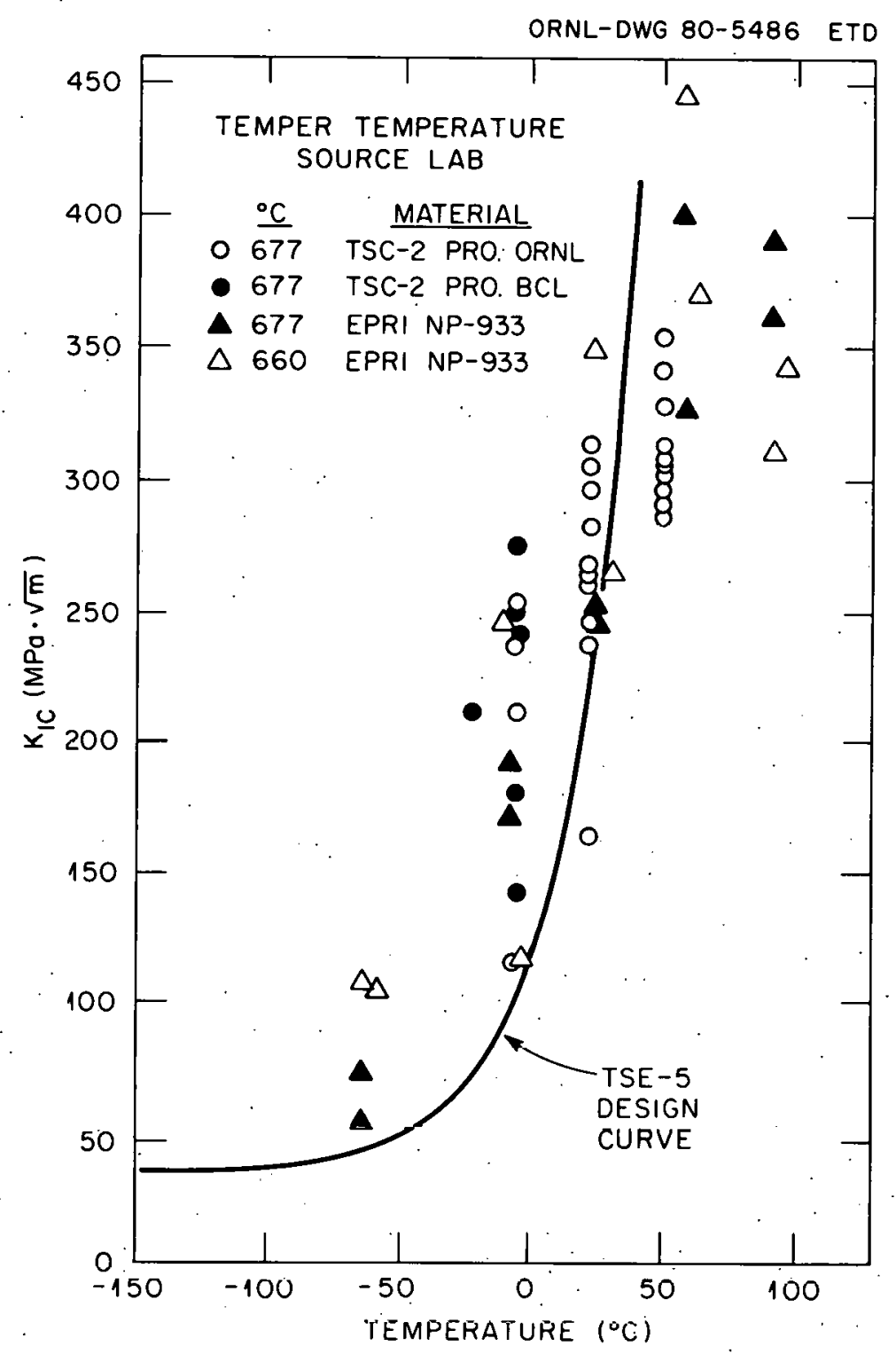

Fig. 4.1. Fracture toughness for A508, class 2 material tempered at 677 nnd $660^{\circ} \mathrm{C}$ meaeured with $1 \mathrm{~T}-\mathrm{CT}$ specimens:

experimental data are compared with the specified design curve for TSE-5, which (as mentioned in Ref. 2) is also an acceptable design curve for TSE-5A. Since the resullts of TSE-5 indicate that a long flaw will behave in accordance with lower-bound toughness, ${ }^{2}$ the lower bound of the experimental data should be compared with the design curve.

As explained in Ref. 2, the RTNDT for the design curve in Figs. 4.1 and 4.2 is $-34^{\circ} \mathrm{C}$, and a reasonable range of acceptability for TSE-5A is 


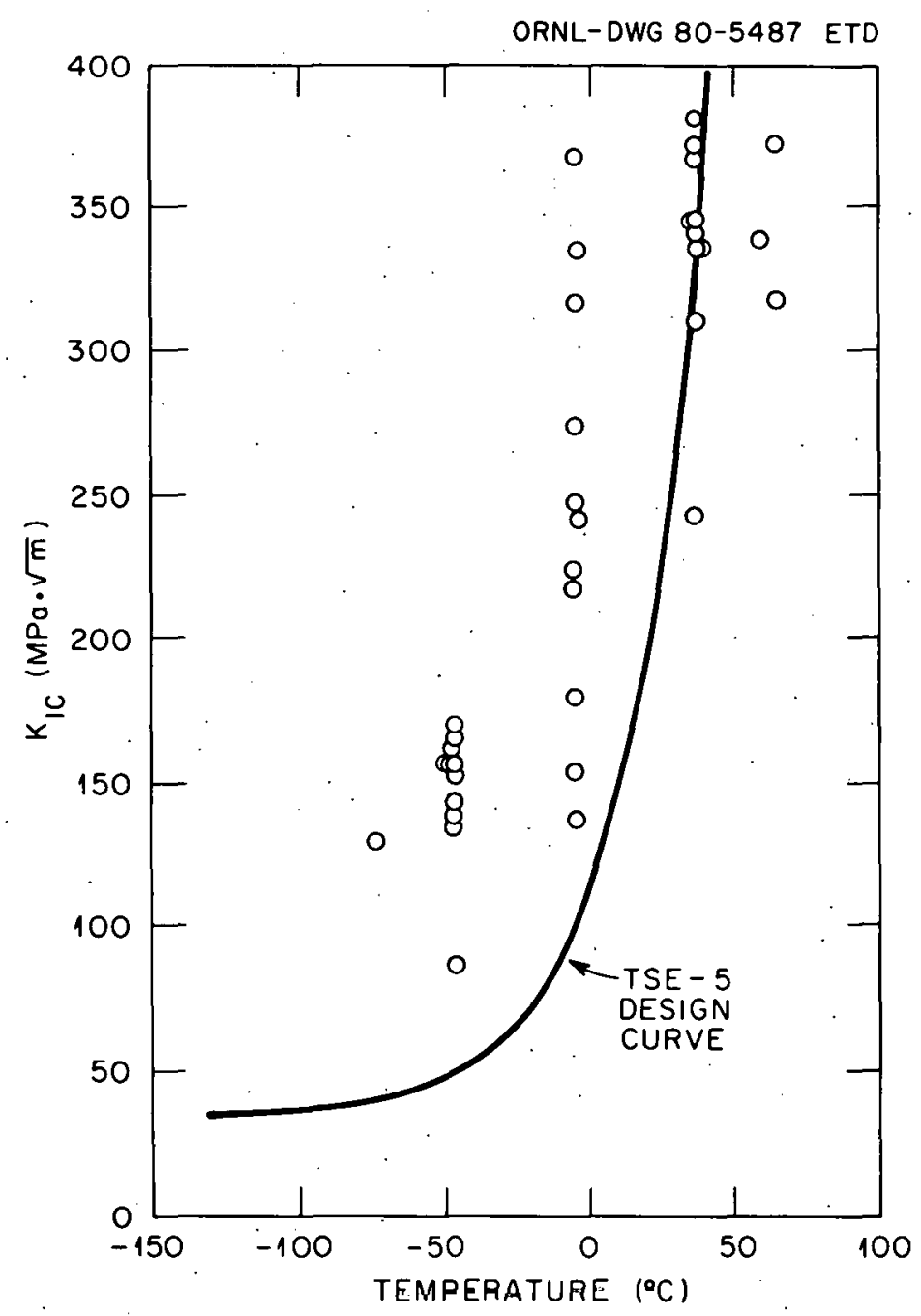

Fig. 4.2. Fracture toughness for TSC-2 prolongation tempered at $707^{\circ} \mathrm{C}$ measured with $1 \mathrm{~T}-\mathrm{CT}$ specimens.

approximately -34 to $-18^{\circ} \mathrm{C}$. On the basis of (1) an assumption that the appropriate lower-bound curve for the material is one drawn through the lowest data points in Figs. 4.1 and 4.2 (excluding upper-shelf points) and (2) a comparison of data in the midtransition region, the $\mathrm{RT}_{\mathrm{NDT}}$ values. for tempering temperatures of 677 and $707^{\circ} \mathrm{C}$ appear to be -17 and $-26^{\circ} \mathrm{C}$ respectively. Thus, the higher tempering temperature appears to be the better of the two. However, the lower-shelf toughness for the higher tempering temperature is too high, while for the lower tempering temperature it is acceptable. Therefore, a tempering temperature of $679 \pm 3^{\circ} \mathrm{C}$ was specified for TSE-5A. The corresponding acceptable thermal shock is 
the same, or perhaps somewhat more severe, as that achieved during TSE-5. The critical-crack-depth curves corresponding to $\mathrm{RT}_{\mathrm{NDT}}=-18^{\circ} \mathrm{C}$ and the TSE-5 thermal transient are shown in Fig. 4.3.

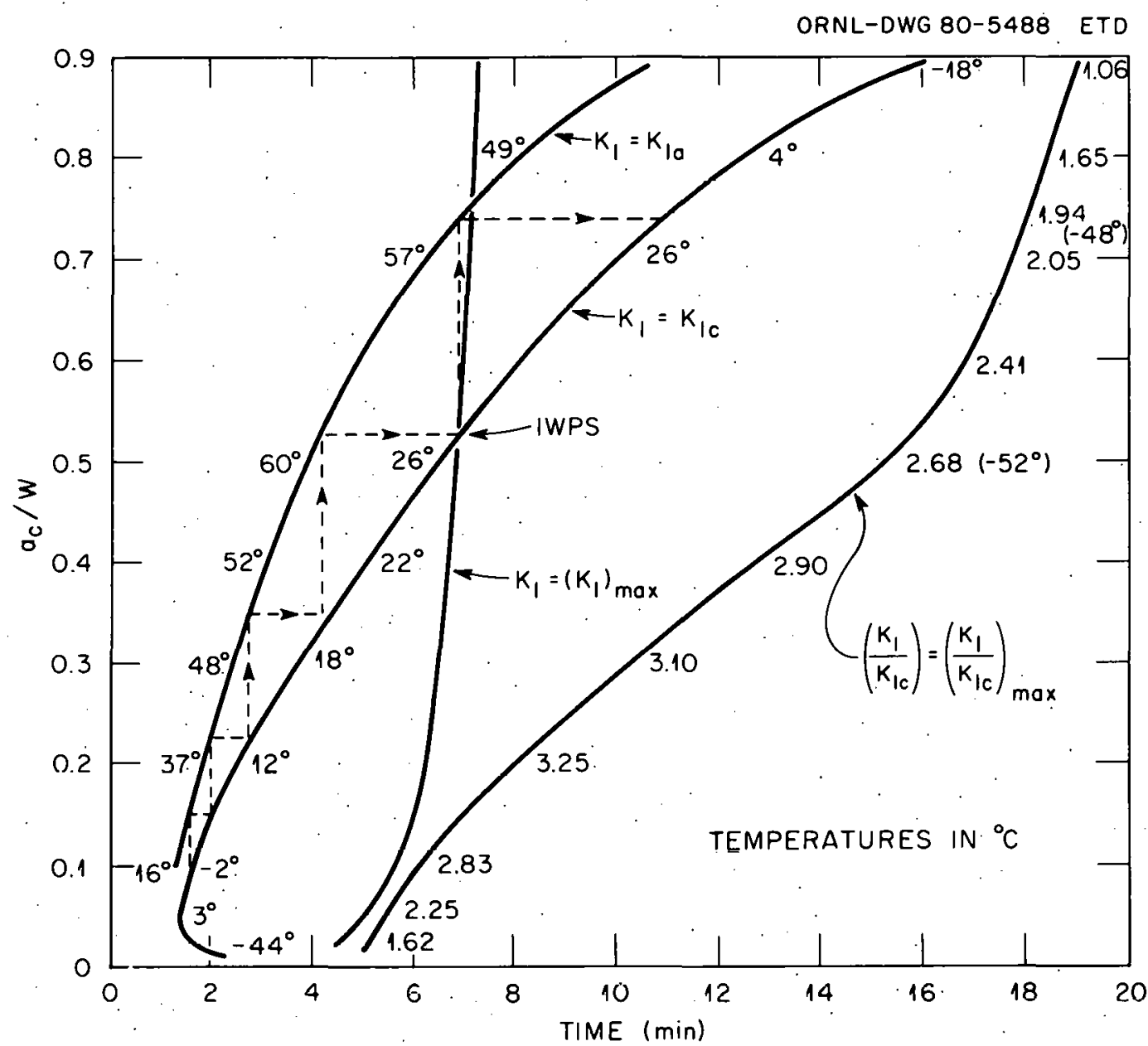

Fig. 4.3. Pretest critical-crack-depth curves for ISE-5A $\left(\mathrm{RT}_{\mathrm{NDT}}=\right.$ $-18^{\circ} \mathrm{C}$, TSE-5 thermal transient).

\subsection{Tempering of TSC-2 Prolongation}

After selecting a tempering temperature $\left(679 \pm 3{ }^{\circ} \mathrm{C}\right.$ ) for $\mathrm{TSC}-2$ (TSE-5A test cylinder), the TSC-2 prolongation, machined to the same inside diameter. (ID) and outside diameter (OD) as for the finished test cylinder, was tempered with the same specified temperature. Tempering was done in a radiant furnace (with radiant heaters on all surfaces, including the door but excluding the floor). The prolongation was mounted vertically on 
several fire brick that were located on a metal pallet. This arrangement allowed natural circulation of air through the center of the cylinder; there was no circulating fan in the furnace. Ten thermocouples were used to determine the temperature distribution throughout the prolongation during tempering. Prior to the tempering treatment, the thermocouples were calibrated at room temperature and at $660^{\circ} \mathrm{C}$. The only significant temperature gradient observed in the prolongation during the tempering treatment was in the vertical direction. The gradient was linear, and the variation from end to end was $16^{\circ} \mathrm{C}$. At midlength of the prolongation, the indicated temperature was $679 \pm 2{ }^{\circ} \mathrm{C}$ during the $4-\mathrm{h}$ soak period.

The vertical gradient in temperature in the prolongation during tempering was the result of radiant heat being applied to the upper end of the prolongation and not to the bottom end. This problem will be alleviated when TSC-2 is tempered by insulating both ends of the test cylinder.

\subsection{Residua1-Stress Study with TSC-2 Prolongation}

Following tempering of the TSC-2 prolongation, residual stresses on the inner surface were measured by first mounting strain gage rosettes on the inner surface and then sawing out small pieces of the wall having the gages attached. Five rosettes were used along a single axial line. By this means the residual stresses were found to be approximately $-70 \mathrm{MPa}$.

l'he residual stresses are primarily a result of the water-quench portion of the heat treatment. Because of plastic flow in tension near the quenched surfaces during the quench treatment, the residual stress near the surfaces is compressive and high. A steep gradient in residual stress exists near the surface, and over the central portion of the wall the residual stress is moderate and uniform tension.

Following the water-quench treatment, $32-$ and $38-\mathrm{mm}$ sections of material were removed by machining from the inner and outer surfaces respectively. This process removed most of the residual stresses, which otherwise would range as high as $700 \mathrm{MPa}$ or more. For TSC-1 (TSE-5 test cylinder) this process, plus tempering at $613^{\circ} \mathrm{C}$ for $4 \mathrm{~h}$, reduced the innersurface residual stress to approximately $-120 \mathrm{MPa} .^{1}$ The lower residual compressive stresses for the TSC-2 prolongation presumably are a result 
of a higher tempering temperature for the latter prolongation $\left(679^{\circ} \mathrm{C}\right.$ for $4 \mathrm{~h})$.

Because of the steep gradient in residual stress near the surfaces and the relatively low residual tensile stress elsewhere, the residual stresses in TSC-2 are not expected to have a significant effect on $K_{I}$ during TSE-5A.

\section{4 Machining of TSC-2 (TSE-5A Test Cylinder)}

The design and machining of TSC-2 are the same as for TSC-1 with two exceptions:

1. The three thermocouple-thimble holes at midlength were changed from 25-mm-diam drilled holes to rectangular tapered holes 25 by $25 \mathrm{~mm}$ on the inside and 25 by $37 \mathrm{~mm}$ on the outside, with the long dimension running in the circumferential direction. The tapered sides are in radial planes containing the longitudinal centerline of the cylinder. Thermocouple thimbles that fit these holes will be unaffected by surface contact between thimble and hole and thus will provide accurate temperature dis-. tributions throughout the transient.

2. A 3.2-mm-diam radial hole through the test-cylinder wall, located $\sim 80 \mathrm{~mm}$ from the long axial flaw on the inner surface, is provided in TSC-2 for electrical-lead egress for each. of nine COD gages. Previously, these leads were attached to the inner surface and extended to the end of the test cylinder, where they exited through the upper flange. The longitudinal runs of the leads created perturbations in the rubber cement coating that could introduce significant asymmetries in quenching during the thermal shock experiment.

Machining of the tapered holes was done with electrical-discharge machining (EDM), using an outrigged ELOX machine. A job such as this had not been attempted previuusly in the Oak Ridge area, but in spite of some unique features, the job was completed successfully.

\subsection{EB-We1d Fl,awing .}

Initial flaws for TSE-1 through 5 were created by means of the EBwcld-flawing technique. ${ }^{4}$ For the first four test cylinders, EB-weld 
cracking was spontaneous as the torch moved on and allowed the weld to cool. For TSE-5, cracking of the EB weld required $\sim 50 \mathrm{~h}$ of hydrogen charging. Both materials were A508 with class 2 chemistry, but the first four cylinders were in a quench-only condition, while the TSE-5 cylinder (TSC-1) was tempered at $613^{\circ} \mathrm{C}$. Developmental EB welds with TSC-1 material indicated that tempering temperature had no effect on cracking; all welds required many hours of hydrogen charging. Also, EB-weld depth was ruled out as a factor. Thus, the difference in cracking was attributed to small differences in chemistry.

EB-weld development work for TSE-5A, using TSC-2 material (same as TSC-1) with a tempering temperature of $679^{\circ} \mathrm{C}$, has resulted in cracking with only $4 \mathrm{~h}$ of hydrogen charging. No immediate explanation has been found for these results.

Concern over these specific cracking details is that cross cracks developed in the TSC-1 flaw but not in the flaws for the first four experiments. Cross cracks are not desirable, and apparently the more hydrogen charging required, the greater the chance of cross cracks. No cross cracks have been observed yet during the most recent development work ( $4 \mathrm{~h}$ charging time).

One possible way to reduce charging time or perhaps to eliminate it altogether is to degrade the $E B$ weld with copper or sulfur. We are attempting to introduce sulfur into the EB-weld fusion zone by placing an iron-sulfur compound on the work piece in the path of the torch. Thus far, no effect on required hydrogen charging time has been noted:

\subsection{Rubber Cement Coating. Development}

During the latter part of or just after TSE-5 and preliminary heat transfer tests, the rubber cement coating ( $3 M-N F 34$ ) on the inner surface of the test cylinder blistered and peeled. This had not occurred in previous experiments and could not be explained, other than to assume that the surface was not properly cleaned. Contact was made with Minnesota Mining and Manufacturing Company (3M) personnel to seek clues, but none were forthcoming. However, $3 \mathrm{M}$ recommended that in the future $3 M-34$ be used instead of $3 \mathrm{M}-\mathrm{NF} 34$ because the chemical makeup of the latter product 
was sensitive to the source of petroleum-base material, while the other was not. Furthermore, 3M-34 should have better adhesion under any circumstances, particularly in this application.

Test sprays with $3 \mathrm{M}-34$ were conducted in the spray-test facility (same interior dimensions as TSC-2) until a satisfactory spray was obtained. This same spray was then applied to one end of a steel bar that was $100 \mathrm{~mm}$ diam by $150 \mathrm{~mm}$ long, while the end to be sprayed was flush with the inner surface of the spray-test cylinder. 'After an appropriate drying time followed by heating to $100^{\circ} \mathrm{C}$, the sprayed end.was quenched with liquid nitrogen. The quench time was much longer than had been expected.

\subsection{Posttest Analysis of TSE-5 \\ S. K. Iskander D. G. Ball}

\subsubsection{Introduction}

Variation of the three-dimensional stress-intensity factor $\left(K_{I}\right)$ along the final crack front in the TSE-5.test cylinder (TSC-2) has been determined by the finite-element method using two meshes differing in the number of degrees of freedom (DOF). Results of the analysis using the mesh with the fewer DOF (designated the "coarse" mesh for brevity) have been reported previously. ${ }^{2}$ In this report, the results of the analysis using the "finer" mesh have been compared with those of the coarser one.

Linear elastic fracture mechanics (LEFM) studies have also been performed to determine the difference in the two-dimensional $\mathrm{K}_{\mathrm{I}}$ values for a long axial crack of a thermally shocked thick cylinder when approximated as a $90^{\circ}$ segment rather than the usual $180^{\circ}$ model.

\subsubsection{Three-dimensional calculations of final arrested crack shape in TSC-2}

The shape of the final crack front in TSC-2 was not uniform but decreased toward the free ends and intersected the free-end planes at an angle other than $90^{\circ}$. The variation of $\mathrm{K}_{\mathrm{I}}$ along this crack front was obtained by means of a three-dimensional finite-element analysis and was reported for the previous report period. ${ }^{2}$ Results indicated that the $\mathrm{K}_{\mathrm{I}}$ 
values near the. free ends of the cylinder were slightly higher (10\%) than those near the midlength. For a similar cylinder in which the crack depth was uniform in the longitudinal direction, the $\mathrm{K}_{\mathrm{I}}$ values dropped to zero at the free ends, and the variation of the two-dimensional $\mathrm{K}_{\mathrm{I}}$ values corresponding to the same crack depths as in the TSC-2 final crack shape tended to increase sharply near the end, as shown in Fig. 4.4.

Each of the above $\mathrm{K}_{\mathrm{I}}$ distributions can be explained qualitatively, and the two-dimensional results are considered to be quite accurate. However, a comparison of the two- and three-dimensional results does not really establish the accuracy of the three-dimensional results; therefore the possibility remains that the three-dimensional mesh may not be adequate. To investigate this possibility, a mesh with about $70 \%$ more nodes

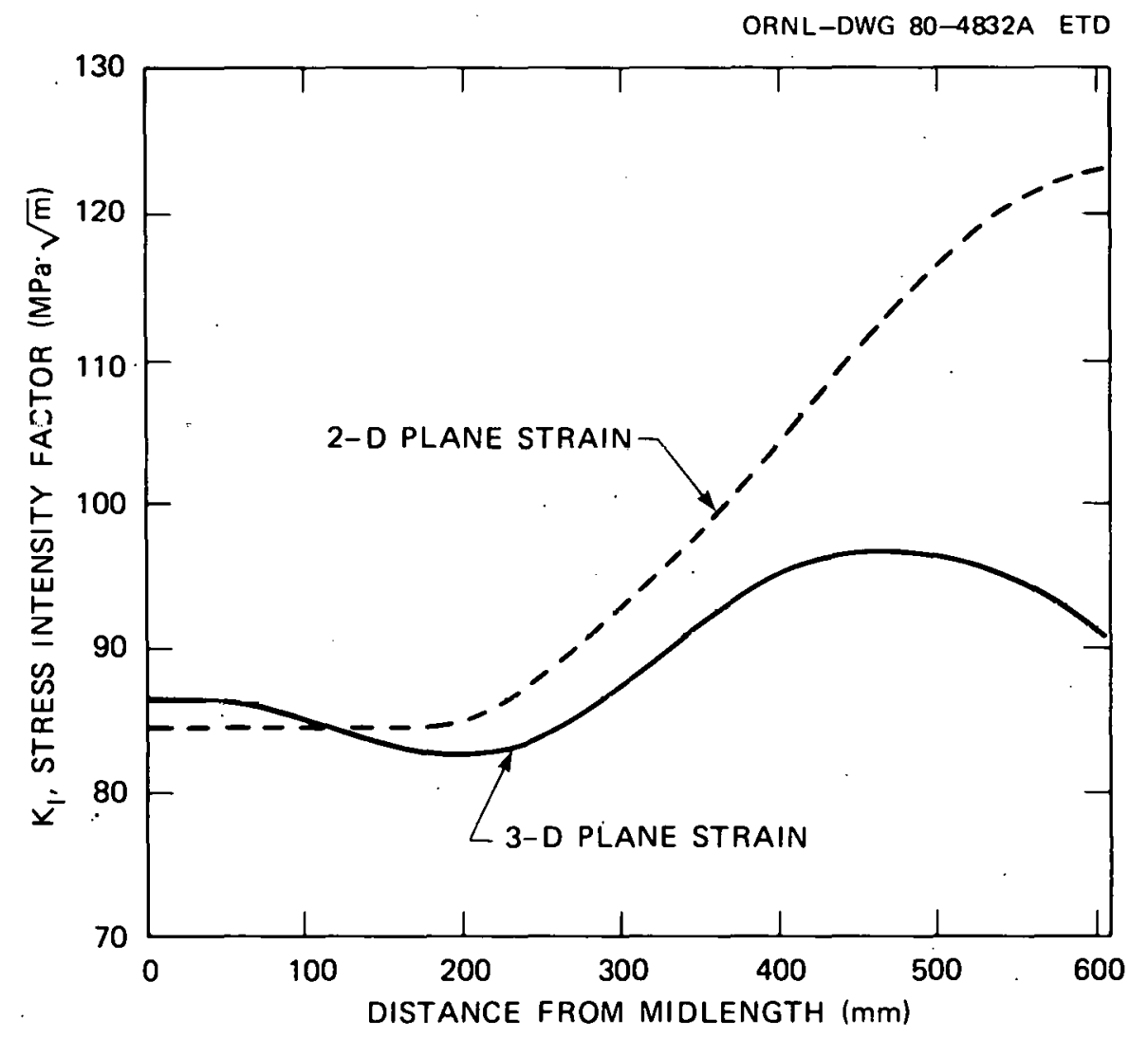

Fi.g. 4.4. Variation of three-dimensional $\mathrm{K}_{\mathrm{I}}$ values as a function of distance from midlength using two different meshes, designated as (a) coarse and ( $b$ ) fine meshes. Two-dimensional $K_{I}$ values for corresponding fractional depths of crack are also shown (Ref. 1). 
has been generated. Most of the extra nodes are near the crack front and. near the free ends, because these are the regions where the previous results are to be checked. Figure 4.5. shows the two finite-element meshes: the coarser one, for which results have been reported previously, and the finer one, which is discussed in this report. Figure 4.5 shows the dis-. tribution of the nodes through the cylinder wall in the plane of the flaw; the three-dimensional mesh is obtained by rotating these meshes about the cylinder axis. The details of the finite-element modeling and some data from the computer run using the ADINA code are reported in Table 4.1.
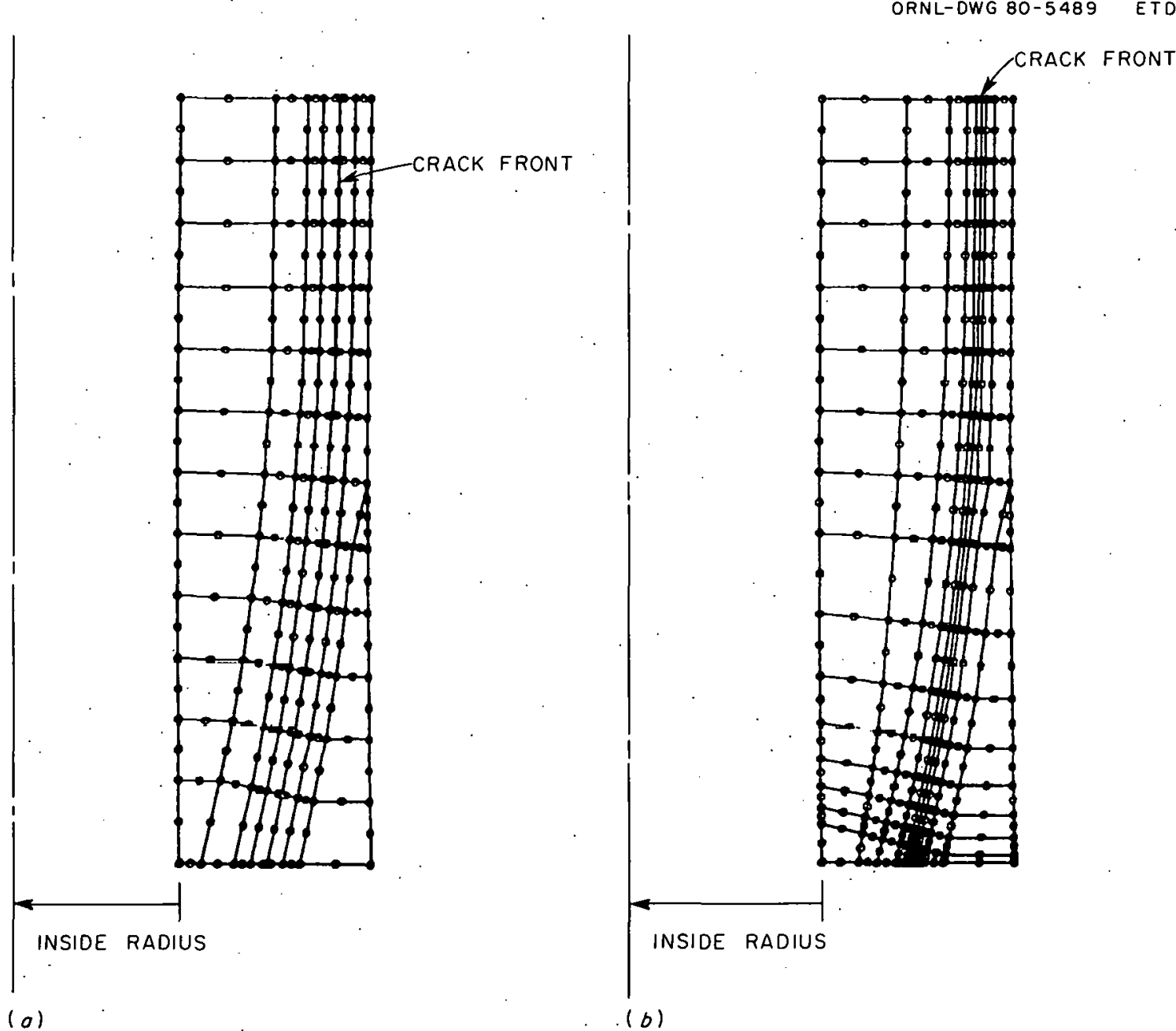

Fig. 4.5. Distribution of nodes through cylinder wall in plane of flaw for (a) coarse and (b) fine mesh. Finite-element three-dimensional model is generated by rotating these planes about axis of cylinder. 
Table 4.1. Miscellaneous data related to three-dimensional finite-element analysis with ADINA 78 code using 2964 kilobytes of fast memory and finer mesh

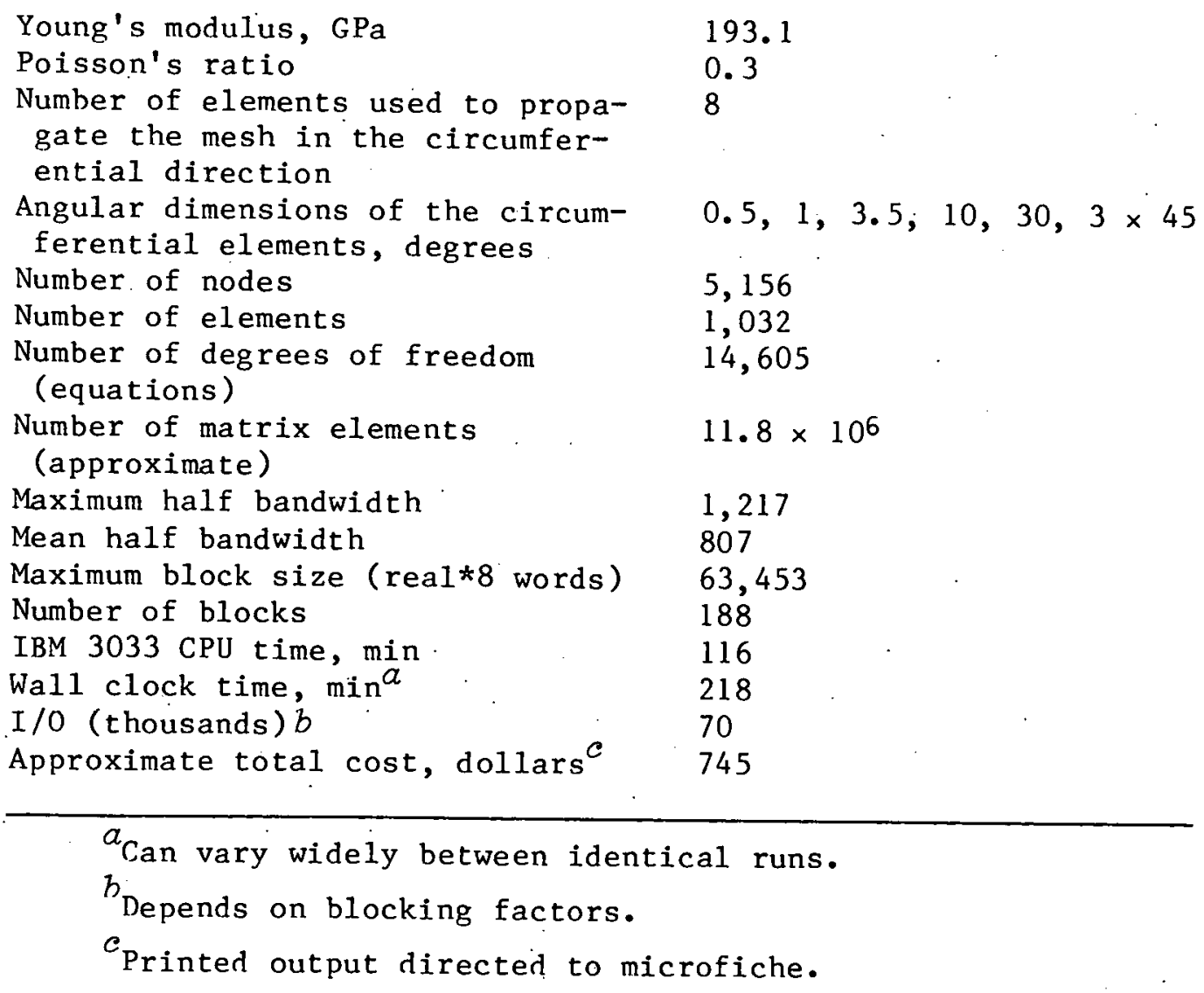

These latter data are useful as a guide in planning similar analyses; as can be seen in Table 4.1, these runs are expensive and utilize considerable amounts of the available computer resources.

The variations of $K_{I}$ along the crack front for the final crack shape at a time of $3.43 \mathrm{~min}$ in the transient are given in Table 4.2. These values have been plotted in Fig. 4.4 to compare them with those of the previous analysis using the coarser mesh. The trends of both analyses are similar - namely, the $\mathrm{K}_{\mathrm{I}}$ values tend to increase toward the free ends. The maximum variation of the refined-mesh $\mathrm{K}_{\mathrm{I}}$ values from those obtained from the coarse mesh is $5 \%$ and occurs near the free ends. Thus, the three-dimensional $\mathrm{K}_{\mathrm{I}}$ values appear reasonably accurate, and the stressintensity factor does, in fact, appear to increase toward the free ends 
Table 4.2. Variation of stress-intensity factor $K_{I}$ as function of axial distance from midlength for final arrested crack shape in TSE-5 using refined mesh

$$
\text { Time in transient }=3.43 \mathrm{~min}
$$

\begin{tabular}{cc}
\hline $\begin{array}{c}\text { Distance from } \\
\text { midlength }\end{array}$ & $\begin{array}{c}\text { Stress-intensity } \\
(\mathrm{mm})\end{array}$ \\
factor KI \\
$(\mathrm{MPa} \cdot \sqrt{\mathrm{m}})$
\end{tabular}

\begin{tabular}{cc}
\hline 0 & 87.7 \\
50.8 & 87.5 \\
102 & 86.7 \\
152 & 84.8 \\
203 & 84.1 \\
254 & 86.4 \\
305 & 90.2 \\
356 & 94.8 \\
422 & 99.2 \\
472 & 100 \\
513 & 99.4 \\
544 & 98.7 \\
566 & 98.2 \\
584 & 97.6 \\
597 & 96.1 \\
\hline
\end{tabular}

because of the shallower crack depth. As hypothesized in the previous progress report, the shape of the crack front tends to a geometry for which $\mathrm{K}_{\mathrm{I}} / \mathrm{K}_{\mathrm{Ia}}$ is unity.

\subsubsection{Two-dimensiona1 LEFM analysis of long axial crack modeled as $90^{\circ}$ segment}

Utilizing the symmetry of the geometry [Fig. 4.6(a)], a single long axial crack in a cylinder is usually modeled as a $180^{\circ}$ segment [Fig. 4.6(b)]. The question arose as to the feasibility of using only a $90^{\circ}$ segment [Fig. 4.6(c)], thercby saving computer time.

The comparison of two analyses is given in Table 4.3, which shows the $\mathrm{K}_{\mathrm{I}}$ values obtained by using either a $180^{\circ}$ or a $90^{\circ}$ model. The results show an increase of about 20 to $30 \%$ in the $90^{\circ}$ model over those obtained utilizing the $180^{\circ}$ model. This increase may occur because the $90^{\circ}$ segment 
ORNL-DWG 80-5490 ETD

(a)

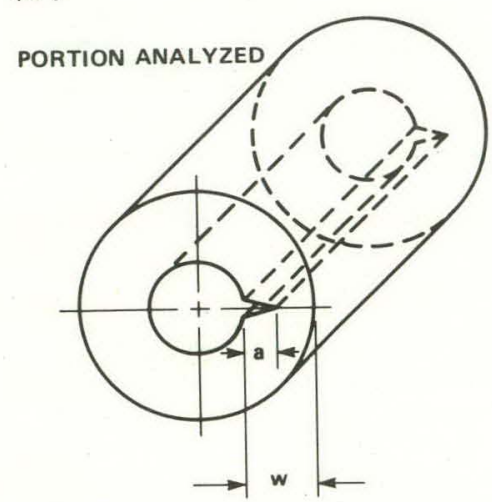

(b)

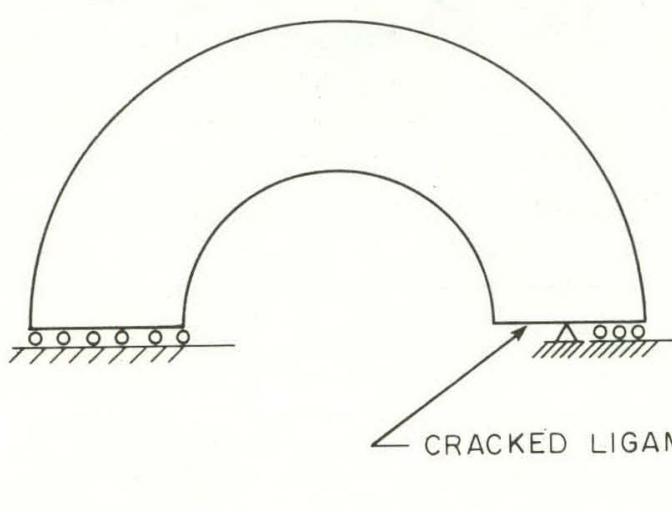

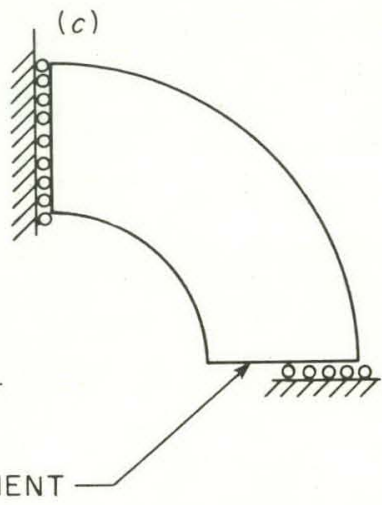

(d)

(e)
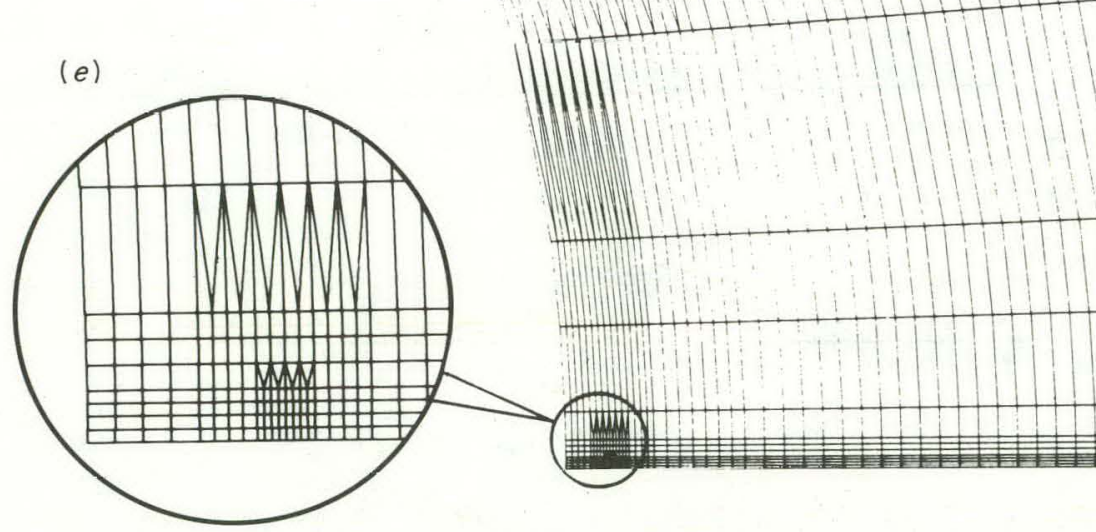

11111
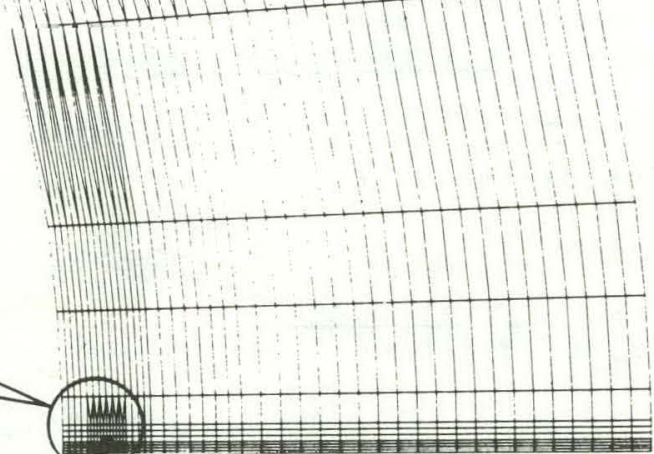

Fig. 4.6. Two-dimensional plane-strain modeling of (a) a single axial crack in a cylinder, (b) usual $180^{\circ}$ finite-element model, and (c) $90^{\circ}$ segment "mode1." Details of distribution of nodes in vicinity of crack are shown in (d) and (e) (scales used in horizontal and vertical directions are unequa1). 
Table 4.3. Variation of two-dimensional stressintensity factor $K_{\mathrm{I}}$ with time for fractional crack depth of $a / W=0.500$ when modeled as a $180^{\circ}$ and $90^{\circ}$ segment

\begin{tabular}{cccc}
$\begin{array}{c}\text { Time in } \\
\text { transient } \\
\text { (min:s) }\end{array}$ & $\begin{array}{c}\mathrm{K}_{\mathrm{I}} \text { values }(\mathrm{MPa} \cdot \sqrt{\mathrm{m}})^{a} \\
180^{\circ} \text { model }\end{array}$ & $90^{\circ}$ model & $\begin{array}{c}\text { Difference from } \\
180^{\circ} \text { model } \\
(\%)\end{array}$ \\
\hline $0: 30$ & 24.0 & 31.2 & 30 \\
$1: 00$ & 45.8 & 59.1 & 29 \\
$1: 30$ & 64.2 & 82.5 & 29 \\
$1: 46$ & 78.1 & 99.6 & 27 \\
$2: 00$ & 85.9 & 108.9 & 27 \\
$2: 30$ & 99.4 & 125.9 & 27 \\
$2: 58$ & 114.2 & 143.2 & 25 \\
$3: 26$ & 122.5 & 153.4 & 25 \\
$4: 00$ & 130.3 & 163.0 & 25 \\
$5: 00$ & 141.5 & 175.7 & 24 \\
$7: 00$ & 145.9 & 180.9 & 24 \\
$10: 00$ & 136.7 & 168.9 & 24 \\
$15: 00$ & 114.5 & 141.2 & 23 \\
$20: 00$ & 88.9 & 109.6 & 23 \\
& & & \\
\hline
\end{tabular}
code.

$a_{5}$ These were calculated by means of the FMECH

actually models two cracks $180^{\circ}$ apart, thus increasing the cylinder flexibility. The accuracy of the $180^{\circ}$ calculation has been checked by means of an independent method and determined to be about 4\% (Ref. 2).

The variation of the differences with respect to time for this crack depth indicates that the steep temperature gradients at the iuitial portion of the transicnt, in relation to the 1 nration of the crack root, influence the results.

Further, the number of nodes used in the $90^{\circ}$ model are about $62 \%$ of those used in the $180^{\circ}$ model because a large portion of the nodes are in the crack region.

Results of this analysis are in contrast to those obtained by the University of Maryland (see Sect. 2.3) because the latter results correspond to a shallower flaw $(a / W=0.2$ compared with 0.5$)$, for which bending effects are much less. As flaw depth increases, the bending effect increases, and the accuracy of the model becomes morc important. 


\subsection{Thermal Shock Material Characterization}
W. J. Stelzman
D. A. Canonico

The fracture toughness ( $K_{I c}$ ) characterization of the thermal shock prolongation TSP-2 segment that was tempered at $707^{\circ} \mathrm{C}$ for $4 \mathrm{~h}$ has been completed. Latest results from CT-oriented iT compact specimens, primarily at $-4^{\circ} \mathrm{C}$, are listed in Table 4.4. Results from Table 4.4 and results previously reported ${ }^{6}$ are plotted in Fig. 4.7. Over the test temperatures examined, the results at $-4^{\circ} \mathrm{C}$ showed the greatest variation between 140 and $367 \mathrm{MPa} \cdot \sqrt{\mathrm{m}}$. None of the results were valid in accordance with ASTM E 399 criteria.

We also examined the through-thickness variation of $\mathrm{K}_{\mathrm{IC}_{\mathrm{C}}}$ at $-18^{\circ} \mathrm{C}$ and the variation of $\mathrm{K}_{\mathrm{Ic}}$ with temperature at the one-third-depth location (152-mm-thick wall) from the inner wall of prolongation.TSP-1 using $0.394 \mathrm{~T}$

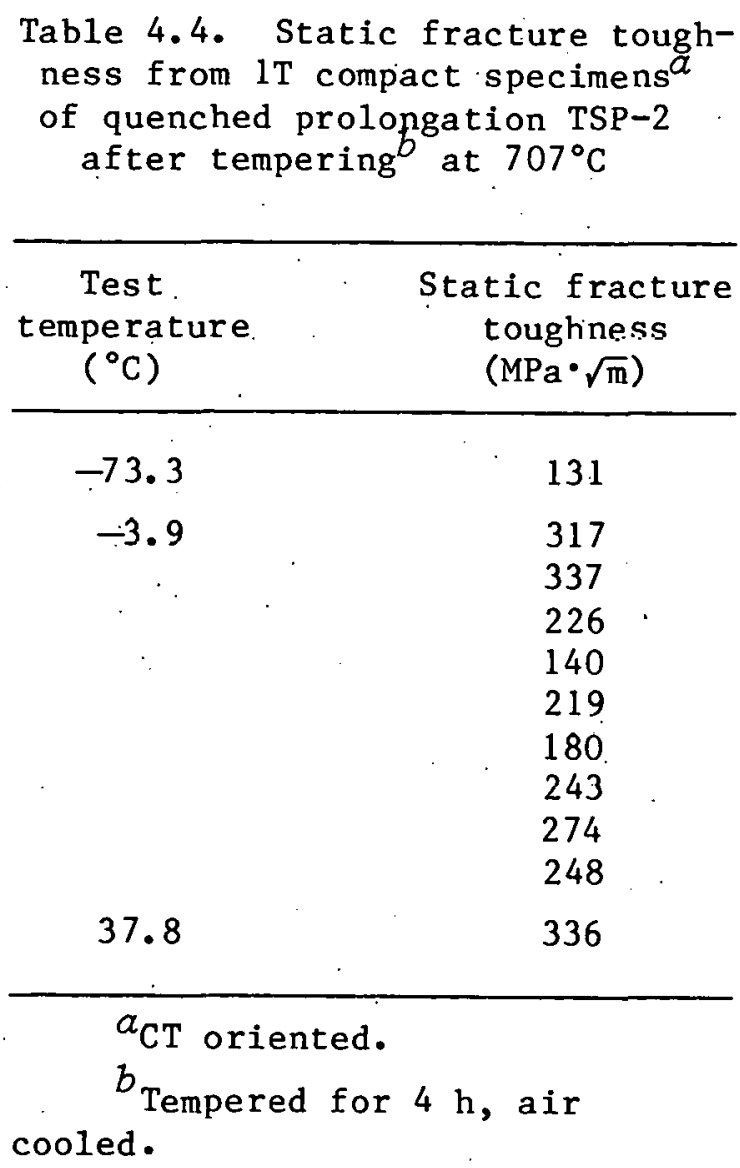




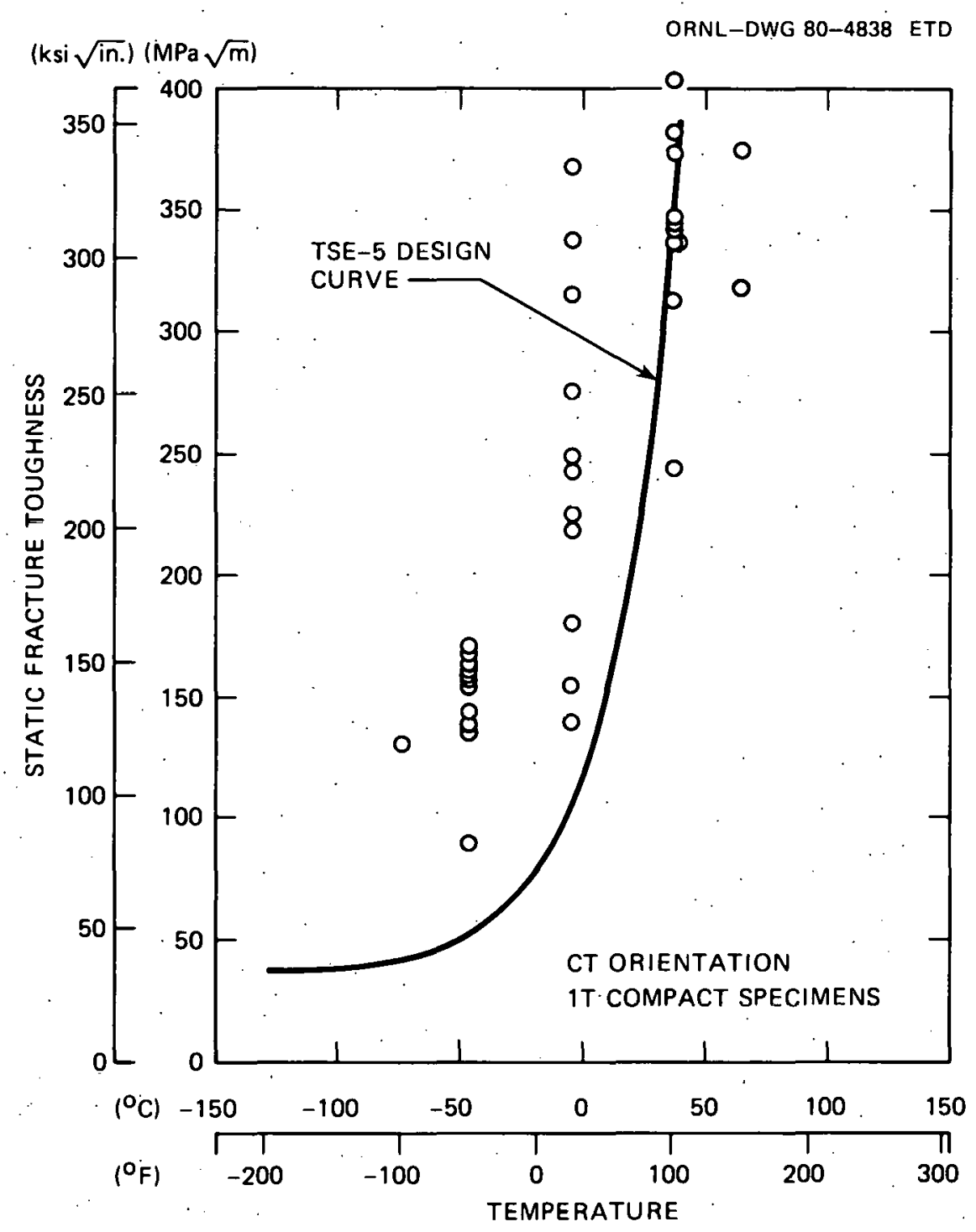

Fig. 4.7. Variation of static fracture toughness from $1 \mathrm{~T}$ compact specimens from prolongation TSP-2 (SA 508) after tempering at $707^{\circ} \mathrm{C}$ for $4 h$ and cooling in air.

compact specimens $\left(\mathrm{C}_{\mathrm{V}} \mathrm{T} \mathrm{CS}\right)$. The material from TSP-1 had the same temper as thermal shock vessel TSC-1 used in experiment TSE-5: $613^{\circ} \mathrm{C}$ for $4 \mathrm{~h}$. The effect of specimen size was examined by comparing the $\mathrm{C}_{\mathrm{V}} \mathrm{T}$ CS results with previously reported ${ }^{6}$ results from $1 \mathrm{~T}$ and $2 \mathrm{~T}$ compact specimens. A11 specimens had the tip of the fatigue crack at the same depth location from the inner surface of TSP-1 (one-third-depth location). 
Results of the through-thickness survey at $-18^{\circ} \mathrm{C}$ are summarized in Table 4.5 and plotted in Fig. 4.8. The lower-bound values appear to increase between the inner surface and midthickness of the prolongation. This is contrary to what would be expected. Prolongation TSP-1, as quenched, was originally $216 \mathrm{~mm}$ thick. Subsequent machinings removed $32 \mathrm{~mm}$ from each surface, leaving a 152-mm-thick prolongation prior to the $613^{\circ} \mathrm{C}$ temper. Therefore, the $\mathrm{K}_{\mathrm{Ic}}$ values should be fairly uniform across the thickness, or, if some of the more rapidly cooled material near the surface were still present, the $K_{I c}$ values should be somewhat higher near the surfaces. One explanation would be that if additional specimens were tested, then the lower limit would be near that obtained for the other locations; it too would lie near $55 \mathrm{MPa} \cdot \sqrt{\mathrm{m}}$. The $55 \mathrm{MPa} \cdot \sqrt{\mathrm{m}}$ value agrees with the $52 \mathrm{MPa} \cdot \sqrt{\mathrm{m}}$ lower-bound value previously reported. 6

Results from the study of $\mathrm{K}_{\mathrm{Ic}}$ variation with temperature using $\mathrm{C}_{\mathrm{V}} \mathrm{T} C \mathrm{CS}$ from the one-third-depth location are listed in Table 4.6 and plotted in Fig. 4.9. The lower-bound values tend to increase with test temperature between -3.9 and $37.8^{\circ} \mathrm{C}$. Additional tests at $-73.3^{\circ} \mathrm{C}$ would be necessary to establish a more reliable lower bound.

Results of the specimen size comparison with specimens obtained from prolongation TSP-1 after tempering at $613^{\circ} \mathrm{C}$ for $4 \mathrm{~h}$ are listed in Table 4.7. The comparison is made at $-18^{\circ} \mathrm{C}$ and shows that, for the specimens tested, the lower-bound fracture toughness decreases with incrcasing specimen size.

The test results of the $\mathrm{C}_{\mathrm{V}} \mathrm{T}$ CS obtained from the $0.3 \mathrm{t}$ depth were added to the $1 \mathrm{~T}$ and $2 \mathrm{~T}$ compact specimen data previousl.y reported. ${ }^{6}$ These results are presented in Fig. 4.10, which contains all the compact specimen data obtained from the $0.3 \mathrm{t}$ depth location for material tempered at $613^{\circ} \mathrm{C}$.

\subsection{Fractographic Studies}

D. A. Canonico W. J. Stelzman

The large variation in fracture toughness values exhibited in Fig. 4.10 is attributcd to crack extension behavior during testing. This type of behavior is illustrated in Figs. 4.11 and 4.12, which were previously discussed in Ref. 7. Ductile extension of the fatigue crack can occur 
Table 4.5. Fracture toughness at several depth locations in thermal shock prolongation $\mathrm{TS} \dot{\mathrm{P}}-\mathrm{l}^{a}$ using $0.394 \mathrm{~T}$ compact specimens $b$ tested at $-18^{\circ} \mathrm{C}$

\begin{tabular}{|c|c|c|c|c|}
\hline \multirow{2}{*}{$\begin{array}{c}\text { Depth } \\
\text { 1.ncation }\end{array}$} & \multirow{2}{*}{$\begin{array}{l}\text { Number of } \\
\text { specimens }\end{array}$} & \multicolumn{3}{|c|}{ Range of $\mathrm{K}_{\mathrm{IC}}(\mathrm{MPa} \cdot \sqrt{\mathrm{m}})$} \\
\hline & & $\mathrm{High}$ & Average & Low \\
\hline $0.06 \mathrm{t}$ & 4 & 109 & 85 & 58 \\
\hline $0.17 \mathrm{t}$ & 5 & 132 & 108 & 67 \\
\hline $0.33 \mathrm{t}$ & 5 & 190 & 140 & 91 \\
\hline $0.50 t$ & 5 & 203 & 173 & 159 \\
\hline $0.67 t$ & 4 & 144 & 91 & 58 \\
\hline $0.83 \mathrm{t}$ & 5 & 186 & 153 & 90 \\
\hline
\end{tabular}

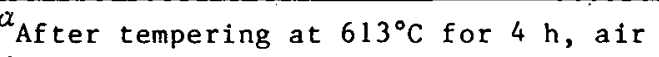

${ }^{b}$ CT oriented.

${ }^{c}$ Depth in the 152-mm-thick wall; inner wall $=0 t$.

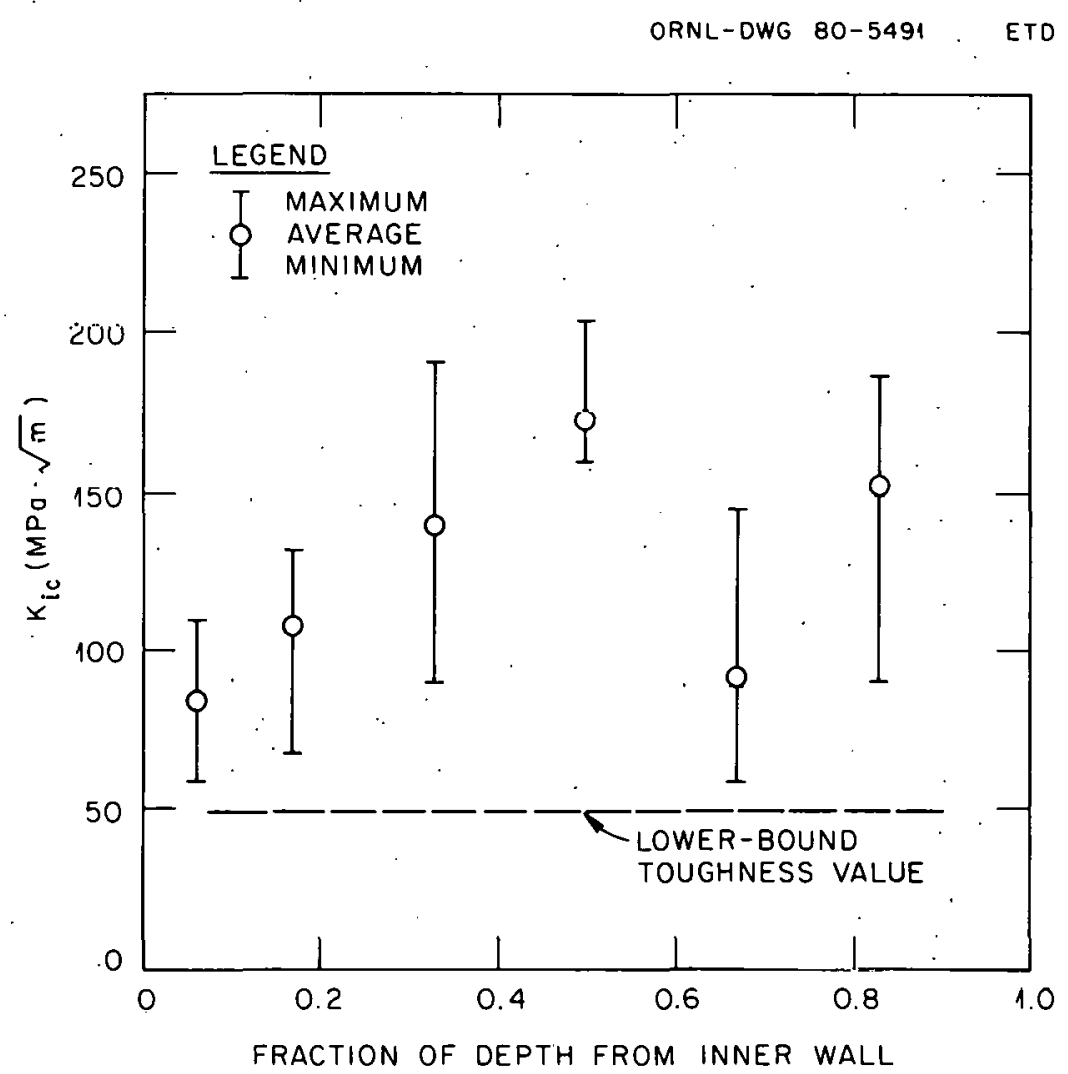

Fig. 4.8. Effect of depth on fracture toughness of prolongation TSP-l after tempering at $613^{\circ} \mathrm{C}$ for $4 \mathrm{~h}$ : CT-oriented, 10-mm-thick compact specimens tested at $-18^{\circ} \mathrm{C}$. Lower-bound toughness value is from Fig. 4.4 . 
Table 4.6. Variation. of fracture toughness with remperature at onc-third-depth location ${ }^{a}$ in thermal shock prolongation TSP-1 $b$ using $0.394 \mathrm{~T}$ compact specimens ${ }^{c}$

\begin{tabular}{ccccc}
\hline $\begin{array}{c}\text { Test } \\
\text { temperature } \\
\left({ }^{\circ} \mathrm{C}\right)\end{array}$ & $\begin{array}{c}\text { Number of } \\
\text { specimens }\end{array}$ & & \multicolumn{2}{l}{ Range of $\mathrm{K}_{\mathrm{Ic}}(\mathrm{MPa} \cdot \sqrt{\mathrm{m}})$} \\
\cline { 5 - 6 } & & High & Average & Low \\
-73.3 & 3 & 105 & 83 & 66 \\
-3.9 & 3 & 105 & 67 & 42 \\
-17.8 & 5 & 190 & 140 & 91 \\
10.0 & 6 & 230 & 174 & 108 \\
37.8 & 6 & 234 & 187 & 117
\end{tabular}

\footnotetext{
$a_{\text {Inner wall }}=0 t ; 152-\mathrm{mm}$-thick wall.

${ }^{b}$ After tempering at $613^{\circ} \mathrm{C}$ for $4 \mathrm{~h}$, air
} cooled.

${ }^{c} \mathrm{CT}$ oriented.

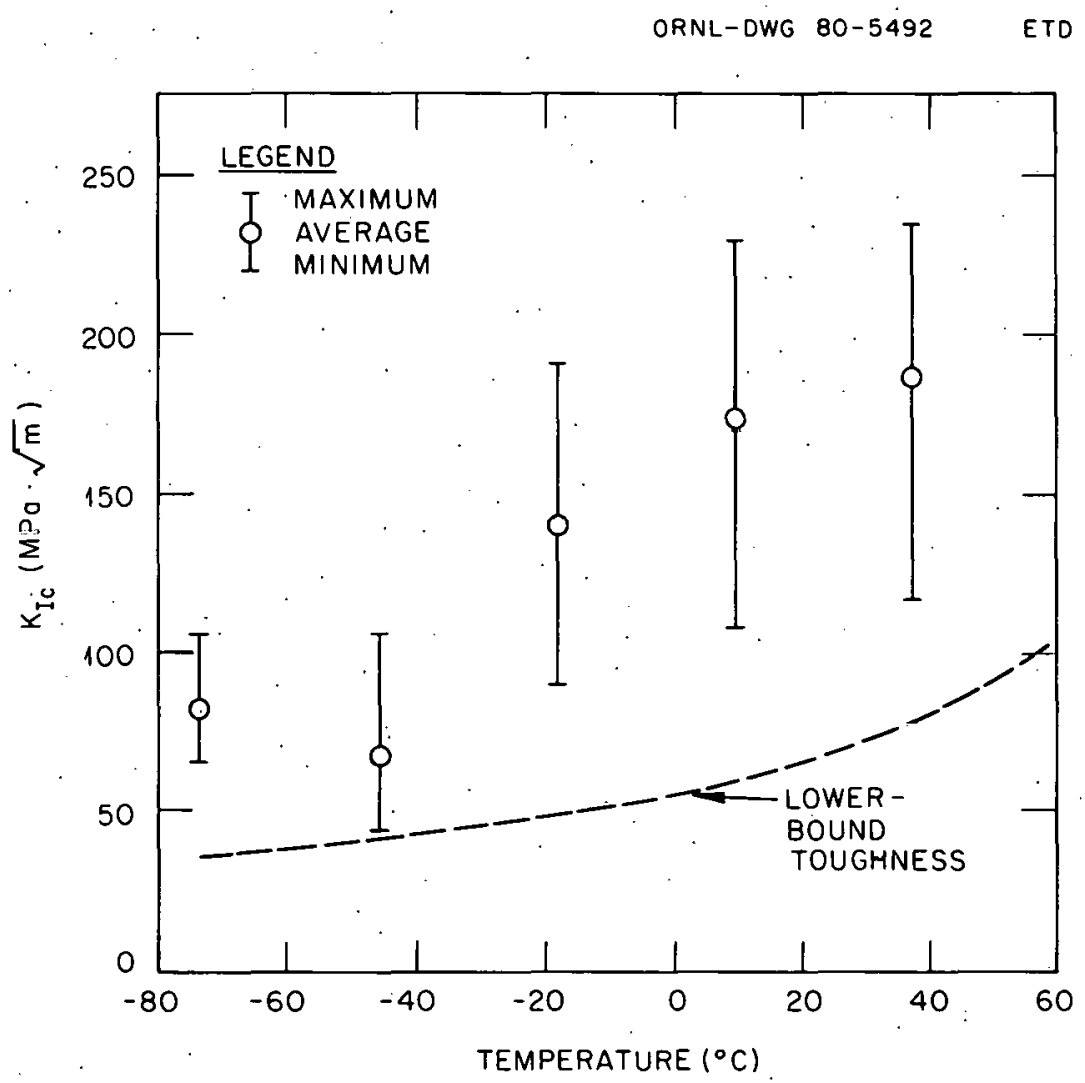

Fig. 4.9. Variation of fracture toughness with temperature at onethird-depth location in prolongation TSP-1 after tempering at $613^{\circ} \mathrm{C}$ for $4 \mathrm{~h}$ : CT-oriented, $10-\mathrm{mm}-$ thick compact specimens. Lower-bound toughness value. is from Fig. 4.4 . 
Table 4.7. Effect of specimen size on fracture toughness of thermal shock prolongation $\mathrm{TSP}-1^{a}$ from compact specimens $^{b}$ from the 0.33 t depth $^{c}$ and tested at $-18^{\circ} \mathrm{C}$

\begin{tabular}{|c|c|c|c|c|}
\hline \multirow{2}{*}{$\begin{array}{c}\text { Specimen } \\
\text { size }\end{array}$} & \multirow{2}{*}{$\begin{array}{l}\text { Number of } \\
\text { specimens }\end{array}$} & \multicolumn{3}{|c|}{ Range of $\mathrm{K}_{\mathrm{Ic}}(\mathrm{MPa} \cdot \sqrt{\mathrm{m}})$} \\
\hline & & $\mathrm{High}$ & Average & Low \\
\hline $0.394 \mathrm{~T}$ & 5 & 190 & 140 & 91 \\
\hline $1 \mathrm{~T}$ & 4 & 151 & 116 & 86 \\
\hline $2 \mathrm{I}$ & 5 & 114 & 90 & 53 \\
\hline
\end{tabular}

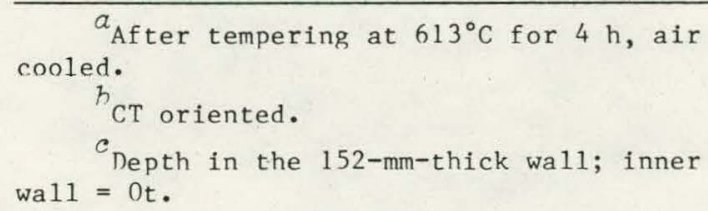

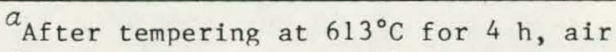

${ }^{h} \mathrm{CT}$ oriented.

${ }^{c}$ Depth in the 152-mm-thick wa11; inner wa11 $=0 \mathrm{t}$.

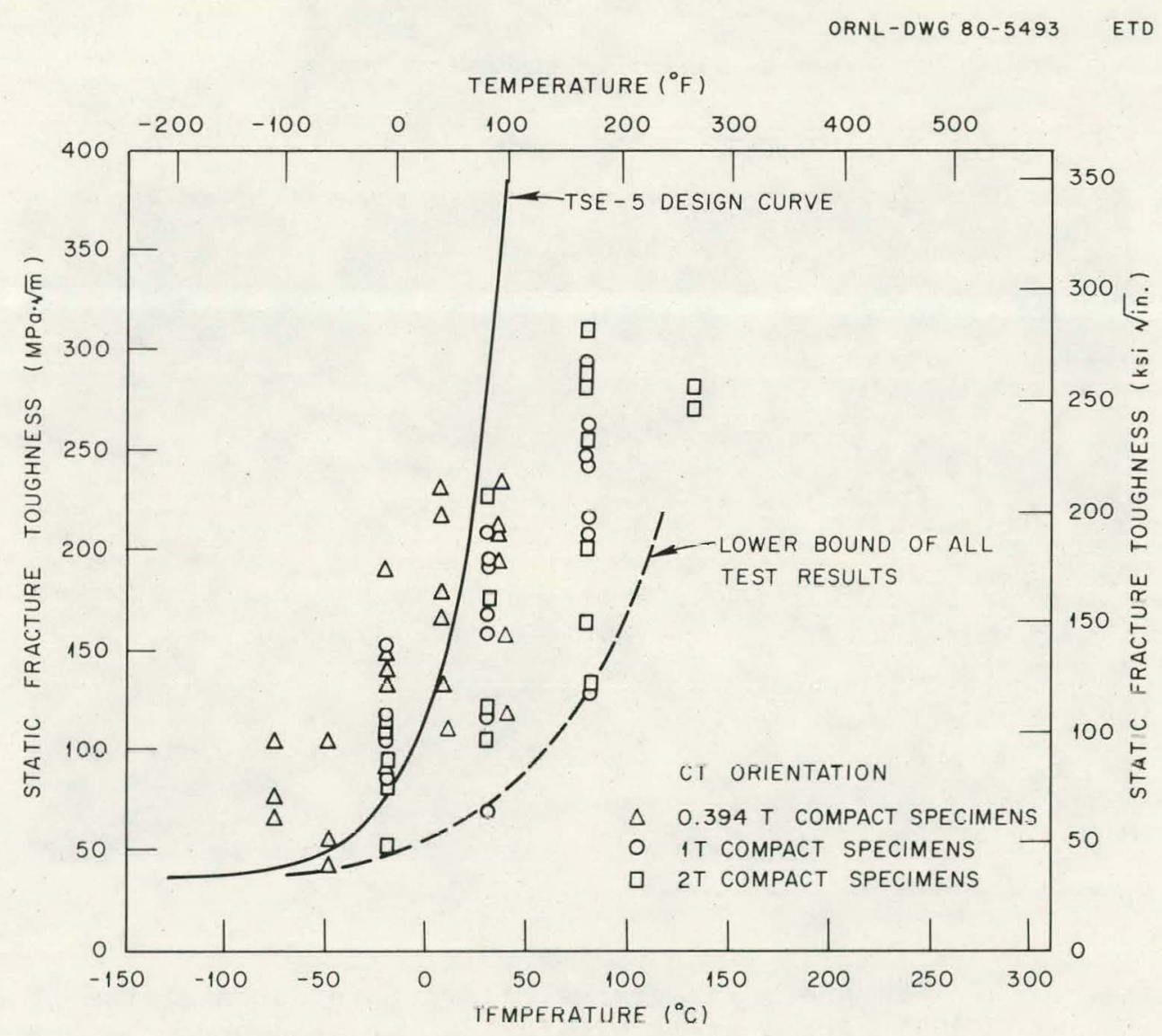

Fig. 4.10. Variation of static fracture toughness from $0.394 \mathrm{~T}, 1 \mathrm{~T}$, and $2 \mathrm{~T}$ compact specimens from prolongation TSP-1 (SA 508) after tempering at $613^{\circ} \mathrm{C}$ for $4 \mathrm{~h}$ and cooling in air. These specimens were machined so that their fatigue cracks resided at the $0.3 t$ depth from inner surface of prolongation. 


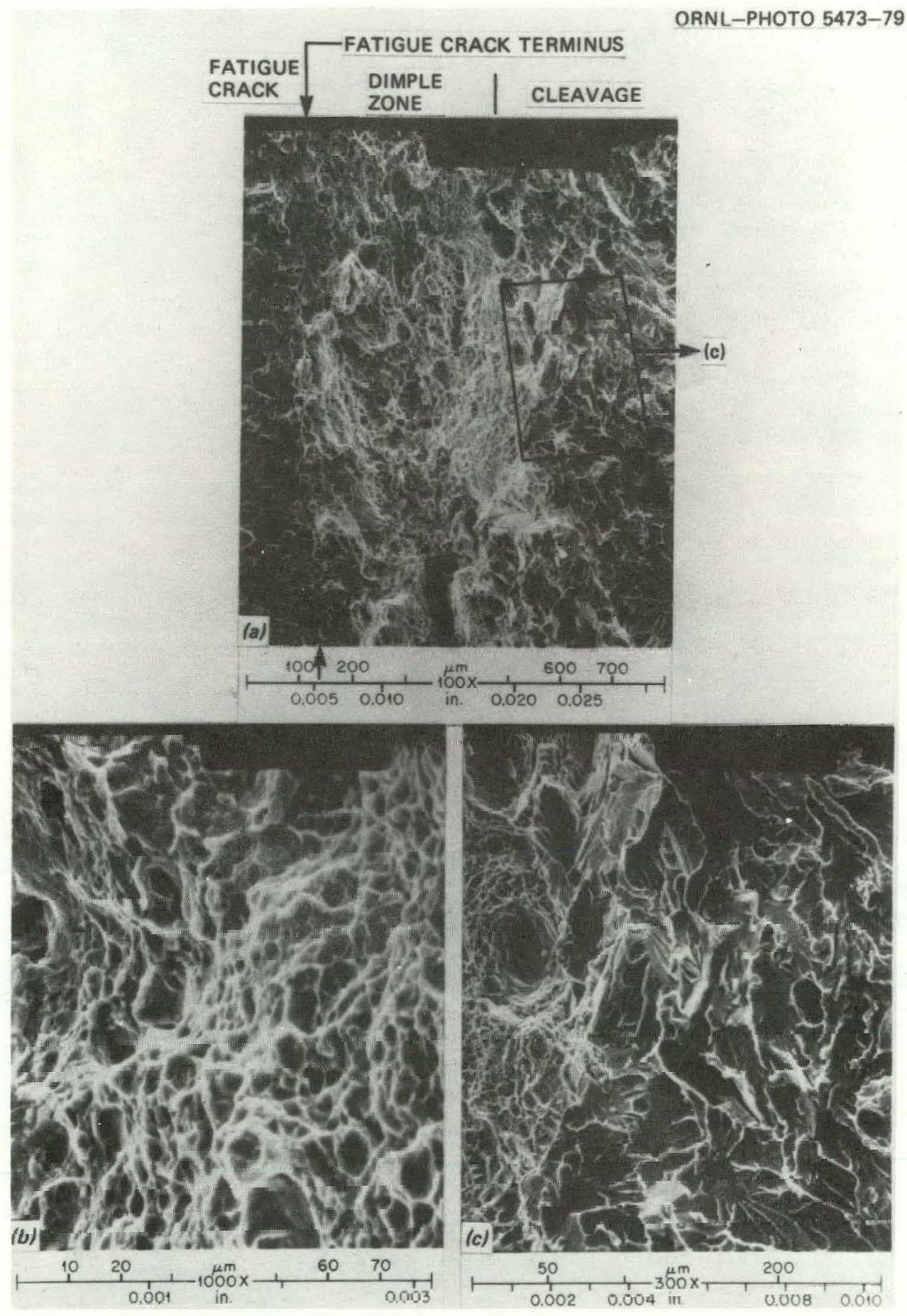

Fig. 4.11. SEM photomicrographs of fracture surface from $1 \mathrm{~T}$ compact specimen $8 \mathrm{SC} 31$ tested at $38^{\circ} \mathrm{C}$ with fracture toughness of $208 \mathrm{MPa} \cdot \sqrt{\mathrm{m}}$. (a) Fracture morphology at crack propagation site. Initial fracture, which extends for an average of about $0.25 \mathrm{~mm}$, is dimple mode, at which point the continued fracture is by cleavage mode; (b) dimple mode fracture at site of crack initiation; (c) cleavage fracture after dimple fracture. 


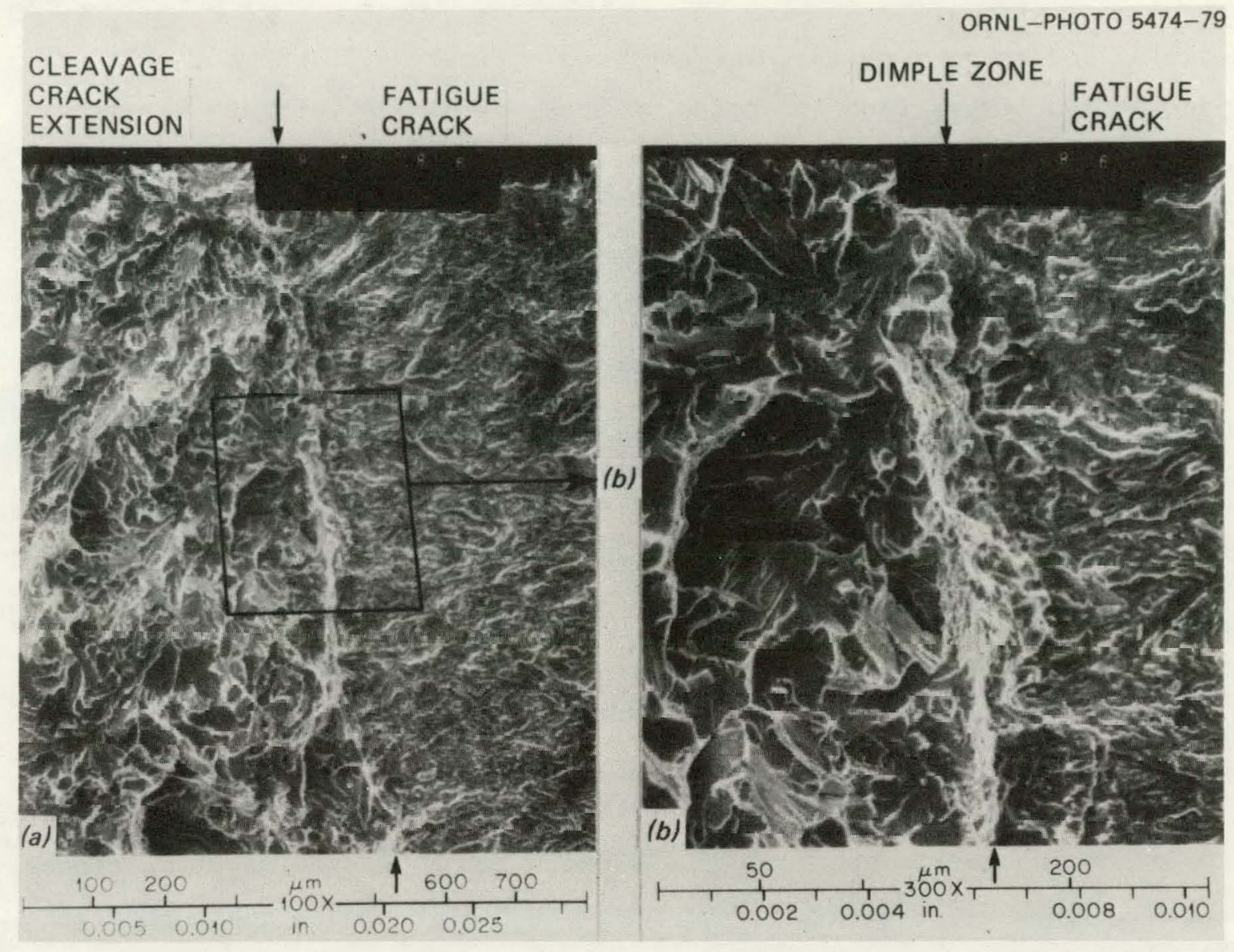

Fig. 4.12. SEM photomicrographs of fracture surface from $1 \mathrm{~T}$ compact specimen $9 \mathrm{SCl}$ tested at $38^{\circ} \mathrm{C}$ with fracture toughness of $98 \mathrm{MPa} \cdot \sqrt{\mathrm{m}}$. (a) Fracture morphology at site of crack extension. There is limited dimple mode failure $(0.038 \mathrm{~mm})$ prior to the onset of cleavage fracture; (b) region of ductile fracture (dimple mode). Original reduced $12 \%$.

prior to the onset of fast fracture. The degree of tearing can be related to the fracture toughness exhibited by the compact specimen being tested. The effect of this tearing is the basis for the explanation of the fracture toughness differences between $1 \mathrm{~T}$ compact specimen numbers TSP-31 and -32. These specimens, both of which were machined from prolongation material that had been tempered for $4 \mathrm{~h}$ at $613^{\circ} \mathrm{C}$, were tested at $82^{\circ} \mathrm{C}$. Specimen TSP-31 exhibited $210 \mathrm{MPa} \cdot \sqrt{\mathrm{m}}$, whereas TSP-32 exhibited $131 \mathrm{MPa} \cdot \sqrt{\mathrm{m}}$. Specimen TSP-31 underwent nearly $0.51 \mathrm{~mm}$ of ductile crack extension prior to the onset of fast fracture. TSP-32 underwent only $0.15 \mathrm{~mm}$ of ductile tearing prior to abrupt fracture. Both specimens 
failed before maximum load was achieved. Figure 4.13 shows the loaddeflection curves from the tests of these specimens. Figure 4.14 shows the fracture surfaces. Ductile tearing at the terminus of the fatigue crack is evident in TSP-31.

This behavior is believed to be caused by the presence of sites of low toughness. Crack extension may occur during testing, particularly when testing is done at temperatures in the $C_{V}$ transition region. This extension, as shown in Fig. 4.11, will occur by dimple mode. Ductile propagation will continue until either the specimen is no longer able to sustain the load and fast fracture (cleavage mode) occurs or the extending crack intersects a site of low toughness, thus triggering fast fracture. The onset of this fast fracture results in a change in the state of loading from static to dynamic. Under these dynamic conditions of loading, the material toughness is not adequate to arrest a running crack, and cleavage mode failure persists.

The amount of ductile tearing that occurs prior to onset of fast fracture governs the fracture toughness exhibited by a specimen. Specimens that exhibit toughness values of near $220 \mathrm{MPa} \cdot \sqrt{\mathrm{m}}$ usually have undergone $0.5 \mathrm{~mm}$ of ductile crack extension prior to onset of cleavage mode fracture.

The hypothesis favoring a site of low toughness appears to be supported in tests conducted near the onset of the $C_{V}$ upper shelf of the TSV-1 (tempered at $613^{\circ} \mathrm{C}$ ). Figure 4.15 shows the fracture surfaces of two $2 \mathrm{~T}$ compact specimens tested at $135^{\circ} \mathrm{C}$. Specimen TSP-4 failed by ductile mode and exhibited large shear lips. TSP-21 failed by predominantly cleavage mode. Figure 4.16 shows the sides of the two specimens. Both specimens exhibited approximately the same fracture toughness. The difference in the fracture mode is evident in the view of the specimens shown in Fig. 4.16. Specimen TSP-4, which failed by ductile tearing, has large plastic hinge regions located on both sides of the specimen, whereas TSP-21 has essentially no hinge region. The test results were as follows:

\begin{tabular}{ccc} 
Specimen No. & $\begin{array}{c}\text { Test temperature } \\
\left({ }^{\circ} \mathrm{C}\right)\end{array}$ & $\begin{array}{c}\text { Fracture toughness } \\
(\mathrm{MPa} \cdot \sqrt{\mathrm{m}})\end{array}$ \\
${$\cline { 1 - 2 }$} }$ & 135 & 272 \\
TSP-21 & 135 & 281
\end{tabular}




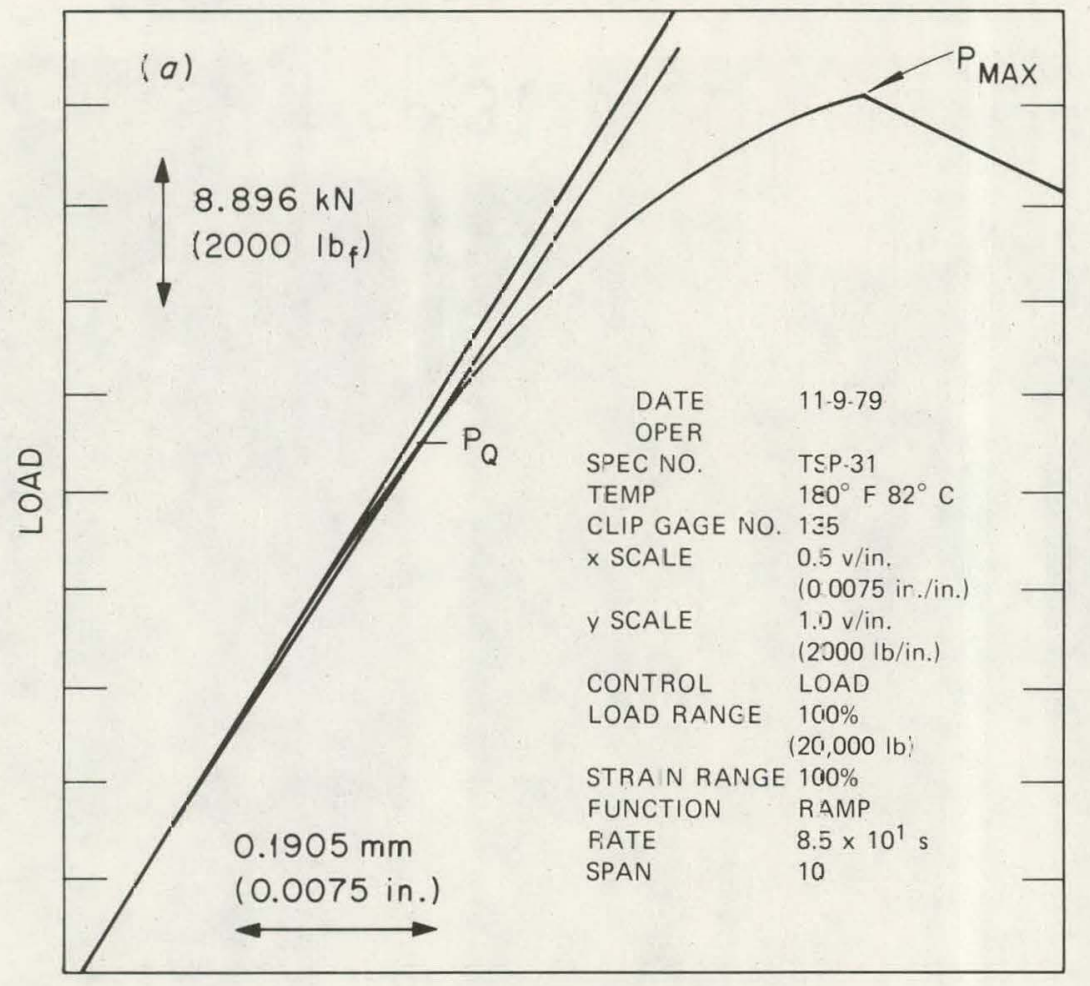

DEFLECTION

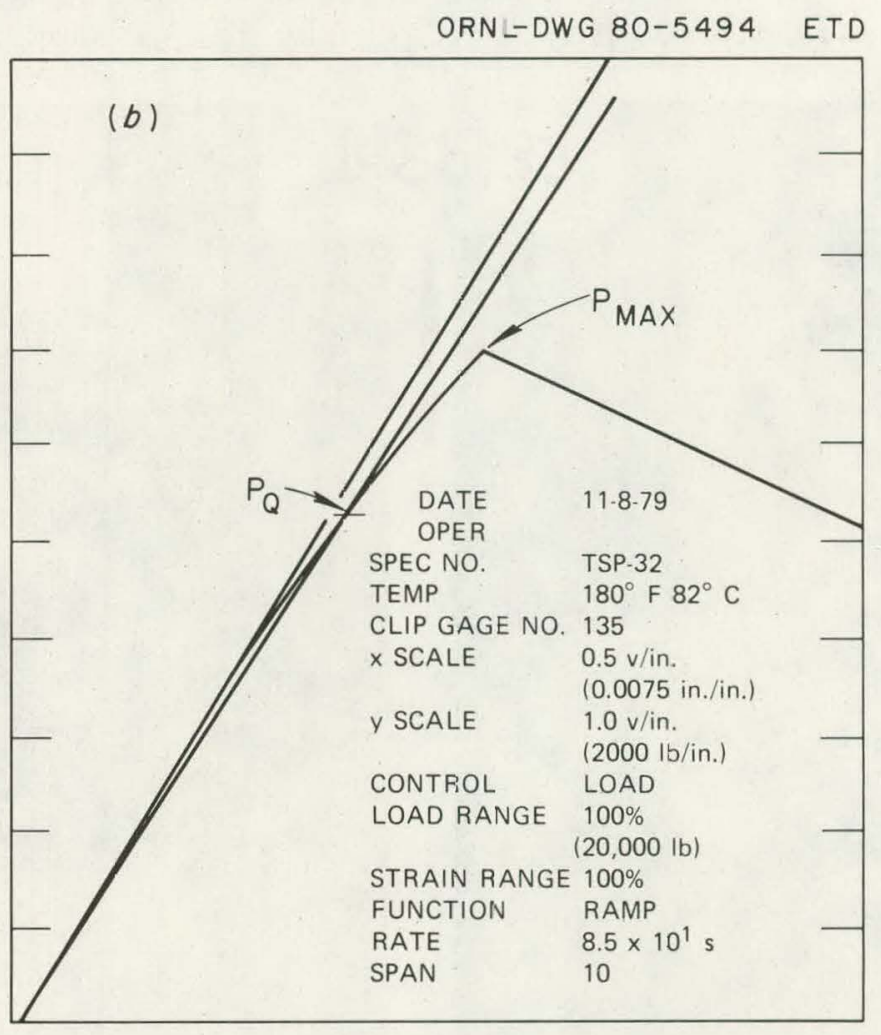

DEFLECTION

Fig. 4.13. Reproduction of load-deflection records from test of $1 \mathrm{~T}$ compact specimens (a) TSP-31 and (b) TSP-32. Note that neither reached maximum load yet both underwent ductile (dimple mode) tearing. 


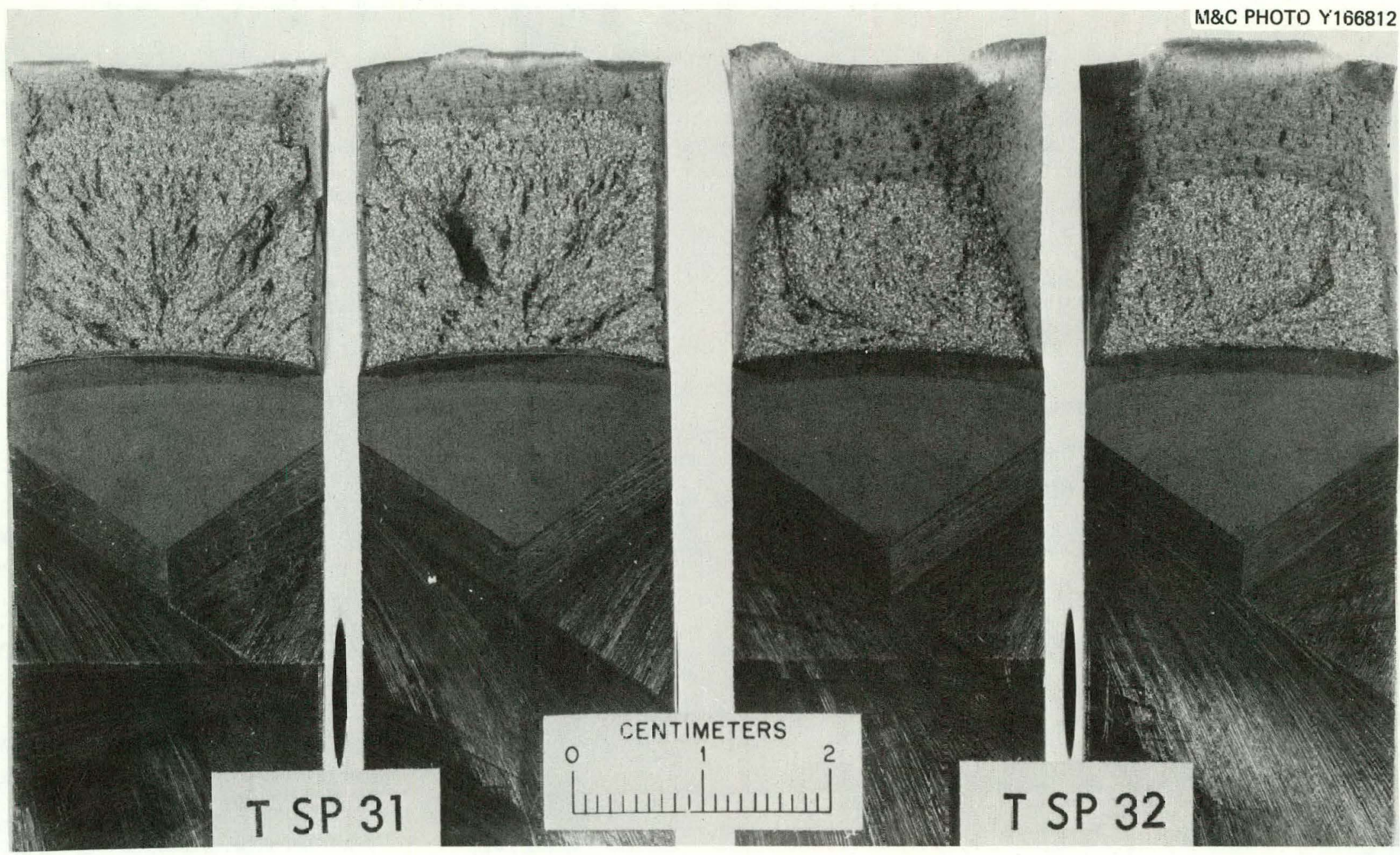

Fig. 4.14. Fracture surfaces from $1 T$ compact specimens TSP-31 and TSP-32. Outward appearance of greater area of shear fracture on surface of TSP-32 belies relative toughesses exhibited by specimers; both were tested at $82^{\circ} \mathrm{C}$. ISP-31 exhibited $210 \mathrm{MPa} \cdot \sqrt{\mathrm{m}}$ and TSP-32 exhibited $131 \mathrm{MPa} \cdot \sqrt{\mathrm{m}}$. Small ductile crack extension (about $0.5 \mathrm{mn}$ ) that occurred in TSP-31 prior to fast cleavage mode fracture can be correlated with higher toughness. Crack in specimen TSP-32 only extended about $0.15 \mathrm{~mm}$ prior to cleavage fracture. 

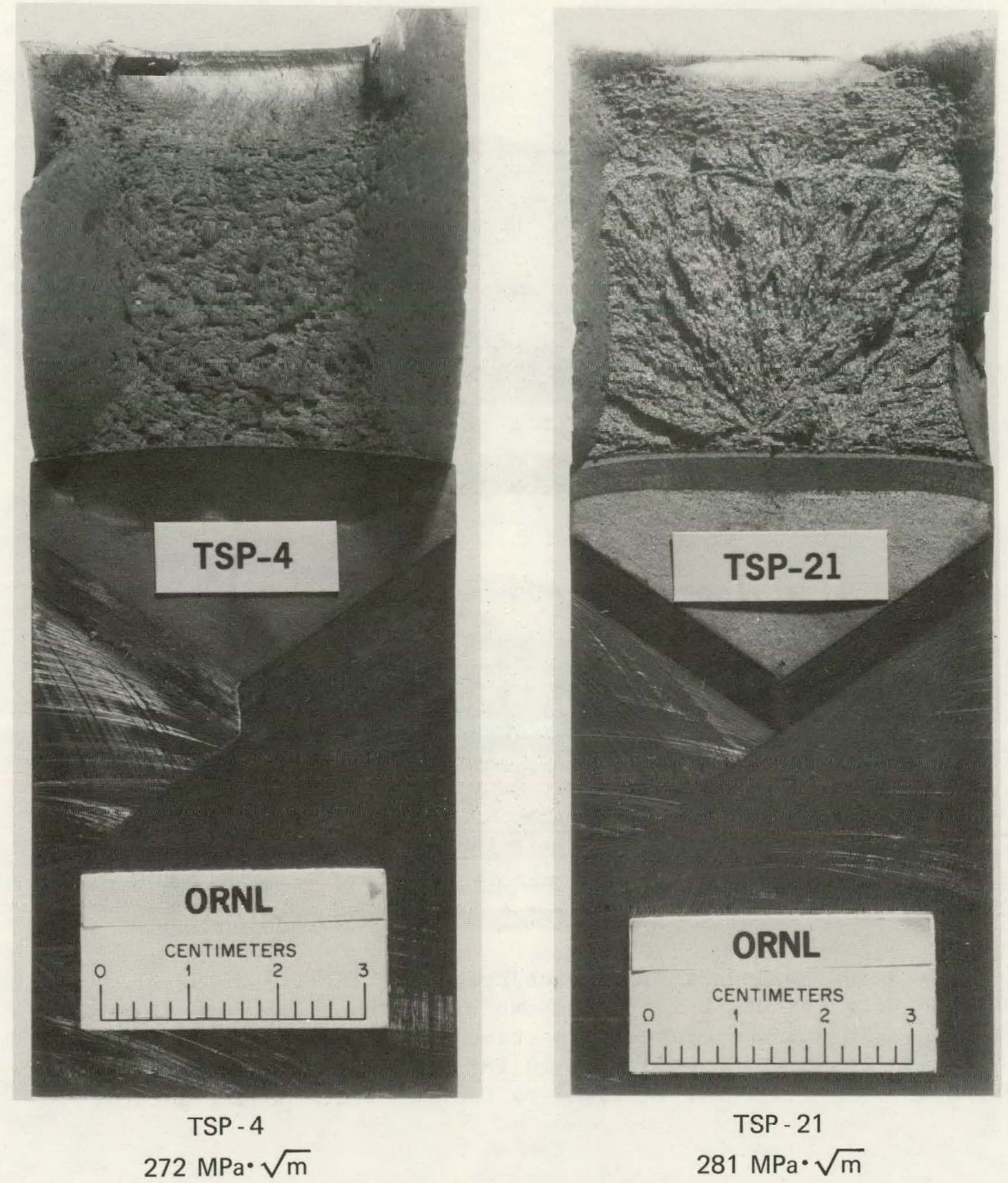

FRACTURE TOUGHNESS

Fig. 4.15. Fracture surfaces from $2 \mathrm{~T}$ compact specimens tested at $135^{\circ} \mathrm{C}$. Both specimens exhibited about the same fracture toughness. TSP -4 failed by ductile tearing. TSP-21 underwent about $1.5 \mathrm{~mm}$ of ductile tearing until a low toughness site was intersected. At this point, rapid cleavage mode fracture occurred. Initiation site is clearly identified in fracture surface. 


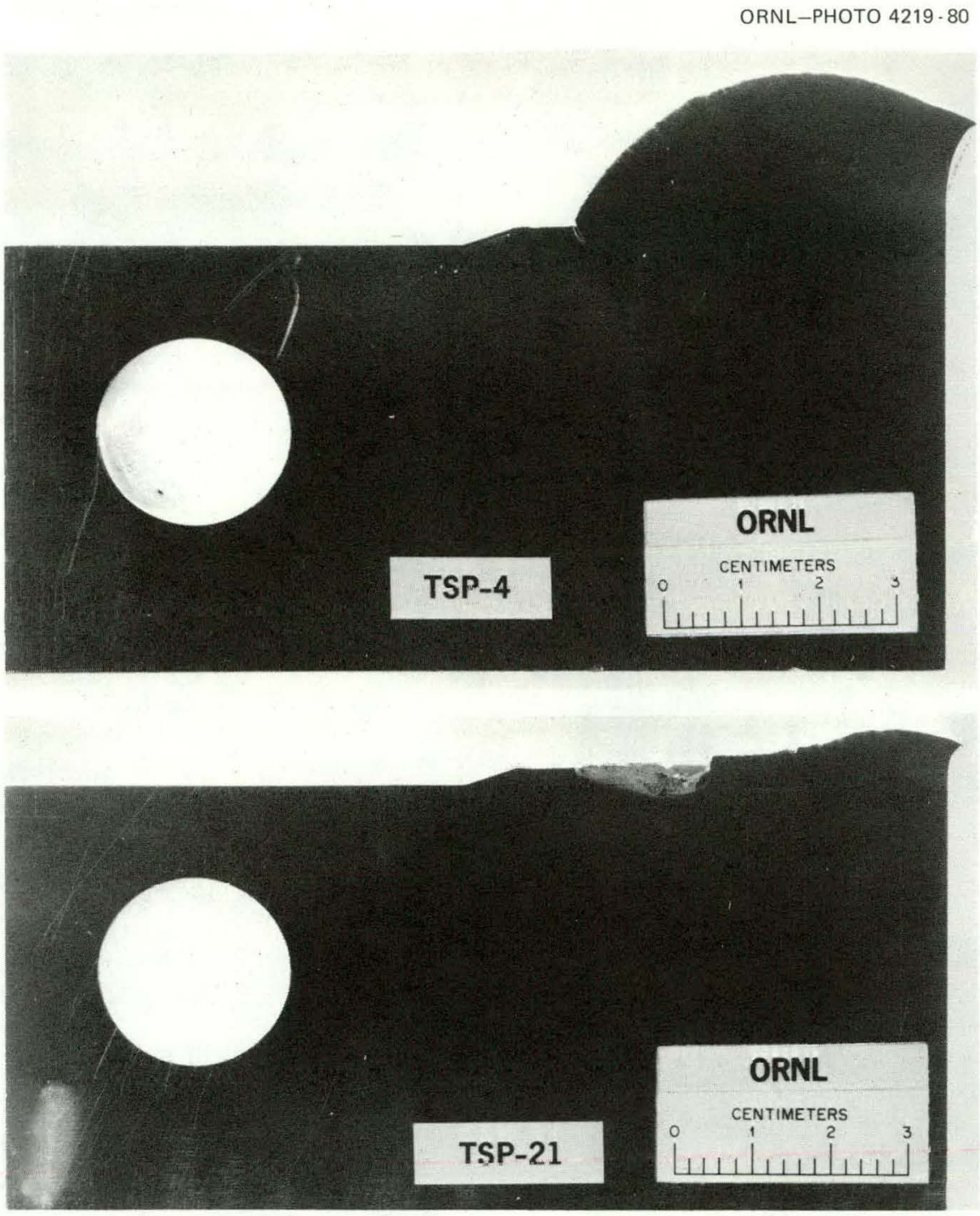

Fig. 4.16. Sides of $2 \mathrm{~T}$ compact specimens TSP-4 and TSP-21. Both specimens were tested at $135^{\circ} \mathrm{C}$ and exhibited about the same fracture toughness, 272 and $281 \mathrm{MPa} \cdot \sqrt{\mathrm{m}}$ respectively. TSP-4 failed by complete ductile tearing. Crack extension in TSP-21 was initially by ductile tearing for about $1.5 \mathrm{~mm}$, followed by fast cleavage mode fracture.

The degree of ductile tearing and an enlargement (original magnification about $20 x$ ) of the initiation site in the two specimens is shown in Fig. 4.17. The crack in TSP-21 extended by dimple fracture mode (for a distance of about $1.5 \mathrm{~mm}$ ) until a low toughness site was intersected. At that point in the test rapid fracture occurred, resulting in a dynamic rate of loading. Fracture of the specimen then occurred by cleavage mode. 

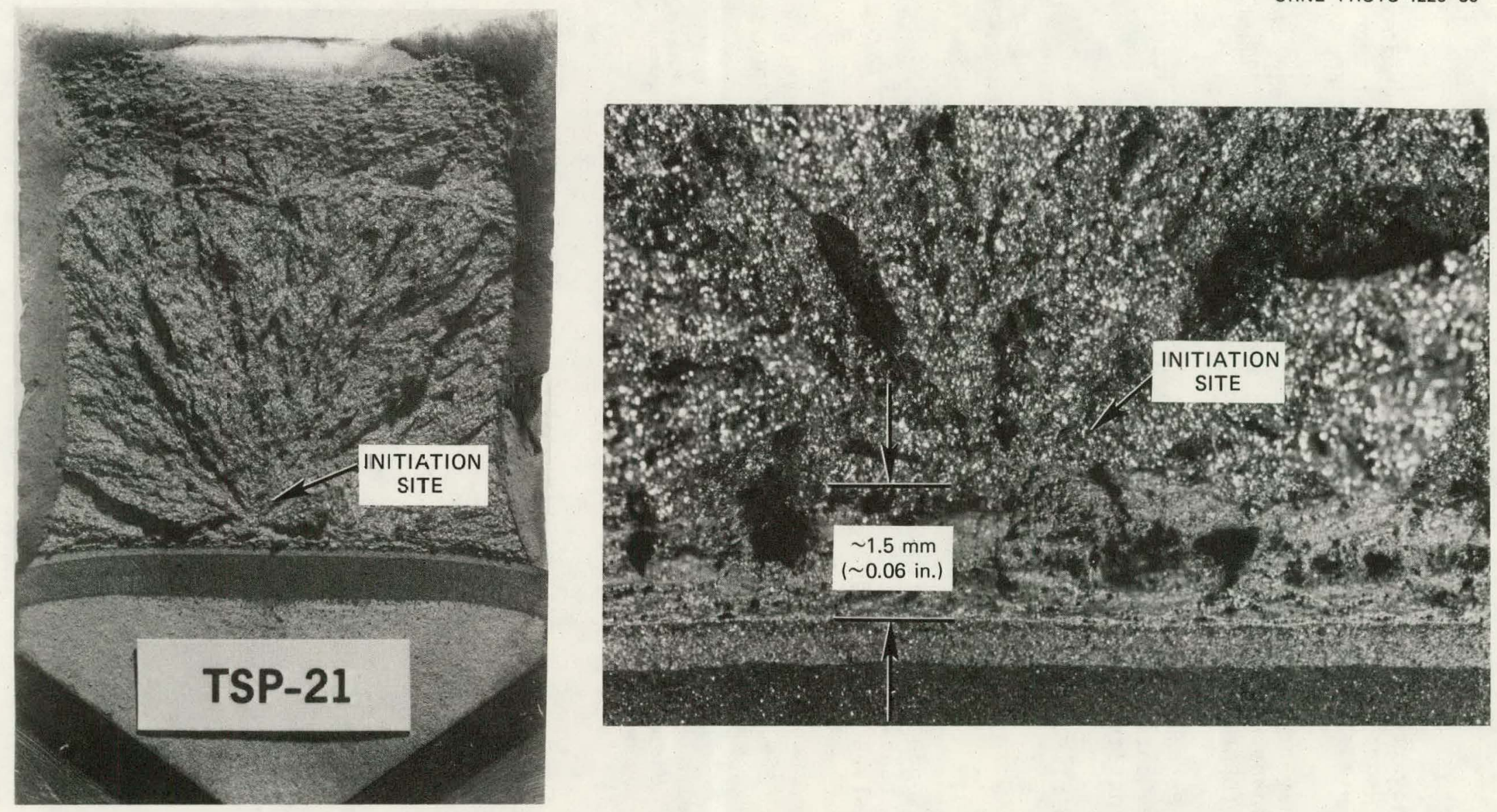

Fig. 4.17. Initiation site in specimen TSP-21, which is clearly identified. About $1.5 \mathrm{~mm}$ of ductile crack extension occurred before onset of fast cleavage mode fracture. 


\section{$\underline{\text { References }}$}

1. R. D. Cheverton, S. E. Bolt, and P. P. Holz, "Thermal Shock Investigations," Heavy-Section Steel Technology Program Quart. Prog. Rep. July September 1979, NUREG/CR-1197 (ORNL/NUREG/TM-370), pp. 52-80.

2. R. D. Cheverton et al., "Thermal Shock Investigations," Heavy-Section Steel Technology Program Quart. Prog. Rep. January-March 1980, NUREG/ CR-1477 (ORNL/NUREG/TM-393), pp. 16-36.

3. Nuclear Pressure Vessel Steel Data Base, EPRI NP-933, prepared by Fracture Control Corporation, Goleta, Calif., for Electric Power Research Institute, December 1978.

4. P. P. Holz, Flaw Preparations for HSST Program Vessel Fracture Mechanics Testing: Mechanical-Cyclic Pumping and Electron-Beam WeldHydrogen-Charge Cracking Schemes, NUREG/CR-1274 (ORNL/NUREG/TM-369), May 1980.

5. S. K. Iskander, Two Finite-Element Techniques for Computing Mode I Stress-Intensity Factors in Two- and Three-Dimensional Problems, NUREG/CR-1499 (ORNL/NUREG/CSD/TM-14) (to be published).

6. W. J. Stelzman and D. A. Canonico, "Thermal Shock Investigations," Heavy-Section Steel Technology Program Quart. Prog. Rep. JanuaryMarch 1980, ORNL/NUREG/TM-393, pp. 31-35.

7. W. J. Stelzman and D. A. Canonico, "Thermal Shock Material Characterization," Heavy-Section Steel Technology Program Quart. Prog. Rep. July-September 1979, ORNL/NUREG/TM-370, pp. 74-79. 


\section{PRESSURE VESSEL INVESTIGATIONS* \\ 5.1 Intermediate Test Vessel $\mathrm{V}-8 \mathrm{~A}$}

$$
\text { P. P. Holz }
$$

Babcock and Wilcox Company (B\&W), Alliance Research Center., Alliance, Ohio, under subcontract is proceeding with trials to develop a special welding process for low-upper-shelf-energy ( 47.5 to $74.6 \mathrm{~J})$ weld metal with 450- to 620-MPa yield strength to provide a flaw site for the vessel $\mathrm{V}-8$ test. 1

The three preliminary trial weldments have been made; two of the three heat-treatment runs are completed; run three is under way. The first heat-treatment samples are being machined into test specimens; others are being cut for machining. The welds are made with SA533 B1 steel and SFA 5.23 type EF-2 electrodes and three different fluxes. The fluxes are actually differently proportioned batched mixes of Linde 60 and Linde 80 fluxes. The postweld heat treatment (PWHT) parameters for the weldments are listed in Table 5.1 .

Table 5.1. Postweld heat treatment parameters for trial welds

\begin{tabular}{lccc}
\hline & $\begin{array}{c}\text { Temperature } \\
\left({ }^{\circ} \mathrm{C}\right)\end{array}$ & $\begin{array}{c}\text { Holding } \\
\text { time } \\
(\mathrm{h})\end{array}$ & $\begin{array}{c}\text { Cooling } \\
\text { rate } \\
(\mathrm{K} / \mathrm{h})\end{array}$ \\
\hline Trial 1 & $538-566$ & $48-52$ & $5.6-8.3$ \\
Trial 2 & $566-593$ & $48-52$ & $5.6-8.3$ \\
Trial 3 & $593-621$ & $48-52$ & $5.6-8.3$ \\
\hline
\end{tabular}

The B\&W staff has also completed, at their sponsorship and expense, a series of welding experiments with varied commercially batched flux mixes. These experiments were conducted with mixes of Linde 60 and Linde 80 flux powders to guide mix selections so as to attain the contract-specified yield strength and impact energies with $100 \%$ shear in temperature range of

*Conversions from SI to English units for all SI quantities are listed on a foldout page at the end of this report. 
about 66 to $93^{\circ} \mathrm{C}$. These results imply that a flux mixture-special heattreatment welding procedure looks encouraging.

\subsection{Pressurized Thermal Shock Studies}

W. R. Corwin

Initial scoping studies for pressurized thermal shock testing utilizing an ITV are continuing in both the areas of vessel analysis and facility planning. Computer analyses of a cracked nozzle corner in an ITV under pressurized thermal shock conditions were performed using the ADINAT-ADINA-BIGIF series of codes (described in Chap. 2), and the resulting temperature, stress, and $K_{I}$ distributions were examined. The conditions examined represented a.moderately severe thermal shock to the nozzle-corner region superimposed on a pressure loading of 30 to $40 \%$ in excess of the design pressurc. A comparison of the calculated $\mathrm{K}_{\mathrm{I}}$ values with the estimated fracture toughness of typical A508 class 2 nozzle forging stee ${ }^{2}$ as a function of temperature along the crack front showed that the $\mathrm{K}$ ratio can approach unity within the nozzle corner and may exceed it near the nozzle bore and vessel wall. However, uncertainties in estimating the relevant fracture toughness under conditions of varying material restraint, particularly in the upper transition region and upper shelf, and the limitations inherent in using linear elastic computational models (such as those employed) make a definitive assessment of the structural response difficult; additional work in this area will be necessary. Nonetheless, the results of the analyses are helpful as a rough guide in defining some of the requirements of the testing facility, and work in this area is currently in progress.

\section{References}

1. P. P. Holz, "Intermediate Test Vesse1 V-8A," Heavy-Section Steel Technology Program Quart. Prog. Rep. January-March 1980, ORNL/NUREG/ TM-393, pp. 37-39.

2. J. G. Merkle, G. C. Robinson, P. P. Holz, and J. E. Smith, Test of 6-In.-Thick Pressure Vessels. Series 4: Intermediate Test Vessels $V-5$ and V-9 with Inside Nozzle-Cormer Cracks, ORNL/NUREG-7 (August 1977). 
CONVERSION FACTORS ${ }^{a}$

\begin{tabular}{|c|c|c|}
\hline SI unit & English unit & Factor \\
\hline $\mathrm{mm}$ & in. & 0.0393701 \\
\hline $\mathrm{cm}$ & in. & 0.393701 \\
\hline $\mathrm{m} \ldots$ & $\mathrm{ft}$ & 3.28084 \\
\hline $\mathrm{m} / \mathrm{s}$ & $\mathrm{ft} / \mathrm{s}$ & 3.28084 . \\
\hline $\mathrm{kN}$ & $1 b_{f}$ & 224.809 \\
\hline $\mathrm{kPa}$ & psi & 0.145038 \\
\hline $\mathrm{MPa}$ & $\mathrm{ksi}$ & 0.145038 \\
\hline $\begin{array}{r}\mathrm{MN} \cdot \mathrm{m}^{-3 / 2} \\
(\mathrm{MPa} \cdot \sqrt{\mathrm{m}})\end{array}$ & $k s i \sqrt{i n}$ & 0.910048 \\
\hline $\mathrm{J}$ & $f t-1 b$ & 0.737562 \\
\hline K & ${ }^{\circ} \mathrm{F}$ or ${ }^{\circ} \mathrm{R}$ & 1.8 \\
\hline $\mathrm{kJ} / \mathrm{m}^{2}$ & in. $-1 b / i n .^{2}$ & 5.71015 \\
\hline $\mathrm{W} \cdot \mathrm{m}^{-2} \mathrm{~K}^{-1}$ & $\mathrm{Btu} / \mathrm{h}-\mathrm{ft} \mathrm{t}^{2}-{ }^{\circ} \mathrm{F}$ & 0.176110 \\
\hline $\mathrm{T}\left({ }^{\circ} \mathrm{F}\right)=1.8$ & $\left({ }^{\circ} \mathrm{C}\right)+32$ & . \\
\hline
\end{tabular}

$a_{\text {Mu1tiply SI quantity by given }}$ factor to obtain English quantity. 
NUREG/CR-1627

ORNL/NUREG/TM-401

Dist. Category RF

\section{Internal Distribution}

1. R. G. Berggren

2. S. E. Bolt

3-7. R. H. Bryan

8. J. W. Bryson

9. D. A. Canonico

10. R. D. Cheverton

11. J. M. Corum

12. W. R. Corwin

13. W. B. Cottrel1

14. W. L. Greenstreet

15. R. C. Gwaltney

16. P. P. Holz

17. S. K. Iskander

18. K. K. Klindt

19. J. G. Merkle

20. C. A. Mills
21. S. E. Moore

22. F. R. Mynatt

23. D. J. Naus

24. F. H. Neill

25-26. J. L. Rich

27. G. C. Robinson

28. G. M. Slaughter

29. J. E. Smlth

30. W. J. Stelzman

31. H. E. Trammell

32-36. G. D. Whitman

37. Patent Office

38. Central Research Library

39. Document Reference Section

40-41. Laboratory Records Department

42. Laboratory Records (RC)

External Distribution

43. C. Z. Serpan; Reactor Safety Research, Nuclear Regulatory Commission, Washington, DC 20555

44. M. Vagins, Reactor Safety Research, Nuclear Regulatory Commission, Washington, DC 20555

45. Office of Assistant Manager for Energy Research and Development, DOE, ORO, Oak Ridge, TN 37830

46-47. Technical Information Center, DOE, Dak Ridge, TN 37830

48-477. Given distribution as shown in category RF (NTIS - 10) 